\title{
CDFTBL: A Statistical Program for Generating Cumulative Distribution Functions from Data User's Manual, Version 1.0
}

Prepared for the U.S. Department of Energy Office of Environmental Restoration and Waste Management

(20) Westinghouse

Hanford Operations and Engineering Contractor tor the

U.S. Department of Energy under Contract DE-AC06-87RL10930 
LEGAL DISCLAIMER

This report was prepared as an account of work sponsored by an agency of the United States Government. Neither the

United States Government nor any agency thereof, nor any of their employees, nor any of their contractors, subcontractors

or theif employees, makes any warranty, express or implied, or assumes any legal liability or responsibility for the accuracy, completeness, or any third party's use or the results of such use of any information, apparatus, product, or process disclosed, or represents that its use would not infringe priva:ely owned rights. Reference herein to any specific commercial product, process, or service by trade name. trademark, manufaclurer, or otherwise, does not necessarily constitute or imply its endorsement, recommendation, or favoring by the United States Government or any agency thereof or its contractors or subcontractors. The views and opinions of authors expressed herein do nol necessarily state or reflect those of the United States Government or any agency thereot.

This report has been reproduced from the best available copy. Avallable in paper copy and microfiche.

Available to the U.S. Department of Energy and its contractors from

Office of Scientific and Technical Information

P. 0. Box 62

Oak Ridge, TN 37831

(615) $576-8401$

Available to the public from the U.S. Department of Commerce National Technical Information Service

5285 Port Royal Road

Springfield VA 22161

(703) $487-4650$

Printed in the United States of America

DISCLM-1.CHP $(1.91)$ 


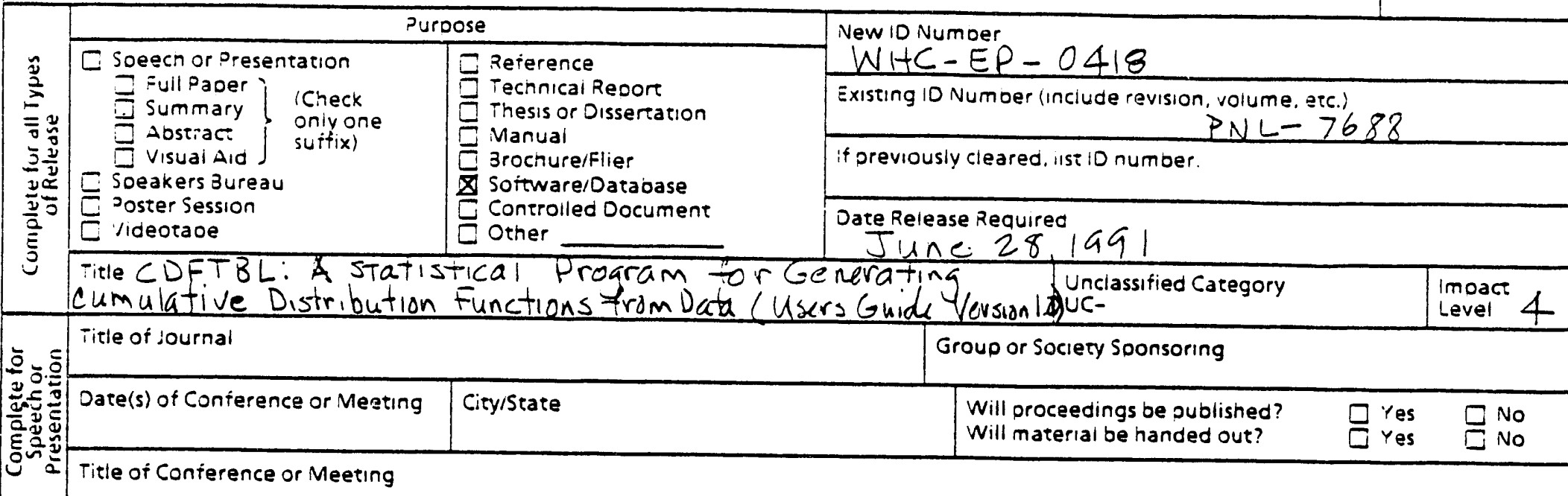

\section{CHECXLIST FOR SIGNATORIES}

Review Reguired ser WHC.C.M.3-4

Glassirication/Unclassified Controlled

Nuclear Information

Patent - General Counsel

Legal - General Counsel

Applied Technology/Exoor

Controlled Information

or International Program

WHC Program

Communications

DOE-RL Program

Puolications Services

Other Program

References Avallable to intended

Audience

Transmit :O DOE.HQ/Office of

scientific and Technical information
Yes No

$\square \quad \nabla$

v

$\square$

$\square$

$\square$

v

$\nabla$

$\nabla$

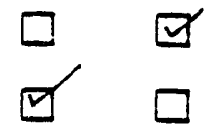

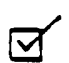

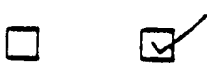

$\checkmark$

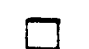

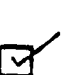

Reviewer

Name (printed)

Signature

Dare

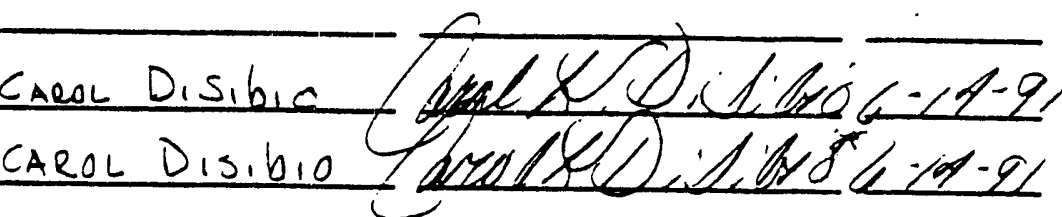

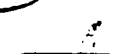

information conforms to all aoplicable requiremerits. The above information is cerified to be correct.

LuthoriRequestor (Printed/Signature)

J.'. SSonnich gen, Jr.p

i

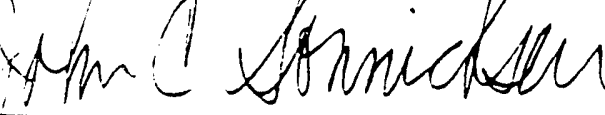

Liesoonside vanager (P:inted/signature)

J.C. Sonnichsen, Jr. For $\bar{y}$. W. cammann

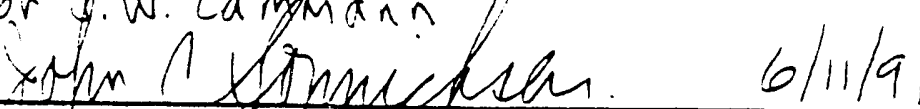

irenged dudience

$\square$ internal $\square$ Soonsor $\square$ External

Oate
M.J. Furman

Leslie A. Brown

Leviewed as

DNL-7688

lestic A. Brown
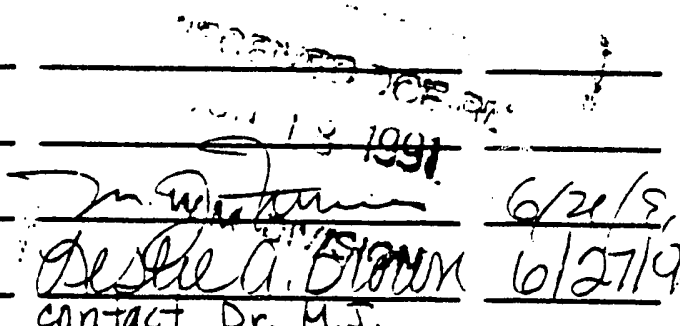

$6 / 215$ contact Dr. M.J.

Fayer

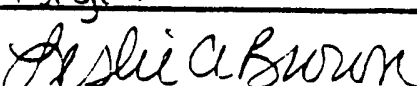

$\frac{1}{10 / 27 / 91}$

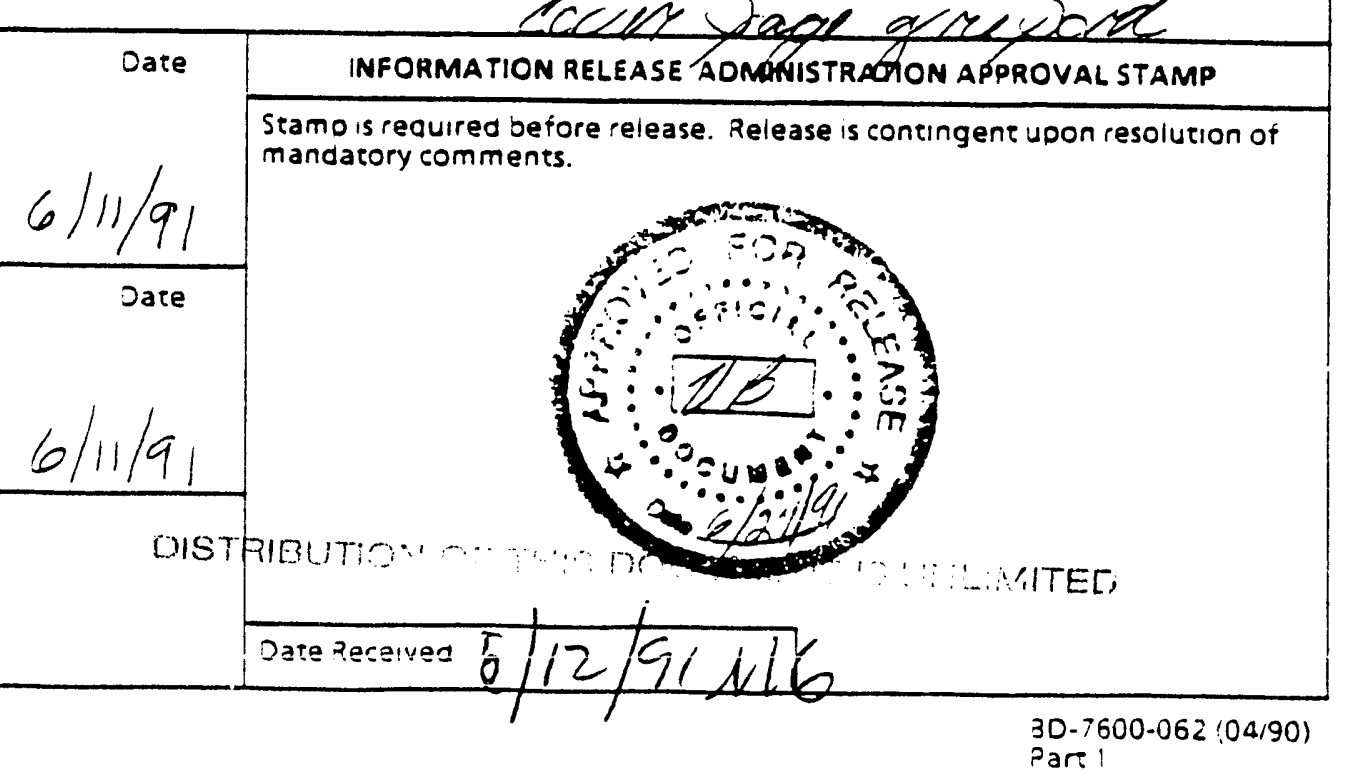


WHC-EP- -0418

DE92 002106

\section{CDFTBL: A Statistical Program for Generating Cumulative Distribution Functions from Data User's Manual, Version 1.0}

Prepared by:

P. W. Eslinger

Pacific Northwest Laboratory

Date Published

June 1991

Prepared for the U.S. Department of Energy Office of Environmental Restoration and Waste Management

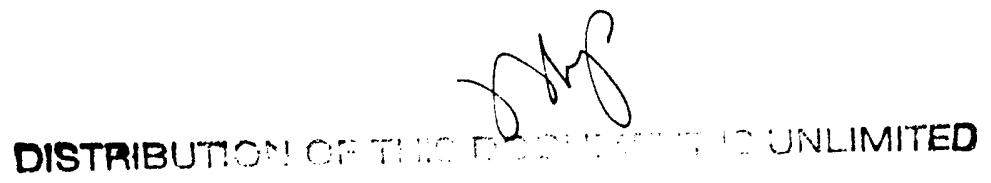


WHC-EP-0418

\title{
CDFTBL: A STATISTICAL PROGRAM FOR GENERATING CUMULATIVE DISTRIBUTION FUNCTIONS FROM DATA
}

USER'S MANUAL, VERSION 1.0

\author{
P. W. Eslinger \\ Pacific Northwest Laboratory
}

\begin{abstract}
This document describes the theory underlying the CDFTBL code and gives details for using the code. The CDFTBL code provides an automated tool for generating a statistical cumulative distribution function that describes a set of field data. The cumulative distribution function is written in the form of a table of probabilities, which can be used in a Monte Carlo computer code. As a specific application, CDFTBL can be used to analyze field data collected for parameters required by the PORMC computer code.
\end{abstract}

Section 2.0 discusses the mathematical basis of the code. Section 3.0 discusses the code structure. Section 4.0 describes the free-format input command language, while Section 5.0 describes in detail the commands to run the program. Section 6.0 provides example program runs, and Section 7.0 provides references. The Appendix provides a program source listing. 


\section{CONTENTS}

1.0 INTRODUCTION . . . . . . . . . . . . . . . . . . . . . 1

1.1 MOTIVATION . . . . . . . . . . . . . . . . . . . . . . 1

1.2 PURPOSE

2.0 MATHEMATICAL BASIS . . . . . . . . . . . . . . . . . 1

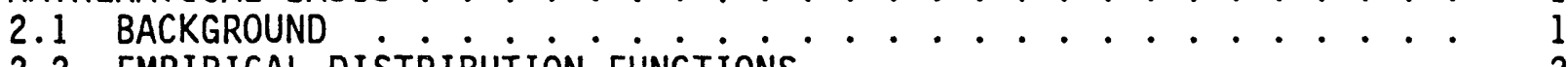

2.2 EMPIRICAL DISTRIBUTION FUNCTIONS . . . . . . . . . . . . . . . 2

2.3 CUMULATIVE DISTRIBUTION FUNCTIONS BASED ON SAMPLE UENSITY

ESTIMATES . . . . . . . . . . . . . . . . . . . . 3

2.4 RANDOM-SAMPLE ASSUMPTION ................... . . . 4

2.5 PRACTICAL USE CONSIDERATIONS . . . . . . . . . . . . . . . 4

3.0 CODE STRUCTURE AND PROGRAM EXECUTION . . . . . . . . . . . . 5

3.1 INPUT AND OUTPUT FILES . . . . . . . . . . . . . . . . . . 5

3.1.1 The Input File.................... 5

3.1.2 Description of the Output Files . . . . . . . . . . 6

3.2 RUNNING THE PROGRAM . . . . . . . . . . . . . . . . . . . . 6

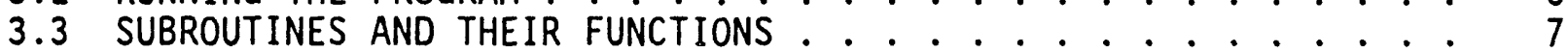

3.4 VARIABLE DEFINITIONS AND DIMENSION PARAMETERS . . . . . . . . . . . 7

3.5 ERROR MESSAGES . . . . . . . . . . . . . . . . . . . . . 7

4.0 DESCRIPTION OF FREE-FORMAT COMMAND LANGUAGE . . . . . . . . . . . . 11

4.1 RECORD TYPES . . . . . . . . . . . . . . . . . . . . . 11

4.1.1 The Keyword Record . . . . . . . . . . . . . . . . 11

4.1.2 Continuation Records ................. 12

4.1.3 Comment Records ................... 12

4.2 ELEMENTS OF THE INPUT RECORD . . . . . . . . . . . . . . . . . 13

4.2.1 The Keyword ................... 13

4.2.2 The Modifier .................... 13

4.2.3 The Numeric Field . . . . . . . . . . . . . . . 14

4.2.4 The Separator Field . . . . . . . . . . . . . . . 15

4.2.5 The Terminator Field................. 16

4.2.6 The Comment Field . . . . . . . . . . . . . . . . 16

5.0 DETAILED DESCRIPTION OF KEYWORD COMMANDS . . . . . . . . . . . . 17

5.1 DISTRIBU COMMAND ..................... 18

5.1.1 Purpose ....................... 18

5.1.2 Syntax ....................... 19

5.1.3 Examples......................... 20

5.2 END COMMAND.......................... . . . 20

5.2.1 Purpose ...................... . 20

5.2.2 Syntax.................... . 20

5.2.3 Example ..................... . 21

5.3 PLOT COMMAND . . . . . . . . . . . . . . . . . . . . . . . . . . . . . . . 21

5.3.1 Purpose ........................... . . . . . 21

5.3.2 Syntax........................ . . . . 21

5.3.3 Examples...................... 21 


\section{CONTENTS (continued)}

5.4 PRINT COMMAND ....................... . . 22

5.4.1 Purpose ........................... 22

5.4 .2 Syntax ......................... 2 . .

5.4.3 Examples......................... 22

5.5 PROBABIL COMMAND ....................... 23

5.5.1 Purpose .. . . . . . . . . . . . . . . . . 23

5.5.2 Syntax . . . . . . . . . . . . . . . . 23

5.5.3 Examples...................... 24

5.6 SAMPLE COMMAND . . . . . . . . . . . . . . . . . . . . . . . 24

5.6 .1 Purpose ....................... 24

5.6.2 Syntax ...................... . 24

5.6.3 Examples......................... 24

5.7 TRANSFOR COMMAND ........................ . . . 25

5.7 .1 Purpose . . . . . . . . . . . . . . . . . 25

5.7 .2 Syntax ....................... 25

5.7 .3 Examples........................ 25

5.8 USER COMMAND . . . . . . . . . . . . . . . . . . . . . . . . . 26

5.8.1 Purpose ........................ 26

5.8 .2 Syntax....................... 26

5.8.3 Example ...................... . 26

6.0 EXAMPLE RUNS AND CODE VERIFICATION . . . . . . . . . . . . . . 27

6.1 EXAMPLE 1............................. . . . 27

6.2 EXAMPLE 2................................ . . . . . 27

6.3 EXAMPLE 3............................. . . . . . . 34

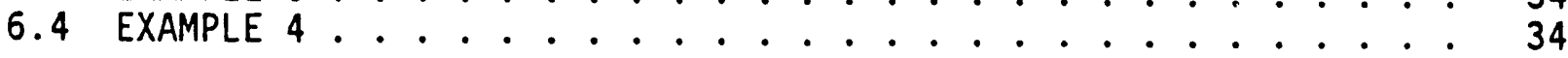

7.0 REFERENCES .......................... . . . . 45

APPENDIX

A Source Code Listing . . . . . . . . . . . . . . . . . . A-1 
WHC-EP-0418

\section{LIST OF FIGURES}

1 Interpolation Approach to Inverting the Cumulative Distribution Function . . . . . . . . . . . . . . . . . . 2

2 Subroutine Calling Hierarchy for the COFTBL . . . . . . . . . . . 10

\section{LIST OF TABLES}

1 Example Interactive Outputs by the CDFTBL . . . . . . . . . . . 7

2 Modules and Their Function . . . . . . . . . . . . . . 8

3 Parameter Definitions in the CDFTBL Code. . . . . . . . . . . 10

4 Keywords and Their Functions for the CDFTBL Code . . . . . . . . . . 18

5 DISTRIBU Keyword Numeric Value Description . . . . . . . . . . . . 19

6 PLOT Keyword Modifiers and Their Descriptions . . . . . . . . . . . . 21

7 PRINT Keyword Numeric Value Explanations . . . . . . . . . . . . 22

8 PROBABIL Keyword Numeric Value Explanations . . . . . . . . . . . 23

9 Sample Keyword Numeric Value Explanations . . . . . . . . . . . . 25

10 TRANSFOR Keyword Numeric Value Explanations . . . . . . . . . . . 26

11 Input Data File for Example 1: EXAMPLE1.DAT. . . . . . . . . . . 28

12 Report File for Example 1: EXAMPLE1.RPT . . . . . . . . . . . 29

13 Input Data File Example 2: EXAMPLE2.DAT . . . . . . . . . . . 31

14 Report File for Example 2: EXAMPLE2.RPT . . . . . . . . . . . 32

15 Input Data File Example 3: EXAMPLE3.DAT . . . . . . . . . . . . 35

16 Report File for Example 3: EXAMPLE3.RPT . . . . . . . . . . . . 36

17 Input Data File Example 4: EXAMPLE2.DAT . . . . . . . . . . . 39

18 Report File for Example 4: EXAMPLE4.RPT . . . . . . . . . . . 40

19 Plot File for Example 4: EXAMPLE4.PLT . . . . . . . . . . . . . 42 
WHC-EP-0418

This page intentionally left blank. 
WHC-EP-0418

\section{CDFTBL: A STATISTICAL PROGRAM FOR GENERATING CUMULATIVE DISTRIBUTION FUNCTIONS FROM DATA}

USER'S MANUAL, VERSION 1.0

\subsection{INTRODUCTION}

\subsection{MOTIVATION}

When using a Monte Carlo computer code such as PORMC (Runchal and Sagar 1989) to analyze the effects of uncertainties in input data on a performance measure, statistical distributions must be chosen for selected input parameters. When data on the parameter of interest are available, the appropriate statistical distribution can be specified in one of two ways. First, a classical statistical distribution can be chosen that approximates the data, then the analytical form for the distribution can be incorporated into the Monte Carlo code. Second, the data can be used to generate a statistical distribution in the form of a table of values. This table can then be input into the Monte Carlo code without the intermediate step of choosing an appropriate analytical form for the distribution. An automated technique for building the table of values is, therefore, a useful analytical tool.

\subsection{PURPOSE}

This document describes the theory underlying the CDFTBL code and gives details for using the code. The CDFTBL code provides an automated tool for generating a statistical cumulative distribution function (CDF) from a set of input data.

\subsection{MATHEMATICAL BASIS}

\subsection{BACKGROUND}

A Monte Carlo computer code must be able to generate sets of values that behave as if they were random samples from specified probability distributions. A variety of techniques can be used to generate the desired values, many of which depend on the particular distribution chosen. One method, the Probability Integral Transform (PIT) method (Mood et al. 1974, p. 202), can be applied to any continuous statistical distribution.

Let $F(x), 0 \leq F(x) \leq 1$, denote the CDF of a random variable $x$. To apply the PIT method for generating random variables, first generate a value, u, from the uniform $(0,1)$ distribution. Often this can be done using the default random number generator on a computer system. As an alternative, the portable uniform generator written by Lewis et al. (1969) can be used. Next, given the 
value $u$, solve the equation $F(x)=u$ for $x$ [i.e., solve the equation $x=F^{-1}(u)$ for $\left.x\right]$. The value $x$ is from the distribution $F(x)$.

The PIT method is sometimes difficult to implement because a convenient form for $F^{-1}(u)$ may not exist. However, if the distribution is defined in terms of a table of $(x, F(x))$ pairs, then linear interpolation can be used to choose the appropriate $x$ value given a value $u[=F(x)]$. Figure 1 shows the interpolation approach. The interpolation can be performed at any desired accuracy by increasing the number of values entered in the table.

Figure 1. Interpolation Approach to Inverting the Cumulative Distribution Function.

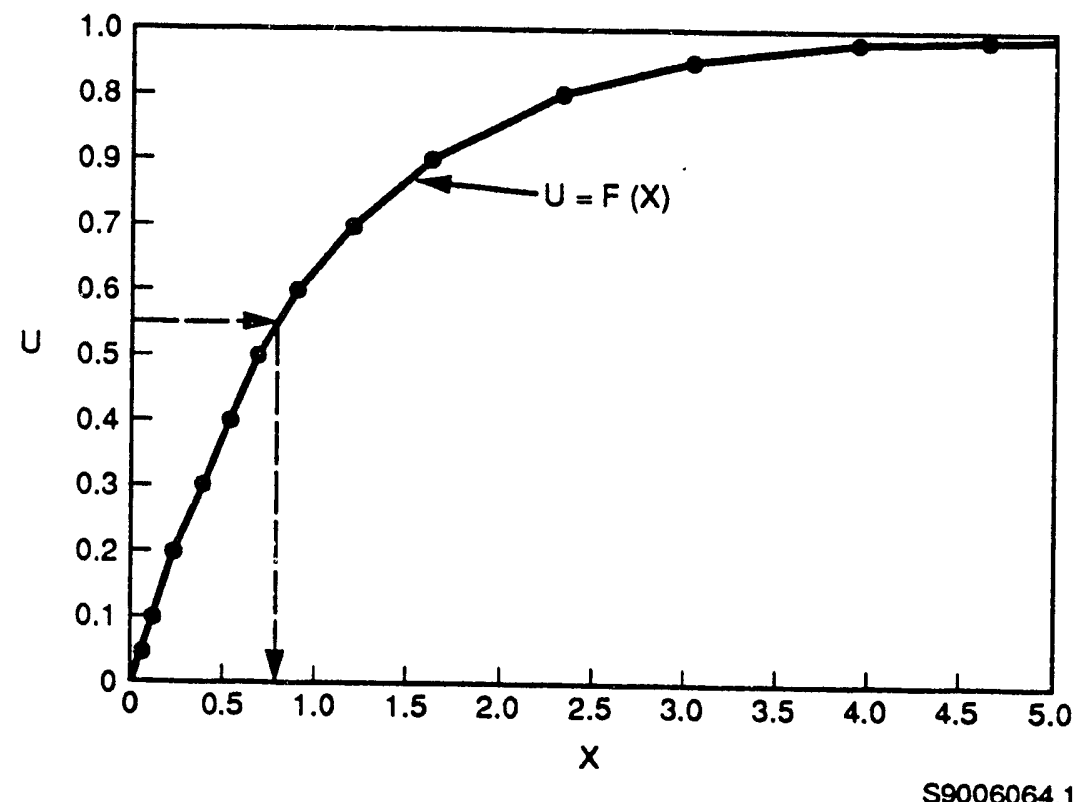

The CDFTBL code generates a table of $[x, F(x)]$ pairs given a set of field data. The table need not correspond to any classical analytical CDF. To generate the table, two options are (1) base the table on the empirical distribution function and (2) generate a CDF as the integral of a sample-based probability density function.

\subsection{EMPIRICAL DISTRIBUTION FUNCTIONS}

Consider the case in which $\mathrm{N}$ data points have been collected (a random sample). The data are assumed to come from some unknown distribution with $\operatorname{CDF} F(x)$. The empirical distribution function $E F(x)$ (Mood et al. 1974, p. 264) estimates the CDF usirg the sample data. The empirical CDF is defined as follows:

$$
E F(x)=n(x) / N
$$


where $n(x)$ is the number of data values that are less than or equal to $x$. If all of the data values are unique, $E F(x)$ has jumps of height of $1 / N$ at each of the data locations. The jumps in $E F(x)$ have height $k / N$ at location $x$ if $k$ of the data values have the same value $x$, i.e., if there are $k$ ties in the data set at location $x$.

When a data set with $k$ ties at a location $x$ is encountered, the data are modified to eliminate the ties. The data are adjusted to have a spread of $(1 / k) \%$ of the distance between the next largest and smallest data values. This approach ensures unique $x$ values for separate probability levels in the output table. The data adjustments are made after data transformations are performed.

The analyst chooses a set of probabilities, $\left\{p_{i}\right\}$, to use in the output table of $(x, p)$ pairs. Then, linear interpulation can be performed on the function $E F(x)$ to find the $x$ values corresponding to each of the $p_{i}$.

A special case arises when a chosen $p_{i}$ is less than $1 / N$ and the table of probabilities is being generated using the empirical CDF approach. In that case, the desired $x$ value may be less than the smallest observed data value. The code assigns $p_{i}$ to the smallest data value $(x)$ for each $p_{i}$ less than $1 / N$.

\subsection{CUMULATIVE DISTRIBUTION FUNCTIONS BASED ON SAMPLE DENSITY ESTIMATES}

Consider again the case in which $N$ data points have been collected (a random sample). The data are assumed to come from some unknown distribution with CDF $F(x)$. The CDF $F(x)$ can be considered as the integral of the probability density function over the range $-\infty$ to $x$. Another approach to finding a sample-based CDF is to generate a density estimate based on the sample values and then integrate it to obtain the CDF.

A class of sample density estimators called kernel estimators was considered by Parzen (1962). The kernel density estimator has the form

$$
g(y)=\frac{1}{n c_{N} s_{N}} \sum_{i=1}^{N} w\left[\left(y-x_{i}\right) /\left(c_{N} s_{N}\right)\right]
$$

where

$$
\begin{aligned}
\left\{c_{N}\right\} & =\text { a sequence of constants converging to zero at an appropriate rate } \\
S_{N} & =\text { a scale (standard deviation) estimator } \\
w & =\text { a smooth density on the real line } \\
x_{i} & =\text { a sample data value. }
\end{aligned}
$$


For application purposes, $w$ is defined as:

$$
w(z)= \begin{cases}0.75\left(1-z^{2}\right) & \text { if }|z|<1 \\ 0 & \text { otherwise. }\end{cases}
$$

This kernel has been shown to have optimal mean-squared-error properties for density estimation (Epanechnikov 1969). The scale estimator used is the median absolute deviation divided by 0.6745 , as suggested by Berar (1977). The sequence $\left\{c_{N}\right\}$ chosen is $c_{N}=2.283 * N^{-287}$, which is based on work by Eslinger and Wooaward (1990).

The CDFTBL code uses the sample data values to generate the sample density function, using $g(y)$, at a large number of $y$ values. This set of values is then integrated to find the sample-based CDF. Finally, a linear interpolation procedure is done on the sample-based CDF to find ine $x$ values that correspond to the desired set of probabilities, $\left\{p_{i}\right\}$, that are entered in the output probability table of $(x, p)$ pairs.

\subsection{RANDOM-SAMPLE ASSUMPTION}

The most important assumption made about tha data is that the collection of data values entered into the CDFTBL program form a (statistically) random sample. If this assumption is violated, the output. CDF (in the form of a table) may not be representative of the statistical distribution actually defining the physical phenomena that were sampled. The computed CDF will always have the usual (continuous, nonnegative, and integrate to unity) properties even if the random-sample assumption is violated.

Most elementary statistics textbooks (e.g., Strait 1989, p. 330) discuss the concept of a random-sample. The essence of the random-sampie concept is that all data values are collected under identical conditions and are associated with identical governing probability distributions.

\subsection{PRACTICAL USE CONSIDERATIONS}

The two estimation procedures have subtle differences. In general, the empirical CDF approach applies a probability mass of size $1 / N$ at the discrete locations corresponding to the data locations, while the kernelestimation approach spreads the same probability mass over a small region centered at the data location. No strong theoretical reason exists to substantiate the preference of one approach to the other. The author generaliy prefers the kernel-based approach to the empirical-based approach.

The empirical-based approacin may be preferable when some data are obtained "close" to a region el iminated by physical model considerations (e.g., porosity is constrained between 0 and 1). The kernel-based approach spreads the probability mass associated with a data point over a small region; thus, it may assign a non-zero probability to an "impossible" region. The empirical-based approach will assign a zero probability to the regions below 
the smallest data value and above the largest data value. When the user can define "impossible" regions from physical constraints, the ALIAS modifier (see Section 5.1) on the kernel-based approach can be used to force zero probabilities in the regions identified.

Both estimation procedures are "consistent," in that the sample-based CDF converges to the theoretical CDF when a large sample is drawn from some specified probability distribution (Serfling 1980, p. 57; Devroye 1987, p. 37). In addition, convergence rates based on asympt.jtic arguments are available from the same references. The code requires ai least four data values to successfully generate the CDF table. More than four values are desirable because the procedure estimates the shape of an entire function. As a general rule, at least 20 values are required to obtain a representative sample-based CDF. It is preferable to have 100 or more values.

Often when data are collected, one or more values are "outliers" in that they do not lie within the main body of the data. The CDFTBL code does not implement any procedures that detect or treat outliers. The user must closely scrutinize the data used. As a general rule, only those data for which a collection or measurement error can be identified should be discarded; data should not be discarded simply because they are different.

\subsection{CODE STRUCTURE AND PROGRAM EXECUTION}

\subsection{INPUT AND OUTPUT FILES}

The CDFTBL program imposes a restrictive filenaming convention. The single input file must have the name $x x x x x x x x$.dat. The user is free to specify any character sequence for the string represented as $x x x x \times x x x$. The program always writes a report file that will have the name $x \times x x x x x x$.rpt. Depending on the choice of input commands, an optional plot file also will be written. The name of the plot file will be $x x x x x x x x . p 1 t$. A more detailed description of the files is given below.

All inputs to the CDFTBL code are through the data file (except the name of the data file). All outputs (other than the prompt for the data file name) are written to files as well.

\subsubsection{The Input File}

The single input file for the CDFTBL program consists of two sections. The first section contains free-format keyword commands to select program options and define the data set. The second section contains the input data values from which tie probability table is to be generated. The input file is a formatted fila, containing only American Standard Code for Information Interchange (ASCII) characters that the user must generate using a file-editing program. Section 4.0 describes the free-format command language, and Section 5.0 describes in detail the keyword-controlled options. The data values do not require any special input format; however, each line of the input must have the same number of data values. The last line containing data 
values may contain a smaller number of values if the number of data values is not a multiple of the number of values per line.

\subsubsection{Description of the Output Files}

Two separate output files are written by the CDFTBL code. Section 6.0 gives examples of these files.

The first file, called the report file, is written every time the code is executed. If errors are detected in the input keywords, the report file contains only error messages. If no input errors are detected, the report file contains a banner page with identifying information (i.e., code name and date, user name, and run identification number). In addition, it contains the output probability table.

The second file, called the plot file, contains information that can be sent to a general-purpose $(x, y)$ plotting program. This file is written only if the PLOT keyword is used (see Section 5.3 for a description of the PLOT keyword). Three possible plot curves are in this file. First, a copy of the probability table may be written to the plot file. Second, the CDF from which the table values are extracted may be written to the plot file. Third, if the kernel-density estimation approach is used to generate the probability table, the probability density used in the kernel-density estimator may be written to the plot file.

\subsection{RUNMING THE PROGRAM}

The CDFTBL code runs in an interactive mode. Once the code has been compiled and loaded onto a specific computer, the user can initiate the program run by typing the command CDFTBL on an IBM personal computer $(P C)$. On a VAX ${ }^{2}$ the user enters RUN CDFTBL. The code then displays a few 7 ines of information and prompts the user for the data file name. Table l shows an example of the message output by the CDFTBL code.

Assume that the user has created the data file EXAMPLE1.DAT, which is listed in Section 6.0. The user would then enter the text string EXAMPLEI and press the ENTER key. No further interactive responses are necessary.

The program currently uses an uppercase type style for the file extensions (i.e.,. .DAT, .RPT, and.PLT). This convention can be changed by modifying three statements (calls to subroutine CONCAT) in subroutine OPENER. No restrictions are placed on the case of the name the user enters.

\footnotetext{
${ }^{1}$ IBM is a registered trademark of International Business Machines Inc.

${ }^{2} V A X$ is a trademark of the Digital Equipment Corporation.
} 
Table 1. Example Interactive Outputs by the CDFTBL Code.

Cumulative Distribution Function Estimation

\begin{tabular}{l} 
CDFTBL $1.0 \quad$ Run ID $=900117155358$ User $=X \times X \times X X \times . \times X X X X X$ \\
\hline There is 1 input file and 2 output files \\
The input file name must have the form "FILE.DAT" \\
The output file names will have the form "FILE.XXX" \\
The following filenaming convention is used. \\
FILE.DAT : Input - control data and sample values \\
FILE.RPT : Report file \\
FILE.PLT : (optional) plot file for the CDF \\
Enter the data iile name (WITHOUT extension) $>$
\end{tabular}

\subsection{SUBROUTINES AND THEIR FUNCTIONS}

The CDFTBL code has 28 modules, in which a module is either a FORTRAN subroutine or function. To the extent possible, each module has been assigned a single, distinct mathematical function. Subroutine IDENC is the only subroutine that is machine or operating-system dependent. The code listing in the Appendix gives versions of the subroutine for the IBM PC using the Lahey F77L compiler (Lahey 1987) and the VAX VMS ${ }^{\prime}$ operating system. Table 2 lists the modules alphabetically with a brief description of their major function.

Figure 2 shows the calling hierarchy for subroutines. Some utility subroutines (e.g., PAGER, SEPCHR, and XFKEY) are called from more than one routine.

\subsection{VARIABLE DEFINITIONS AND DIMENSION PARAMETERS}

The CDFTBL code was designed such that all global variables are contained in common blocks. Because the variables are defined in internal comments in the source code, a description of the variables is given here. The Appendix contains a complete listing of the source code.

The CDFTBL code uses PARAMETER statements to define the dimensions of various arrays. Depending on the problem that is run, the user may need to change the dimension of five arrays. Table 3 shows the parameters and their definitions.

\subsection{ERROR MESSAGES}

The CDFTBL code performs extensive checks on keyword inputs. If an error is detected, an error message is written to the report file and program execution is halted before the probability table is generated. Each error message identifies the subroutine that detected the error and gives an

\footnotetext{
'VMS is a trademark of the Digital Equipment Corporation.
} 
Table 2. Modules and Their Function. (sheet 1 of 2)

\begin{tabular}{|c|c|}
\hline Module & Description \\
\hline BANNER & Writes a banner page to the report file. \\
\hline CDFTBL & $\begin{array}{l}\text { Main (top-level) module for the program. Schedules all } \\
\text { functions for the code. }\end{array}$ \\
\hline CEXIST & $\begin{array}{l}\text { Part of the set of routines called by RDBLK to decode keyword } \\
\text { commands. Determines if an eight-letter keyword is one of the } \\
\text { modifiers for the current data record. }\end{array}$ \\
\hline COMCHR & $\begin{array}{l}\text { Part of the set of routines called by RDBLK to decode keyword } \\
\text { commands. Determines if an input character is a comment } \\
\text { identifier. }\end{array}$ \\
\hline CONCAT & Used to append extensions to the end of a file name. \\
\hline DCDSEP & $\begin{array}{l}\text { Part of the set of routines called by RDBLK to decode keyword } \\
\text { commands. Examines data in the input record and transfers } \\
\text { character and numeric data into storage vectors. }\end{array}$ \\
\hline EMPIR & $\begin{array}{l}\text { Computes the output table of probabilities using the empirical } \\
\text { distribution function method. }\end{array}$ \\
\hline EPAN & $\begin{array}{l}\text { Computes the output table of probabilities using the kernel- } \\
\text { density integration method. }\end{array}$ \\
\hline FINSEP & $\begin{array}{l}\text { Part of the set of routines called by RDBLK to decode keyword } \\
\text { commands. Locates all of the separators in the current input } \\
\text { record. }\end{array}$ \\
\hline FNAME & $\begin{array}{l}\text { Part of the set of routines called by RDBLK to decode keyword } \\
\text { commands. Extracts a file name (character string) from an } \\
\text { input card image. }\end{array}$ \\
\hline GALIAS & $\begin{array}{l}\text { Performs density aliasing operations through calls to the } \\
\text { function GKERN. }\end{array}$ \\
\hline GKERN & Evaluates the kernel density estimate at a single location. \\
\hline IDENC & $\begin{array}{l}\text { Generates identification variables for each run of the code. } \\
\text { Operating-system dependent. }\end{array}$ \\
\hline INPUTS & $\begin{array}{l}\text { Controls the reading of keyword commands and data values from } \\
\text { the input data file. }\end{array}$ \\
\hline OPENER & Opens the input and report files. \\
\hline PAGER & Writes a one-line header to an output file. \\
\hline PRNTER & Prints a table of the input data values to the report file. \\
\hline RDBLK & $\begin{array}{l}\text { Controlling module of the set of modules that decode keyword } \\
\text { data. }\end{array}$ \\
\hline SAVTTL & $\begin{array}{l}\text { Part of the set of routines called by RDBLK to decode keyword } \\
\text { commands. Moves the contents of the input record, following } \\
\text { the first separator, into an output array. }\end{array}$ \\
\hline
\end{tabular}


Table 2. Modules and Their Function. (sheet 2 of 2)

\begin{tabular}{|c|c|}
\hline Module & Description \\
\hline SCALE & $\begin{array}{l}\text { Computes the scaled median absolute deviation for the data } \\
\text { set. }\end{array}$ \\
\hline SEPCHR & $\begin{array}{l}\text { Part of the set of routines called by RDBLK to decode keyword } \\
\text { commands. Determines if a single irput character is a } \\
\text { separator character. }\end{array}$ \\
\hline SORT & Performs an algebraic sort on a data vector. \\
\hline TIES & Checks for any tied values in the input data set. \\
\hline TIES2 & Adjusts the data set to eliminate ties in the input data set. \\
\hline TRAANS & Performs transformations on the input data. \\
\hline UPCASE & $\begin{array}{l}\text { Part of the set of routines called by RDBLK to decode keyword } \\
\text { commands. Converts alphabetic characters to uppercase. }\end{array}$ \\
\hline WRITER & $\begin{array}{l}\text { Writes the final results of the program to the report and plot } \\
\text { files. }\end{array}$ \\
\hline XFKEY & $\begin{array}{l}\text { Part of the set of routines called by RDBLK to decode keyword } \\
\text { commands. Transfers keywords from an input record to a } \\
\text { storage iocation. }\end{array}$ \\
\hline
\end{tabular}


Figure 2. Subroutine Cailing Hierarchy for the CDFTBL Code.

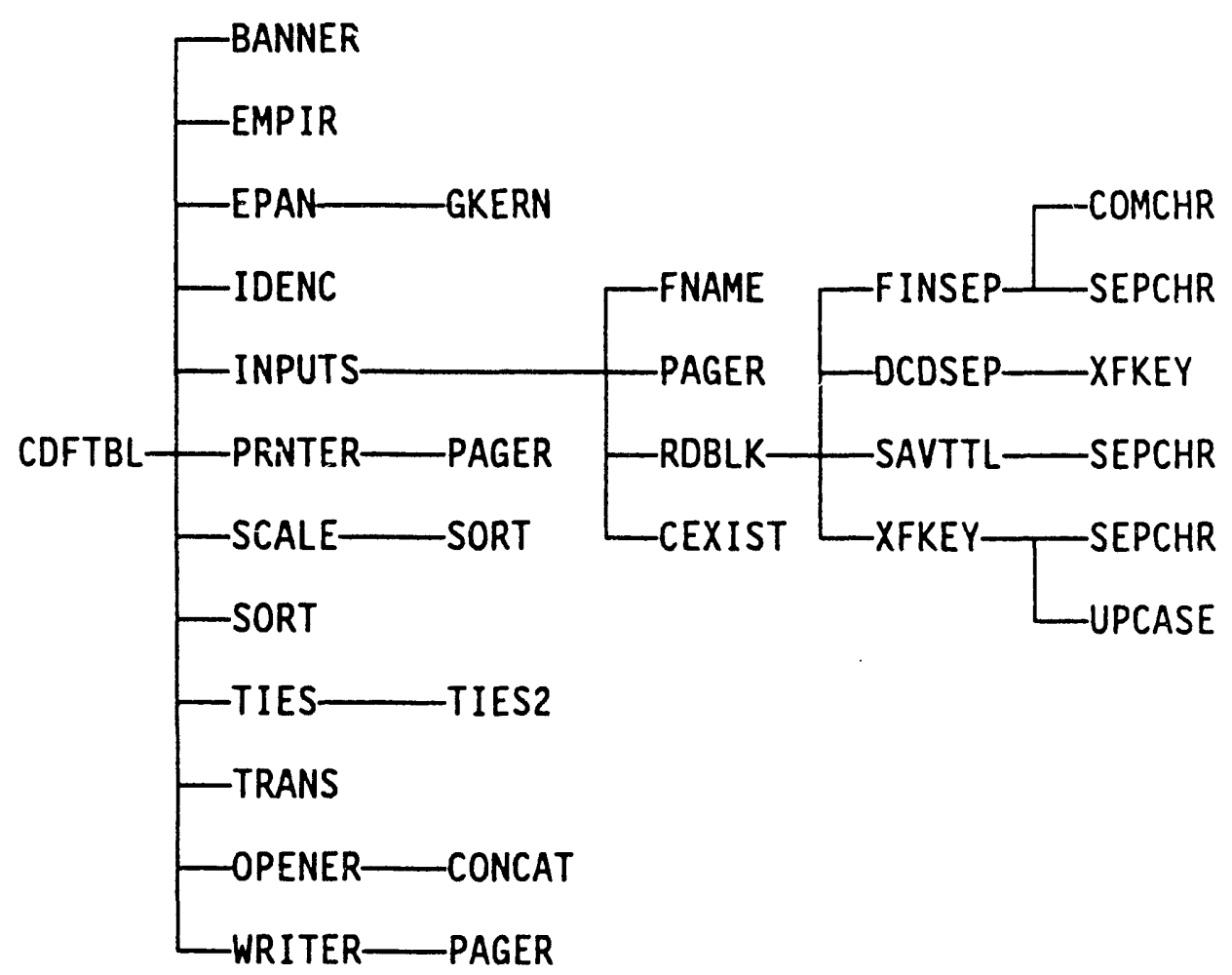

Table 3. Parameter Definitions in the CDFTBL Code.

\begin{tabular}{|c|c|c|}
\hline Parameter & Value & Definition \\
\hline MAXDAT & 1000 & $\begin{array}{l}\text { Maximum number of input data values that can be } \\
\text { used. }\end{array}$ \\
\hline MAXINT & 2000 & $\begin{array}{l}\text { Maximum number of integration steps that can be used } \\
\text { with the kernel density method for generating the } \\
\text { output probability table. }\end{array}$ \\
\hline MXALP & 500 & $\begin{array}{l}\text { Maximum rumber of modifiers that can be used in the } \\
\text { output probability table. }\end{array}$ \\
\hline NKEYS & 50 & $\begin{array}{l}\text { Maximum number of modifiers that can be contained in } \\
\text { a single keyword record, including any associated } \\
\text { continuation records. }\end{array}$ \\
\hline NVALS & 501 & $\begin{array}{l}\text { Maximum number of numerical values that can be } \\
\text { contained in a single keyword record, including any } \\
\text { associated continuation records. }\end{array}$ \\
\hline
\end{tabular}


WHC-EP-0418

indication of the user action to rorrect the error. The error messages are not discussed here in additional detail because the run-time error messages give explicit instructions for correcting problems that are detected.

\subsection{DESCRIPTION OF FREE-FORMAT COMMAND LANGUAGE}

The user interface with CDFTBL is through a free-format command language. This command language reduces user input to a set of conversational, Englishlike commands. In most cases, the commands are largely free of any requirements of format and hierarchy.

The free-format data input routine (ADATA) used in PORFLO and PORMC was developed by A. K. Runchal (Runchal and Sagar 1989). A similar functionality in input structure was desired for CDFTBL because it is a preprocessor for PORMC. The RDBLK set of routines were developed separately by Westinghouse Hanford to provide this functionality. Although the routines are independent, the input conventions for CDFTBL are almost identical to those used in PORFLO. As such, the description that follows was taken from the PORFLO User's Guide (Runchal and Sagar 1989) and is included herein with only minor modification.

The free-form language reads the input data in distinct blocks. Each block begins with a keyword (Section 4.1.1) that identifies the nature of the data within the block. The character and numeric data in a block may include several lines of an input data file. The numeric data within a block apply to the keyword at the start of the block. Character data may be modifiers (i.e., user 'options'), comments, or even inconsequential text that enhance the user readability of the input. A block ends when the next keyword, or an end-of-file, is encountered.

Within the input file, three record types are recognized: keyword, comment, and continuation. These record types are described in Section 4.1. Within each record of the input file are six distinct data types, which are described in Sertion 4.2.

\subsection{RECORD TYPES}

Three types of records are described in detail in the following sections. Each 80-column card image (record) read from the data file is considered to correspond to one of these record types. Only the first 80 columns of a record are processed; any further characters are truncated.

\subsubsection{The Keyword Record}

Function: The keyword record indicates the purpose of the numeric and character data on the keyword record and any subsequent continuation records. 
WHC-EP-0418

Structure: The keyword has the following attributes.

- A keyword record must begin with a keyword in column 1 .

- Only one keyword per record is allowed.

- Ine keyvord may be followed by modifiers and numerical fields.

- The keyword, the modifiers, and the numerical fields must be separated from one another by separator fields.

- Any character or numeric data in a keyword record after the first occurrence of a terminator is ignored.

\subsubsection{Continuation Records}

Function: A continuation record continues the input of numeric and character data started by the preceding keyword record.

Structure: The following rules are to be followed.

- The continuation record must begin with a separator as the first character of the record.

- A continuation record must always occur after a keyword record for that group.

- A continuation record must consist only of a combination of modifiers and numerical fields isolated from each other by separators.

- Any character or numerical data in a continuation record after the first occurrence of a terminator is ignored.

- Any number of continuation records may follow a keyword record.

\subsubsection{Comment Records}

Function: The comment record enhances the clarity and readability of the input.

Structure: The comment record has the following attributes.

- A comment record must begin with a slash (/), asterisk (*), dollar sign (\$), or exclamation point (!) in the first column of the record. Any combination of characters can follow the first character.

- A comment record is not processed. No numerical or character data are extracted. 
WHC-EP-0418

- A comment record cannot be extended by a continuation record.

- A comment record can be inserted anywhere in the input.

\subsection{ELEMENTS OF THE INPUT RECORD}

One or more of the following six basic elements form an input record: keyword, modifier, numeric field, separator field, terminator field, and comment field. These elements are described in the following subsections.

\subsubsection{The Keyword}

Function: The keyword identifies an input group.

Structure: The keyword has the following attributes.

- A keyword must begin in the first column of a record.

- The keyword must start with one of the characters ' $a$ ' through ' $z$ ' or ' $A$ ' through ' $Z$ '.

- The keyword may consist of any character except separator or terminator characters. The concept of a keyword is similar to that of a variable name in FORTRAN.

- The keyword may be from one to eight characters in length.

- The keyword is terminated with the first occurrence of a valid separator or terminator character.

- The keyword may be entered in upper- or lowercase.

Examples:

$A B C D, A 123$, and B\&C are all valid examples of a keyword. The keyword specifications ABCDEFGH, ABCDefgh, and AbCdEfG'nXXX (where $X$ can be any character) are all equivalent because only the first eight characters are significant and the input is case-insensitive.

' $A B, \$ A,=$ junk, and . HELP, are examples of invalid keyword specifications. Each starts with a separator or comment character.

Note that the specifications of $A B C^{\prime}, A B C \$$, and $A B C$ ( as keywords, although valid, are all equivalent to $A B C$ because the last character of each example is either a separator or a terminator.

\subsubsection{The Modifier}

Any character information in an input record following a keyword, except that embedded in a numeric or comment field, is treated as a modifier. 
Function: The modifier contains character data that help interpret the other data in the record. Many program options are implemented through the use of modifiers.

Structure: The modifier has the following attributes.

- A modifier in any input group, if present, must follow the keyword.

- The modifier is identical to the keyword in its structure, except it cannot start in column 1 of the record.

- The modifier must be separated from the keyword, other modifiers, or numeric data by a separator or terminator field.

Examples:

The structure of the modifier is identical to that of a keyword, except it cannot start in the first column of a record. Examples of keywords are given in Section 4.2.1.

\subsubsection{The Numeric Field}

Any numeric characters in a keyword or continuation record, except those embedded in a keyword, modifier, or comment field, are treated as numeric data.

Function: A numeric field contains numeric data for input variables.

Structure: The numeric field has the following attributes.

- A numeric field is a continuous string of characters that must begin with the numeric character set. In this context, the numeric character set consists of the numerals $(0-9)$, the decimal point (.), and the plus $(+)$ and minus $(-)$ operators.

- The numeric field cannot contain embedded blanks or separators.

- A numeric field must consist only of the numeric character set defined above, the asterisk $\left(^{*}\right)$, and the exponent in lower- (e) or uppercase $(E)$. It must not contain any other characters.

- The plus (+) or minus (-) sign, if present, must immediately precede the numerical value without any intervening blank or other characters; or, if used in an exponent, it must follow immediately after the exponent character e or $E$.

- The asterisk (*) or the exponent ( $E$ or e), if present, must be embedded; the numeric field must not begin or end with one of these characters.

- A numeric field must be separated from the keyword, modifiers, and other numeric fields by a valid separator or terminator field. 
- A numeric field can be located anywhere on a keyword or continuation record, except in column 1 .

- The numeric values can be specified in any of the following formats:

- Integer (e.g., 999)

- Real (e.g., 999.0 or -.99)

- Exponent (e.g., 9.99E+C2 or 9.99E-1).

- Successive, repetitive, or identical numeric values may be specified using the asterisk (*) option. Thus, $(30 ., 30 ., 30$.$) may be$ represented as $(3 * 30$. or $3 * 3 . E+1)$; embedded separators or nonnumeric characters must not appear in such specifications.

\section{Examples:}

The input character strings $1,0.1234, .567,+123,-1.005,1.2 \mathrm{e}+0$, $1.35 \mathrm{EO}$, and $3 * 1.2$ are all valid examples of a numeric field. The input specifications of $123,123 ., 1.23 \mathrm{e} 02,+0.123 \mathrm{E}+3,1 * 123$, and $1 * 1.23 \mathrm{E}+02$ are all equivalent.

The strings $1 A B, 11 \times 11$, and $1+2$ are examples of invalid numerical fields. The first two fields have embedded nonnumeric values, and the last field has a legal numeric character ( + ) embedded within the field.

A specification of 1.2 ) 2 or $1.2=2$, although valid, will be equivalent to specifying the two separate numeric fields of 1.2 and 2 because of the embedded separator character. A specification of $1.2 \$ 2$ is equivalent to 1.2 because of the presence of the terminator character $(\$)$.

\subsubsection{The Separator Field}

Function: A separator field separates the keyword, the modifiers, and the numeric fields of an input record.

Structure: Any continuous string of characters in an input record that consists of only characters from the separator character set is treated as a separator field. The valid separator characters are the space (), the comma $($,$) , the equal sign (=)$, the colon $(:)$, the semicolon $(;)$, the apostrophe ('), the left paren '(', and the right paren ')' characters.

Any character with a storage code (FORTRAN ICHAR function) less than 10 will also be treated as a separator character. This convention allows tab characters to be treated as separators.

\section{Examples:}

The sequence of characters, $1:::)),======,=1$, and $(;)$ are all valid separator fields. However, the characters (a) and (i) are not valid separator fields. In the first case, the character 'a' will be processed as a modifier; in the second case, the character 'l' will be processed as a numeric field. 


\subsubsection{The Terminator Field}

Function: A terminator ends input from an individual keyword or continuation record; however, subsequent continuation cards are processed normally. It also provides a vehicle for the user to insert comments in those records.

Structure: The terminator field has the following attributes.

- The dollar sign (\$) aird exclamation point (!) are the only valid terminators.

- The terminator ends the input for the keyword or continuation record in which it occurs; input associated with that particular keyword may continue in a continuation record that follows.

- The terminator may appear anywhere in a record.

- Any characters following the terminator in that input record are not processed; rather, they are treated as comments.

\section{Examples:}

The character sequences XYZ !Comments now, $\$$ any comments here, and $123.456 \$ 789$ are all examples of sequences with embedded terminators. In the first sequense, $X Y Z$ will be treated as valid character data (either keyword or modifier, depending on its starting location in the input record), whereas the characters following the ! will be ignored. In the second example, the total sequence will be ignored. In the third example, 789 will be ignored, whereas 123.456 will be treated as numeric data.

\subsubsection{The Comment Field}

Function: A comment field provides the vehicle for the user to insert comments into the input stream to enhance the clarity and readability of the input. The comment field may be used in the middle of a keyword and continuation record sequence.

Structure: The comment field has the following attributes.

- A comment field may be in the form of a trailing comment or a comment record.

- A trailing comment field may occur in a keyword or continuation record. It must begin with a terminator character; any combination of characters can follow the terminator character. The comment field is terminated at the end of the $80 \mathrm{th}$ character of that record.

- A comment field in a comment record may consist of any combination of characters. The comment record must begin with a slash (/), asterisk $\left({ }^{*}\right)$, dollar sign $(\$)$, or exclamation point $(!)$ in the first column of the record. 


\section{Examples:}

In the input record ARRAY $=1 ., 2 ., 3 ., 4$. SExample 1, the character string SExample 1 is an example of a trailing comment in a keyword record. Input processing stops with the \$ character; all characters including and following the $\$$ are ignored. The same result would be achieved if $\$$ were replaced with !.

The following are examples of comment records:

$$
\begin{aligned}
& \text { /ARRAY }=1 ., 2 ., 3 ., 4 . \text { SExample } 1 \\
& \text { ^ARRAY }=1 ., 2 ., 3 ., 4 . \text { !Example } 1 \\
& \text { !ARRAY }=1 ., 2 ., 3 ., 4 . \text { SExample } 1 \\
& \text { \$ARRAY }=1 ., 2 ., 3 ., 4 . \text { IExample } 1
\end{aligned}
$$

Ail of these strings of characters will be treated as comment records.

\subsection{DETAILED DESCRIPTION OF KEYWORD COMMANDS}

The method of providing input data to CDFTBL is based on reading freeformat keywords, details of which were described in Section 4.0. Each input command starts with a keyword that identifies the nature of the data to follow. The keyword is followed by alphanumeric data. The following is the notational convention for the description of input commands for CDFTBL.

BOLD The keywords for CDFTBL are shown in uppercase characters in boldface type. The string of keyword characters may be specified by the user in upper- or lowercase. Boldface is used here only for notational purposes; it must not be used as operator input.

CAPS Uppercase characters in standard typeface are modifiers of the CDFTBL keywords that are significant for machine interpretation of user input. The string of characters shown may be specified by the user in either upper- or lowercase.

char Lowercase characters denote information on keyword commands that are not significant for machine interpretation of user input, but improve the clarity or readability of the input. The string of characters shown may be specified by the user in either upper- or lowercase. In addition, they may be omitted or replaced by other character strings by the operator.

The vertical bar indicates a choice; only one of the items separated by the bar (and enclosed in braces or square brackets) may be specified.

\{ $\}$ Braces indicate that the enclosed item (or one of the enclosed items separated from the other enclosed items by vertical bars) is required and must be specified.

[ ] Square brackets indicate that the enclosed item is optional. 
... Ellipses indicate that other, similar items may follow as shown. $\mathrm{Nn} \quad$ The $n$-th numeric value that is associated with an input command.

All input data for CDFTBL are associated with a keyword. A keyword is composed of from one to eight characters. The characters can be any from $A$ to $Z$ in upper- or lowercase. A keyword always begins in the first column of an 80-column record. Table 4 summarizes the keywords for CDFTBL and the ir functions. The remainder of Section 5.0 gives detailed descriptions of the keywords.

Table 4. Keywords and Their Functions for the CDFTBL Code.

\begin{tabular}{|c|c|}
\hline Keyword & Input function \\
\hline DISTRIBU & $\begin{array}{l}\text { Chooses the technique for generating the table of } \\
\text { probabilities. }\end{array}$ \\
\hline END & Denotes the end of keyword inputs. \\
\hline PLOT & Writes a data file that can be used for plotting purposes. \\
\hline PRINT & $\begin{array}{l}\text { Prints tables of data at specified locations in the } \\
\text { processing. }\end{array}$ \\
\hline PROBABIL & Defines the probabilities for the output table of values. \\
\hline SAMPLE & Defines the size of the input data set. \\
\hline TRANSFOR & Performs transformations on the input data values. \\
\hline USER & Specifies a name for the user. \\
\hline
\end{tabular}

The RDBLK routines, which are used to decode the keyword file, convert all alphabetic characters in keywords and modifiers to uppercase. While the casual user need not know this, anyone who modifies the program should be aware of it. The module CEXIST, which checks modifiers against input options, does not make the conversion, but requires uppercase input.

The RDBLK routines also assume that the input characters ' 0 ' through ' 9 ', the characters ' $a$ ' through ' $Z$ ', and the characters ' $A$ ' through ' $Z$ ' have contiguous storage codes. If the operating system/compiler uses a non-ASCII storage code, the numeric and uppercase conversion routines may not function properly.

\subsection{DISTRIBU COMMAND}

\subsubsection{Purpose}

The DISTRIBU keyword is used to choose the type of distribution estimator to use when computing the table of probabilities. 
WHC-EP-0418

\subsubsection{Syntax}

DISTRIBU \{EMPIRICA | KERNEL] [ALIAS N1 N2 N3 ] [BANDWIDT N4] [SCALE N5] [STEPS N6]

Only one of the two modifiers EMPIRICA and KERNEL can be used. If both are entered, the program will terminate because of the input error. In the following description, the number of sample values is denoted by NSIZE (numeric value NI from the SAMPLE keyword).

Four additional modifiers (ALIAS, BANDWIDT, SCALE, and STEPS) may be used if the KERNEL option is selected. The four modifiers can be selected in any combination, but must be entered on the keyword record in alphabetical order. The numeric values $N I$ through $N 6$ described in Table 5 denote the relative positions of the numeric entries. Selection of options may not require a total of six numeric values. The casual user is not likely to ever invoke any of the three modifiers BANDWIDT, SCALE, or STEPS.

Table 5. DISTRIBU Keyword Numeric Value Description. (sheet 1 of 2)

\begin{tabular}{|c|c|c|c|}
\hline $\begin{array}{l}\text { Modifier/ } \\
\text { numeric } \\
\text { field }\end{array}$ & $\begin{array}{c}\text { Numeric } \\
\text { value }\end{array}$ & $\begin{array}{c}\text { Default } \\
\text { value }\end{array}$ & Value remarks and explanations \\
\hline EMPIRICA & -- & -- & $\begin{array}{l}\text { Computes the probability table using the } \\
\text { empirical distribution function. No } \\
\text { additional modifiers or numeric values are } \\
\text { processed. }\end{array}$ \\
\hline KERNEL & -- & -- & $\begin{array}{l}\text { Computes the probability table by using the } \\
\text { kernel density estimator. Four additional } \\
\text { modifiers (ALIAS, BANDWIDT, SCALE, and } \\
\text { STEPS) may be used. }\end{array}$ \\
\hline ALIAS & $\begin{array}{l}\mathrm{N} 1, \mathrm{~N} 2, \\
\mathrm{~N} 3\end{array}$ & -- & $\begin{array}{l}\text { This modifier applies only if KERNEL was } \\
\text { specified and controls aliasing of the } \\
\text { density value. The entry } N 1 \text { can be } 1,2 \text {, or } \\
3 \text {. If } N 1=1 \text {, the left tail of the density is } \\
\text { truncated at the value } N 2 \text { and is folded over } \\
\text { (aliased) onto the remaining domain. If } \\
N 1=2 \text {, the right tail of the density is } \\
\text { truncated at the value } N 2 \text { and is aliased } \\
\text { onto the remaining domain. If } N 1=3 \text {, the } \\
\text { density is truncated between } N 2 \text { and } N 3 \text { and } \\
\text { is aliased onto the remaining domain. }\end{array}$ \\
\hline BANDWIDT & N4 & a & $\begin{array}{l}\text { This modifier applies only if KERNEL was } \\
\text { specified. If BANDWIDT is entered, it must } \\
\text { be followed by a cn value for the kernel } \\
\text { density estimator (see Section } 2.3 \text { ). }\end{array}$ \\
\hline
\end{tabular}


Table 5. DISTRIBU Keyword Numeric Value Description. (sheet 2 of 2)

Modifier/
$\begin{gathered}\text { numeric } \\ \text { field }\end{gathered}$ $\begin{gathered}\text { value } \\ \text { value vefault }\end{gathered} \quad$ Value remarks and explanations

\begin{tabular}{|c|c|c|c|}
\hline SCALE & N5 & $\bar{b}$ & $\begin{array}{l}\text { This modifier applies only if KERNEL was } \\
\text { specified. If SCALE is entered, it must be } \\
\text { followed by a standard deviation estimate } \\
\text { for the data set. }\end{array}$ \\
\hline STEPS & N6 & 1000 & $\begin{array}{l}\text { This modifier applies only if KERNEL was } \\
\text { specified. If STEPS is entered, it must be } \\
\text { followed by the number of integration steps } \\
\text { to use in the trapezoidal integration of the } \\
\text { kernel density. }\end{array}$ \\
\hline
\end{tabular}

If BANDWIDT is not entered, $c_{0}$ is set to $2.283 *$ NSIZE** $(-.287)$.

If SCALE is not entered, a value is generated internally using the median absolute deviation.

\subsubsection{Examples}

The first example below uses the empirical distribution function approach to generating the table of probability values. The second example uses the kernel-density approach to generating the probability values and uses 400 integration steps in the process. The third example uses the kerneldensity approach to generating the table of probabilities and truncates the left tail of the density at -2 . Using this aliasing option, the density value at $x=-2+d x$, for $d x>0$, will be computed as $f(-2+d x)+f(-2-d x)$ where $f\left({ }^{*}\right)$ denotes the density estimate that would be obtained without aliasing. The density value will be set to 0 if $x$ is less than -2 .

DISTRIBU EMPIRICAT

DISTRIBU KERNEL using 400 integration STEPS

DISTRIBU KERNEL ALIAS 1 left tail truncated at -2.0

\subsection{END COMMAND}

\subsubsection{Purpose}

The END keyword informs the program that all keywords have been processed. Anything entered in the input file after this keyword will be treated as data values. The END keyword is required for proper program
execution.

\subsubsection{Syntax}

END

There are no modifiers or numeric values for this keyword. 


\subsubsection{Example}

The following example signals the program that the user has finished entering keywords and is ready to enter data values.

END of the keywords

\subsection{PLOT COMMAND}

\subsubsection{Purpose}

The PLOT keyword will cause an output data file to be written that can be used in a general-purpose line-plotting program. No plots will be generated if this keyword is omitted.

\subsubsection{Syntax}

\section{PLOT [CUMULATIV] [DENSITY] [TABLE]}

Three modifiers are available with the plot card. If none of the modifiers are present, no data will be written to the plot file. The three modifiers shown in Table 6 can be present in any combination and may be entered in any order.

Table 6. PLOT Keyword Modifiers and Their Descriptions.

\begin{tabular}{ll}
\hline Modifier & \multicolumn{1}{c}{ Remarks and explanations } \\
\hline CUMULATI & If the modifier CUMULATI is used, the CDF from which the \\
& table values are extracted is written to the plot file. \\
DENSITY & If the modifier DENSITY is used, the probability density \\
& used in the kernel density estimator is written to the plot \\
& file. This option is operational only if the keyword \\
DISTRIBU KERNEL has been entered. & \\
& If the modifier TABLE is used, a copy of the probability \\
& table is written to the plot file.
\end{tabular}

\subsubsection{Examples}

The first example writes a plot file containing the table of probability values and the entire CDF. The second example writes a plot file containing the kernel density used to generate the table of probability values.

PLOT TABLE CUMULATIVe

PLOT KERNEL density function 


\subsection{PRINT COMMAND}

\subsubsection{Purpose}

The PRINT keyword allows the user to optionally print a table of data values to the report file to examine the data before and after transformations have been performed. No data tables will be printed if this keyword is omitted. The print option applies to the data set after it has been sorted in increasing algebraic order.

\subsubsection{Syntax}

\section{PRINT [BEFORE] [AFTER] [RANGE N1 N2]}

Tables of the data can be written to the report file at two possible locations, before and after transformations are performed. A subset (range) of the data, rather than the entire data set, can be written. Enter the modifier BEFORE if data tables are desired before transformations are performed. Enter the modifier AFTER if data tables are desired after transformations are performed. In Table 7, the number of sample values is denoted by NSIZE (numeric value N1 from the SAMPLE keyword).

Table 7. PRINT Keyword Numeric Value Explanations.

\begin{tabular}{ccccc}
\hline $\begin{array}{c}\text { Numeric } \\
\text { field }\end{array}$ & $\begin{array}{c}\text { Numeric } \\
\text { value }\end{array}$ & Default & \multicolumn{1}{c}{ Remark and explanations } \\
\hline N1 & 1 to NSIZE & 1 & $\begin{array}{l}\text { Lowest index (of the sorted) data set to } \\
\text { write in the data table. This value is } \\
\text { processed only if the modifier RANGE is } \\
\text { present on the input card. } \\
\text { Highest index (of the sorted) data set to } \\
\text { write in the data table. This value is } \\
\text { processed only if the modifier RANGE is } \\
\text { present on the input card. }\end{array}$ \\
\hline
\end{tabular}

\subsubsection{Examples}

The first example prints the entire data set before and after data transformations are performed. The second example prints out the first 20 data values after transformations are performed.

PRINT BEFORE and AFTER

PRINT AFTER transformations for the index $\operatorname{RANGE}(1,20)$ 


\subsection{PROBABIL COMMAND}

\subsubsection{Purpose}

The PROBABIL keyword can be used to define probability levels in the generated table to be written to the report file. A default table will be used if this table is omitted.

\subsubsection{Syntax}

PROBABIL \{ TABLE | INCREMEN $\}\{\mathrm{N} 1\}$ [N2 .... Nn]

The probability levels to be entered in the output table of cumulative probabilities can be defined three ways. First, a default table can be used. Second, a table can be defined by explicitly listing the desired probability levels. Third, a table can be defined by specifying a single probability increment between table entries.

A default set of probabilities has been implemented that uses 35 probability levels. Omit this keyword to choose the default set of values. If this keyword is entered, it overwrites all default values. The default probabilities are $0.0,0.01,0.015,0.02,0.025,0.03,0.04,0.05,0.075,0.1$, $0.15,0.2,0.25,0.3,0.35,0.4,0.45,0.5,0.55,0.6,0.65,0.7,0.75,0.8$, $0.85,0.9,0.925,0.95,0.96,0.97,0.975,0.98,0.985,0.99$, and 1.0. 0ther options are described in Table 8.

Table 8. PROBABIL Keyword Numeric Value Explanations.

\begin{tabular}{|c|c|c|}
\hline $\begin{array}{l}\text { Numeric } \\
\text { field }\end{array}$ & $\begin{array}{l}\text { Numeric } \\
\text { value }\end{array}$ & Remarks and explanations \\
\hline \multirow[t]{2}{*}{ N1 } & $>0$ & $\begin{array}{l}\text { If the modifier TABLE is used, } \mathrm{Nl} \text { denotes the number of } \\
\text { probability levels to include in the table of cumulative } \\
\text { probability values. }\end{array}$ \\
\hline & & $\begin{array}{l}\text { If the modifier INCREMEN is used, } \mathrm{Nl} \text { denotes the common } \\
\text { probability increment between entries in the table of } \\
\text { cumulative probability values. A value of } 0.01 \text { is } \\
\text { suggested. }\end{array}$ \\
\hline$N 2, N 3 .$. & $0<\mathrm{Ni}<1$ & $\begin{array}{l}\text { The next values are read only if the modifier TABLE is } \\
\text { used, then they define the probabilities in the output } \\
\text { table. The first probability must be } 0.0 \text {, and the last } \\
\text { probability must be } 1.0 \text {. Each succeeding value must be } \\
\text { greater than the previous value. Exactly Nl probability } \\
\text { values must be entered. }\end{array}$ \\
\hline
\end{tabular}

Because the table of probabilities and associated values output by this program will be used in a linear interpolation routine in other programs, at least 20 probability levels should be specified. If the data come from a 
distribution that has a wide (mathematical) support, the extreme values in the data tend to be widely separated from the body of the data. Thus, more probability levels near 0 and 1 are needed to maintain interpolation accuracy. The default set of probabilities is suggested for this situation.

\subsubsection{Examples}

The following two examples define a probability table that has 21 entries for probabilities with probability increments of 0.05 between 0 and 1 inclusive.

$\begin{array}{llllllllllllll}\text { PROBABILity TABLE } 21 & 1 \text { individual values } & 0.0 & 0.05 & 0.1 & 0.15 & 0.2 & 0.25 & 0.3\end{array}$ $\begin{array}{lllllllllllllllll}0.35 & 0.4 & 0.45 & 0.5 & 0.55 & 0.6 & 0.65 & 0.7 & 0.75 & 0.8 & 0.85 & 0.9 & 0.95 & 1.0\end{array}$

PROBABILity INCREMENT 0.05

\subsection{SAMPLE COMMAND}

\subsubsection{Purpose}

The SAMPLE keyword defines the number of values in the sample data set and how many values are on each line of the data file. This keyword is required for program execution.

\subsubsection{Syntax}

SAMPLE $\{N 1\}$ [LINE N2]

The presence of the modifier LINE in the input will cause the numeric value N2 to be read and processed; otherwise, N2 will be ignored. Table 9 gives additional explanations for the numeric values.

\subsubsection{Examples}

The first two examples define a data set that has 40 values, with 1 value per line of the input data file. The third example defines a data set with 20 vaiues, entered with 5 values per line.

SAMPLE 40

SAMPLE 40 LINE 1

SAMPLE size 20 with 5 values per LINE 
Table 9. Sample Keyword Numeric Value Explanations.

\begin{tabular}{cccc}
\hline $\begin{array}{c}\text { Numeric } \\
\text { field }\end{array}$ & $\begin{array}{c}\text { Numeric } \\
\text { value }\end{array}$ & Default value & \multicolumn{1}{c}{ Remarks and explanations } \\
\hline N1 & Positive & None & $\begin{array}{l}\text { The number of data values that } \\
\text { will be used for generating the } \\
\text { probability values A lower limit } \\
\text { of } 4 \text { is enforced; however, at } \\
\text { least } 20 \text { are suggested. }\end{array}$ \\
N2 & Positive & $\begin{array}{l}\text { This entry identifies the number } \\
\text { of data values per line in the } \\
\text { input data file. Each line in the } \\
\text { input file must contain N2 data } \\
\text { values. The last line will } \\
\text { contain fewer values if the N1 is } \\
\text { not a multiple of N2. }\end{array}$ \\
\hline
\end{tabular}

\subsection{TRANSFOR COMMAND}

\subsubsection{Purpose}

The purpose of the TRANSFOR keyword is to allow the user to perform common transformations on the input data set before generation of the CDF. No transformations will be done if this keyword is omitted.

\subsubsection{Syntax}

TRANSFOR $\{N 1\} \quad[N 2, N 3]$

This keyword invokes a data transformation option. The first numeric entry is a transformation index.

\subsubsection{Examples}

The first example invokes a logarithm (base 10) transformation on the input data. The second example does a linear transformation that shifts the data by subtracting -2 (adding 2 ) and dividing the result by 3 .

TRANSFORm 1

TRANSFORm type 3 shift -2 divide by 3 
Table 10. TRANSFOR Keyword Numeric Value Explanations.

\begin{tabular}{cccl}
\hline $\begin{array}{c}\text { Numeric } \\
\text { field }\end{array}$ & $\begin{array}{c}\text { Numeric } \\
\text { value }\end{array}$ & $\begin{array}{c}\text { Default } \\
\text { value }\end{array}$ & \multicolumn{1}{c}{ Remarks and explanations } \\
\hline N1 & 0 & 0 & $\begin{array}{l}\text { No data transformation will be performed. } \\
\text { A log base } 10 \text { transformation will be } \\
\text { performed. This requires that all data } \\
\text { values be positive. }\end{array}$ \\
& 1 & $\begin{array}{l}\text { A linear transformation will be performed. } \\
\text { Also required are two additional numerical } \\
\text { values, N2 and N3. The transformation is } \\
X n e w=(X 01 d-N 2) / N 3 .\end{array}$ \\
N2 & Any & None & Shift value in the linear transformation. \\
N3 & Nonzero & None & Divisor in the linear transformation. \\
\hline
\end{tabular}

\subsection{USER COMMAND}

\subsubsection{Purpose}

The USER keyword can be used to define a new user name. A default user

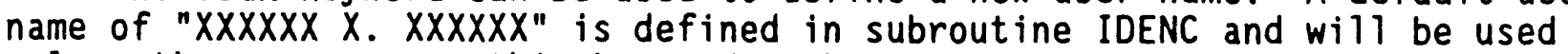
unless the user enters this keyword. The user name is written to all output files.

\subsubsection{Syntax}

USER \{"New Name"\}

The user name can contain up to 16 characters. The name to be entered must be contained between double quotation marks. The default user name is retained if an illegal user name is encountered.

\subsubsection{Example}

In this example the default user name is changed to John Doe. USER "John Doe" 


\subsection{EXAMPLE RUNS AND CODE VERIFICATION}

This section contains four example runs of the code. The examples exercise different features of the code, illustrate the free-form command language, and serve as verification cases for the code.

Two methods were used to verify the code: hand calculations and comparison with analytical solutions. Hand calculations were performed to test the following: (1) data transformations, (2) kernel-density estimates, (3) integration of the kernel density to obtain a CDF, (4) interpolation of the kernel-based CDF to form the output-probability table, (5) empirical CDF estimates, and (6) interpolation of the empirical CDF to form the outputprobability table. The data sorting subroutine was verified by inspection on several data sets.

Several runs of the code were made with large data sets sampled from known probability distributions. For each of these runs, the computed probability table was compared to the analytical CDF for the selected probability distribution. In each case the results were within the range expected from sampling variation.

The CDFTBL code has eight keywords, several of which have multiple options. The code was run enough times to test each keyword individually, and most of the options in their proper combinations. An attempt was made to code exhaustive checks on the keywords to eliminate illegal or unreasonable option combinations.

\subsection{EXAMPLE 1}

Example 1 illustrates the kernel-density estimation technique on a sample of 200 data, which were obtained as a random sample from a standard normal distribution. Table 11 shows the input file, and Table 12 shows the report file.

This example can be used to help verify the implementation of the kernel density estimator. The accuracy of the output CDF table can be checked by comparing it to the analytical standard normal CDF (Strait 1989). The results show reasonable agreement for a sample of 200 data. Another way to examine the accuracy of the estimation technique is to determine if the generated PDF can be considered as being "close" to the PDF of the standard normal distribution using a metric such as the Hellinger metric (Eslinger and Woodward 1990). The PDF generated by this example is acceptable as a standard-normal PDF using this metric.

\subsection{EXAMPLE 2}

Example 2 illustrates the empirical distribution function technique on a sample of 200 data, which were obtained as a random sample from a standard normal distribution. The data used in this example are the same as those used in example 1. Table 13 shows the input file; Table 14 shows the report file. 
WHC-EP-0418

Table 11. Input Data File for Example 1: EXAMPLE1.DAT.

\begin{tabular}{|c|c|c|c|c|}
\hline $\begin{array}{l}\text { ! Input file } \\
\text { DISTRIBUTION } \\
\text { PROBABILITY } \\
\text { SAMPLE Size } \\
\text { USER "PaUI W } \\
\text { END }\end{array}$ & $\begin{array}{l}\text { EXAMPLEl.D } \\
\text { KERNEL } \\
\text { INCREMENT } 0 \\
\text { OO with } 5 \\
\text { Eslinger" }\end{array}$ & $\begin{array}{l}T \text { for the } \\
025 \\
\text { alues per }\end{array}$ & CDFTBL User & s Manual \\
\hline $\begin{array}{r}0.64085 \\
0.12138 \\
0.24989 \\
-1.79454 \\
0.17183 \\
-0.96684 \\
-0.48006 \\
1.10860 \\
-0.06211 \\
-0.24745 \\
-2.80329 \\
0.15881 \\
0.91340 \\
-0.03287 \\
-1.11690 \\
-1.40432 \\
-0.78544 \\
-0.26005 \\
-1.84836 \\
0.56585 \\
0.71942 \\
-0.59664 \\
-0.91995 \\
0.60308 \\
-1.60187 \\
0.07418 \\
0.99004 \\
-1.28231 \\
-1.19759 \\
1.66648 \\
0.81387 \\
-0.12445 \\
1.23301 \\
0.49101 \\
2.01105 \\
-0.33275 \\
1.69000 \\
1.44965 \\
1.06771 \\
-2.66981 \\
\end{array}$ & $\begin{array}{r}0.22846 \\
-0.38882 \\
0.65894 \\
-1.00094 \\
-2.53104 \\
0.31062 \\
-0.94326 \\
-0.81396 \\
-0.55425 \\
-1.12485 \\
0.02076 \\
1.10716 \\
-1.36126 \\
-0.97539 \\
0.97984 \\
-0.13249 \\
1.59368 \\
-0.57094 \\
-0.12579 \\
-0.21985 \\
0.08398 \\
-0.82225 \\
-1.34402 \\
1.07314 \\
0.06867 \\
-0.21813 \\
0.79026 \\
-0.12131 \\
1.08136 \\
-0.06710 \\
-0.03919 \\
-0.74095 \\
0.32693 \\
-1.23658 \\
0.13155 \\
1.36228 \\
-1.66245 \\
-0.31835 \\
0.06645 \\
0.76398 \\
\end{array}$ & $\begin{array}{r}-1.14595 \\
0.45407 \\
0.77606 \\
0.54271 \\
0.17009 \\
-0.91674 \\
0.95084 \\
-1.63515 \\
-1.75557 \\
-0.28577 \\
0.55397 \\
1.96530 \\
-0.16939 \\
1.01676 \\
0.44495 \\
0.71608 \\
-1.02657 \\
0.01283 \\
-0.49458 \\
-0.92563 \\
1.32623 \\
-0.60857 \\
0.61865 \\
-1.49750 \\
0.19505 \\
-0.10331 \\
0.69863 \\
-1.41141 \\
1.32379 \\
1.36977 \\
0.90694 \\
1.33433 \\
-0.94073 \\
-0.84951 \\
-2.39130 \\
-0.60063 \\
-0.57094 \\
-0.15303 \\
0.51676 \\
-0.10199\end{array}$ & $\begin{array}{r}-1.03808 \\
0.26864 \\
0.47764 \\
-0.27218 \\
-0.10363 \\
-0.80962 \\
0.41019 \\
-0.49617 \\
-0.70514 \\
-1.01844 \\
-0.39109 \\
-1.71948 \\
-1.08821 \\
-1.49732 \\
-0.41358 \\
-0.76421 \\
1.36543 \\
0.07222 \\
0.54947 \\
-0.76253 \\
-0.41513 \\
0.03159 \\
-0.08889 \\
-0.58747 \\
-1.42170 \\
-1.63859 \\
-1.18345 \\
0.79185 \\
0.09148 \\
-1.82089 \\
-0.13993 \\
0.69509 \\
0.51258 \\
-0.23464 \\
-1.36184 \\
1.09603 \\
0.12209 \\
-0.22814 \\
-1.04566 \\
1.09158\end{array}$ & $\begin{array}{r}0.25602 \\
-0.45454 \\
-0.38137 \\
0.89912 \\
1.27442 \\
1.98233 \\
0.22383 \\
-0.55313 \\
0.70862 \\
-0.78787 \\
0.20761 \\
0.60075 \\
0.21064 \\
0.43162 \\
0.06351 \\
-0.26686 \\
0.29006 \\
-0.54039 \\
-0.14454 \\
0.92402 \\
1.75942 \\
-0.67760 \\
-0.64575 \\
0.86685 \\
0.00776 \\
-0.61013 \\
0.03783 \\
0.03560 \\
-1.95512 \\
0.46820 \\
-0.52143 \\
-0.03186 \\
0.22641 \\
0.21056 \\
1.21370 \\
-0.53799 \\
-1.34285 \\
2.54004 \\
-1.54310 \\
1.29710\end{array}$ \\
\hline
\end{tabular}


WHC-EP-0418

Table 12. Report File for Example 1: EXAMPLE1.RPT. (sheet 1 of 2)

1

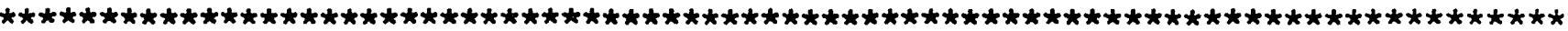

$\star$

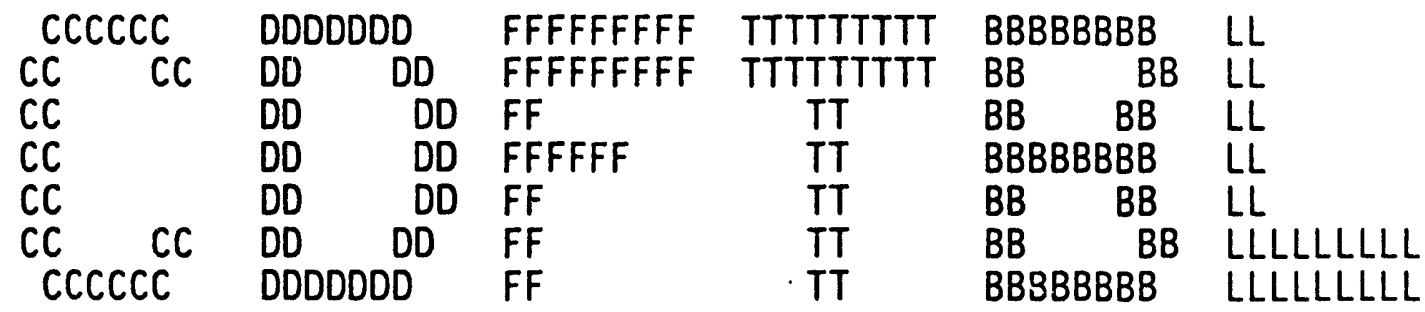

CDFTBL $\quad 1.000$

Last Modified on 13 Jun 1990

Cumulative Distribution Function Estimation

from a User Supplied Data Set

Statistical Program Developed by Paul W. Eslinger Keyword Input Routines Developed by Dave W. Langford

Current Run ID $=900620202841$ User Name $=$ Paul W. Eslinger

System Date $=06 / 20 / 90$ System Time $=20: 28: 41$

\footnotetext{
$\star \star$

1 Program: COFTBL Version: 1.000 User: Paul W. Eslinger Run ID: 900620202841

Cumulative Probabilities Using Kernel Density Estimation

The density estimate was based on 200 values.

The scale estimate was $1.0123 E+00$

The kernel bandwidth value was 0.49901

The probability table has 41 pairs of values.
} 
Table 12. Report File for Example 1: EXAMPLE1.RPT. (sheet 2 of 2)

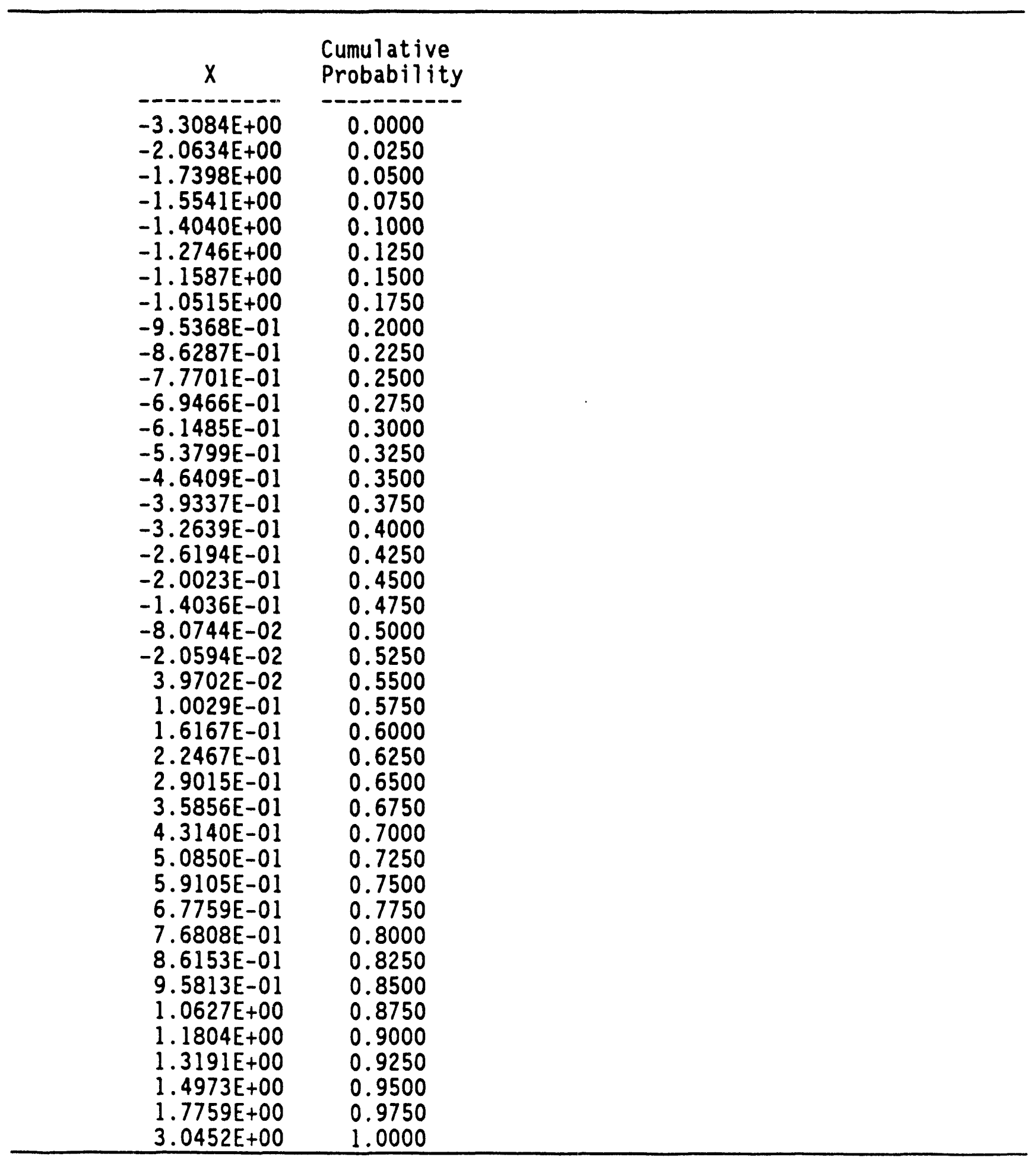


Table 13. Input Data File Example 2: EXAMPLE2.DAT.

\begin{tabular}{|c|c|c|c|c|}
\hline $\begin{array}{l}\text { ! Input file } \\
\text { DISTRIBUTION } \\
\text { PROBABILITY } \\
\text { SAMPLE size } 2 \\
\text { USER " aUI } W . \\
\text { END }\end{array}$ & $\begin{array}{l}\text { EXAMPLE2.D } \\
\text { empirical } \\
\text { NCREMENT } 0 \\
00 \text { with } 5 \\
\text { Esl inger" }\end{array}$ & $\begin{array}{l}\text { Tor the } \\
025 \\
\text { alues per }\end{array}$ & DFTBL User & ; Manual \\
\hline $\begin{array}{r}0.64085 \\
0.12138 \\
0.24989 \\
-1.79454 \\
0.17183 \\
-0.96684 \\
-0.48006 \\
1.10860 \\
-0.06211 \\
-0.24745 \\
-2.80329 \\
0.15881 \\
0.91340 \\
-0.03287 \\
-1.11690 \\
-1.40432 \\
-0.78544 \\
-0.26005 \\
-1.84836 \\
0.56585 \\
0.71942 \\
-0.59664 \\
-0.91995 \\
0.60308 \\
-1.60187 \\
0.07418 \\
0.99004 \\
-1.28231 \\
-1.19759 \\
1.66648 \\
0.81387 \\
-0.12445 \\
1.23301 \\
0.49101 \\
2.01105 \\
-0.33275 \\
1.69000 \\
1.44965 \\
1.06771 \\
-2.66981\end{array}$ & $\begin{array}{r}0.22846 \\
-0.38882 \\
0.65894 \\
-1.00094 \\
-2.53104 \\
0.31062 \\
-0.94326 \\
-0.81396 \\
-0.55425 \\
-1.12485 \\
0.02076 \\
1.10716 \\
-1.36126 \\
-0.97539 \\
0.97984 \\
-0.13249 \\
1.59368 \\
-0.57094 \\
-0.12579 \\
-0.21985 \\
0.08398 \\
-0.82225 \\
-1.34402 \\
1.07314 \\
0.06867 \\
-0.21813 \\
0.79026 \\
-0.12131 \\
1.08136 \\
-0.06710 \\
-0.03919 \\
-0.74095 \\
0.32693 \\
-1.23658 \\
0.13155 \\
1.36228 \\
-1.66245 \\
-0.31835 \\
0.06645 \\
0.76398\end{array}$ & $\begin{array}{r}-1.14595 \\
0.45407 \\
0.77606 \\
0.54271 \\
0.17009 \\
-0.91674 \\
0.95084 \\
-1.63515 \\
-1.75557 \\
-0.28577 \\
0.55397 \\
1.96530 \\
-0.16939 \\
1.01676 \\
0.44495 \\
0.71608 \\
-1.02657 \\
0.01283 \\
-0.49458 \\
-0.92563 \\
1.32623 \\
-0.60857 \\
0.61865 \\
-1.49750 \\
0.19505 \\
-0.10331 \\
0.69863 \\
-1.41141 \\
1.32379 \\
1.36977 \\
0.90694 \\
1.33433 \\
-0.94073 \\
-0.84951 \\
-2.39130 \\
-0.60063 \\
-0.57094 \\
-0.15303 \\
0.51676 \\
-0.10199\end{array}$ & $\begin{array}{r}-1.03808 \\
0.26864 \\
0.47764 \\
-0.27218 \\
-0.10363 \\
-0.80962 \\
0.41019 \\
-0.49617 \\
-0.70514 \\
-1.01844 \\
-0.39109 \\
-1.71948 \\
-1.08821 \\
-1.49732 \\
-0.41358 \\
-0.76421 \\
1.36543 \\
0.07222 \\
0.54947 \\
-0.76253 \\
-0.41513 \\
0.03159 \\
-0.08889 \\
-0.58747 \\
-1.42170 \\
-1.63859 \\
-1.18345 \\
0.79185 \\
0.09148 \\
-1.82089 \\
-0.13993 \\
0.69509 \\
0.51258 \\
-0.23464 \\
-1.36184 \\
1.09603 \\
0.12209 \\
-0.22814 \\
-1.04566 \\
1.09158\end{array}$ & $\begin{array}{r}0.25602 \\
-0.45454 \\
-0.38137 \\
0.89912 \\
1.27442 \\
1.98233 \\
0.22383 \\
-0.55313 \\
0.70862 \\
-0.78787 \\
0.20761 \\
0.60075 \\
0.21064 \\
0.43162 \\
0.06351 \\
-0.26686 \\
0.29006 \\
-0.54039 \\
-0.14454 \\
0.92402 \\
1.75942 \\
-0.67760 \\
-0.64575 \\
0.86685 \\
0.00776 \\
-0.61013 \\
0.03783 \\
0.03560 \\
-1.95512 \\
0.46820 \\
-0.52143 \\
-0.03186 \\
0.22641 \\
0.21056 \\
1.21370 \\
-0.53799 \\
-1.34285 \\
2.54004 \\
-1.54310 \\
1.29710\end{array}$ \\
\hline
\end{tabular}


WHC-EP-0418

Table 14. Report File for Example 2: EXAMPLE2.RPT. (sheet 1 of 2)

$\overline{1}$

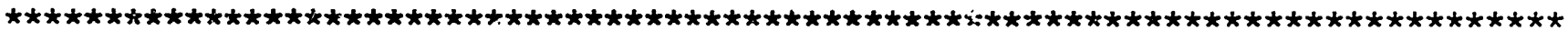

*

\begin{tabular}{|c|c|c|c|c|c|}
\hline \begin{tabular}{l}
\multicolumn{2}{c}{$C C C C C$} \\
$C C \quad C C$ \\
$C C$ \\
$C C$ \\
$C C$ \\
$C C \quad C C$ \\
$C C C C C$
\end{tabular} & $\begin{array}{ll}\text { DDDDDDD } \\
\text { DD } & \text { DD } \\
\text { DD } & \text { DD } \\
\text { DD } & \text { DD } \\
\text { DD } & \text { DD } \\
\text { DD } & \text { DD } \\
\text { DDDDDDD }\end{array}$ & $\begin{array}{l}\text { FFFFFFFFF } \\
\text { FFFFFFFFF } \\
\text { FF } \\
\text { FFFFFF } \\
\text { FF } \\
\text { FF } \\
\text { FF }\end{array}$ & $\begin{array}{c}\text { TTTTTTTTT } \\
\text { TTTTTTTT } \\
\text { TT } \\
\text { TT } \\
\text { TT } \\
\text { TT } \\
\text { TT }\end{array}$ & $\begin{array}{lc}\text { BBBBBBBB } \\
\text { BB }\end{array}$ & $\begin{array}{l}\text { LL } \\
\text { LL } \\
\text { LL } \\
\text { LL } \\
\text { LL } \\
\text { LLLLLLLLL } \\
\text { LLLLLLLLL }\end{array}$ \\
\hline
\end{tabular}

CDFTBL $\quad 1.000$

Last Modified on 13 Jun 1990

Cumulative Distribution Function Estimation from a User Supplied Data Set

Statistical Program Developed by Paul W. Eslinger Kesword Input Routines Developed by Dave W. Langford

Current Run ID $=900620202852$ User Name $=$ Paul W. Estinger

System Date $=06 / 20 / 90$ System Time $=20: 28: 52$

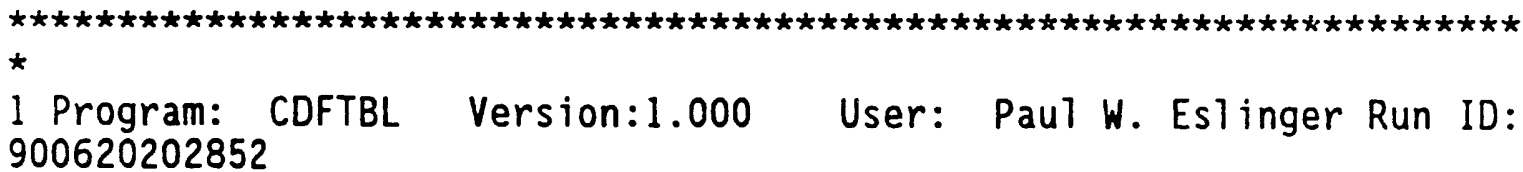

Cumulative Probabilities Using The Empirical Distribution

The density estimate was based on 200 values.

The probability table has 41 pairs of values. 
Table 14. Report File for Example 2: EXAMPLE2.RPT. (sheet 2 of 2)

$\begin{array}{cc}\begin{array}{c}\text { Cumulative } \\ X\end{array} & \text { Probability } \\ -2.8033 \mathrm{E}+00 & 0.0000 \\ -1.9551 \mathrm{E}+00 & 0.0250 \\ -1.7195 \mathrm{E}+00 & 0.0500 \\ -1.5431 \mathrm{E}+00 & 0.0750 \\ -1.4043 \mathrm{E}+00 & 0.1000 \\ -1.2823 \mathrm{E}+00 & 0.1250 \\ -1.1249 \mathrm{E}+00 & 0.1500 \\ -1.0266 \mathrm{E}+00 & 0.1750 \\ -9.4326 \mathrm{E}-01 & 0.2000 \\ -8.4951 \mathrm{E}-01 & 0.2250 \\ -7.8544 \mathrm{E}-01 & 0.2500 \\ -6.7760 \mathrm{E}-01 & 0.2750 \\ -5.9664 \mathrm{E}-01 & 0.3000 \\ -5.5313 \mathrm{E}-01 & 0.3250 \\ -4.9458 \mathrm{E}-01 & 0.3500 \\ -3.9109 \mathrm{E}-01 & 0.3750 \\ -2.8577 \mathrm{E}-01 & 0.4000 \\ -2.3464 \mathrm{E}-01 & 0.4250 \\ -1.5303 \mathrm{E}-01 & 0.4500 \\ -1.2445 \mathrm{E}-01 & 0.4750 \\ -8.8890 \mathrm{E}-02 & 0.5000 \\ -3.1860 \mathrm{E}-02 & 0.5250 \\ 3.5600 \mathrm{E}-02 & 0.5500 \\ 7.2220 \mathrm{E}-02 & 0.5750 \\ 1.2209 \mathrm{E}-01 & 0.6000 \\ 1.9505 \mathrm{E}-01 & 0.6250 \\ 2.2641 \mathrm{E}-01 & 0.6500 \\ 2.9006 \mathrm{E}-01 & 0.6750 \\ 4.4495 \mathrm{E}-01 & 0.7000 \\ 5.1258 \mathrm{E}-01 & 0.7250 \\ 5.6585 \mathrm{E}-01 & 0.7500 \\ 6.5894 \mathrm{E}-01 & 0.7750 \\ 7.1942 \mathrm{E}-01 & 0.8000 \\ 8.1387 \mathrm{E}-01 & 0.8250 \\ 9.2402 \mathrm{E}-01 & 0.8500 \\ 1.0677 \mathrm{E}+00 & 0.8750 \\ 1.1072 \mathrm{E}+00 & 0.9000 \\ 1.2971 \mathrm{E}+00 & 0.9250 \\ 1.3654 \mathrm{E}+00 & 0.9500 \\ 1.6900 \mathrm{E}+00 & 0.9750 \\ 2.5400 \mathrm{E}+00 & 1.0000 \\ & \end{array}$


This example can be used to help verify the implementation of the empirical distribution-function estimator. The accuracy of the output CDF table can be checked by comparing these results to the analytical standardnormal CDF (Strait 1989). The results show reasonable agreement for a sample of 200 data.

\subsection{EXAMPLE 3}

Example 3 illustrates the kernel-density estimation technique on a sample of 50 data, which were obtained as a random sample from a standard uniform distribution. A data transformation is performed to make simulated data from a uniform $(-2,2)$ distribution. Table 15 shows the input file, and Table 16 shows the report file.

This example can be used to help verify the implementation of the datatransformation option and the kernel-density estimator. The datatransformation option can be verified by hand calculations because the data are written out after the transformation is performed. The analytical CDF for the uniform distribution is a straight line with a slope of 0.5 on the interval $(-2,2)$. The results show reasonable agreement with the analytical CDF for a sample of 50 data.

\subsection{EXAMPLE 4}

Example 4 illustrates the kernel-density estimation technique on a sample of 20 data, which were obtained as a random sample from a standard uniform distribution. The ALIAS option is invoked because the density estimate should be zero outside the interval $(0,1)$. A plot file is generated. The STEPS option is used simply to reduce the size of the plot file. The impact of the reduced number of integration steps is that the CDF integrates to 1.0028 instead of 1.0. Table 17 shows the input file, Table 18 shows the report file, and Table 19 shows the plot file.

This example can also be used to help verify the implementation of the kernel-density estimator. The ALIAS option correctly forces the CDF to have a value of zero for data below zero, and a value of one for data above one. If this example were run without the ALIAS option, the output CDF table would assign a nonzero probability outside the unit interval. The analytical CDF for the uniform distribution is a straight line with a slope of one on the unit interval. The results show reasonable agreement with the analytical CDF for a sample of 20 data, although 20 data are generally too few to obtain a density estimate that closely matches an analytical density. 
Table 15. Input Data File Example 3: EXAMPLE3.DAT.

\begin{tabular}{|c|c|c|c|c|}
\hline \multicolumn{5}{|c|}{$\begin{array}{l}\text { InPut file EXAMPLE3.DAT for the CDFTBL User's Manual } \\
\text { DISTRIBUTION KERNEL } \\
\text { PROBABILITY INCREMENT } 0.05 \\
\text { TRANSFORM THE DATA TYPE } 3 \text { SHIFT BY } 0.5 \text { THEN DIVIDE BY } 0.25 \\
\text { SAMPLE Size } 50 \text { with } 5 \text { Values per LINE } \\
\text { PRINT THE DATA BOTH BEFORE AND AFTER TRANSFORMATIONS } \\
\text { USER "PaUT W. ESlinger" } \\
\text { END }\end{array}$} \\
\hline $\begin{array}{l}0.73919 \\
0.54830 \\
0.59866 \\
0.03636 \\
0.56822 \\
0.16681 \\
0.31559 \\
0.86620 \\
0.47524 \\
0.40228 \\
\end{array}$ & $\begin{array}{l}0.59036 \\
0.34870 \\
0.74503 \\
0.15843 \\
0.00569 \\
0.62195 \\
0.17277 \\
0.20783 \\
0.28970 \\
0.13033 \\
\end{array}$ & $\begin{array}{l}0.12591 \\
0.67511 \\
0.78114 \\
0.70634 \\
0.56753 \\
0.17964 \\
0.82916 \\
0.05101 \\
0.03958 \\
0.38753\end{array}$ & $\begin{array}{l}0.14962 \\
0.60590 \\
0.68355 \\
0.39274 \\
0.45873 \\
0.20908 \\
0.65917 \\
0.30989 \\
0.24036 \\
0.15423\end{array}$ & $\begin{array}{l}0.60103 \\
0.32472 \\
0.35146 \\
0.81571 \\
0.89874 \\
0.97628 \\
0.58856 \\
0.29009 \\
0.76072 \\
0.21539\end{array}$ \\
\hline
\end{tabular}


WHC-EP-0418

Table 16. Report File for Example 3: EXAMPLE3.RPT. (sheet 1 of 3)

$\overline{1}$

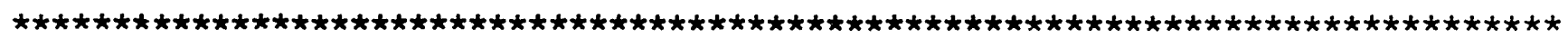

+

\begin{tabular}{|c|c|c|c|c|c|}
\hline $\begin{array}{l}\mathrm{CCCCCC} \\
C C \quad C C \\
C C \\
C C \\
C C \\
C C \quad C C \\
C C C C C\end{array}$ & 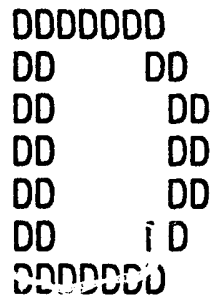 & $\begin{array}{l}\text { FFFFFFFFF } \\
\text { FFFFFFFFF } \\
\text { FF } \\
\text { FFFFFF } \\
\text { FF } \\
\text { FF } \\
\text { FF }\end{array}$ & $\begin{array}{c}\text { TTTTTTTTT } \\
\text { TTTTTTTTT } \\
\text { TT } \\
\text { TT } \\
\text { TT } \\
\text { TT } \\
\text { TT }\end{array}$ & \begin{tabular}{lc}
\multicolumn{3}{l}{ BBBBBBBB } \\
BB & BB \\
BB & BB \\
BBBBBBBB \\
BB & BB \\
BB & BB \\
BBBBBBBB
\end{tabular} & $\begin{array}{l}\text { LL } \\
\text { LL } \\
\text { LL } \\
\text { LL } \\
\text { LL } \\
\text { LLLLLLLLL } \\
\text { LLLLLLLLLL }\end{array}$ \\
\hline
\end{tabular}

CDITBL 1.000

Last Modified on 13 Jun 1990

Cumulative Distribution Function Estimation

from a User Supplied Data Set

Statistical Program Developed by Paul W. Eslinger Keyword Input Routines Developed by Dave W. Langford

Current Run ID $=900620202859$ User Name $=$ Paul W. Eslinger

System Date $=06 / 20 / 90 \quad$ System Time $=20: 28: 59$ 
Table 16. Report File for Example 3: EXAMPLE3.RPT. (sheet 2 of 3) $\star$

1 Program: CDFTBL Version:1.000 User: Paul W. Eslinger Run ID: 900620202859

Data Used in Generating the Probability Table Before Data Transformations

$5.69000 \mathrm{E}-03$

$1.30330 \mathrm{E}-01$

$1.72770 \mathrm{E}-01$

$2.40360 \mathrm{E}-01$

$3.24720 \mathrm{E}-01$

4.02280E-01

$5.68220 E-01$

$6.05900 \mathrm{E}-01$

$7.06340 \mathrm{E}-01$

8.15710E-01
3. 63600E-02

$1.49620 \mathrm{E}-01$

$1.79640 \mathrm{E}-01$

2.89700E-01

$3.48700 \mathrm{E}-01$

4.58730E-01

$5.88560 \mathrm{E}-01$

$6.21950 \mathrm{E}-01$

7.39190E-01

$8.291650 E-01$
3. $95800 \mathrm{E}-02$

1.54230E-01

2.07830E-01

2. $90090 \mathrm{E}-01$

$3.51460 \mathrm{E}-01$

4.75240E-01

5.90360E-01

6.59170E-01

7.45030E-01

8.66200E-01
5. 10100E-02

1. $58430 \mathrm{E}-01$

2.09080E-01

3.09890E-01

$3.87530 \mathrm{E}-01$

5. $48300 \mathrm{E}-01$

$5.98660 \mathrm{E}-01$

$6.75110 \mathrm{E}-01$

$7.60720 \mathrm{E}-01$

8.98740E-01
1.25910E-01

1. $66810 \mathrm{E}-01$

2.15390E-01

3.15590E-01

3.92740E-01

5.67530E-01

$6.01030 \mathrm{E}-01$

$6.83550 \mathrm{E}-01$

$7.81140 \mathrm{E}-01$

$9.76280 \mathrm{E}-01$

1 Program: CDFTBL Version: 1.000 User: Paul W. Eslinger Run ID: 900620202859

Data Used in Generating the Probability Table After Data Transformations

$\begin{array}{lllllr}-1.97724 \mathrm{E}+00 & -1.85456 \mathrm{E}+00 & -1.84168 \mathrm{E}+00 & -1.79596 \mathrm{E}+00 & -1.49636 \mathrm{E}+00 \\ -1.47868 \mathrm{E}+00 & -1.40152 \mathrm{E}+00 & -1.38308 \mathrm{E}+00 & -1.36628 \mathrm{E}+00 & -1.33276 \mathrm{E}+00 \\ -1.30892 \mathrm{E}+00 & -1.28144 \mathrm{E}+00 & -1.16868 \mathrm{E}+00 & -1.16368 \mathrm{E}+00 & -1.13844 \mathrm{E}+00 \\ -1.03856 \mathrm{E}+00 & -8.41200 \mathrm{E}-01 & -8.39640 \mathrm{E}-01 & -7.60440 \mathrm{E}-01 & -7.37640 \mathrm{E}-01 \\ -7.01120 \mathrm{E}-01 & -6.05200 \mathrm{E}-01 & -5.94160 \mathrm{E}-01 & -4.49880 \mathrm{E}-01 & -4.29040 \mathrm{E}-01 \\ -3.90880 \mathrm{E}-01 & -1.65080 \mathrm{E}-01 & -9.90400 \mathrm{E}-02 & 1.93200 \mathrm{E}-01 & 2.70120 \mathrm{E}-01 \\ 2.72880 \mathrm{E}-01 & 3.54240 \mathrm{E}-01 & 3.61440 \mathrm{E}-01 & 3.94640 \mathrm{E}-01 & 4.04120 \mathrm{E}-01 \\ 4.23600 \mathrm{E}-01 & 4.87800 \mathrm{E}-01 & 6.36680 \mathrm{E}-01 & 7.00440 \mathrm{E}-01 & 7.34200 \mathrm{E}-01 \\ 8.25360 \mathrm{E}-01 & 9.56760 \mathrm{E}-01 & 9.80120 \mathrm{E}-01 & 1.04288 \mathrm{E}+00 & 1.12456 \mathrm{E}+00 \\ 1.26284 \mathrm{E}+00 & 1.31664 \mathrm{E}+00 & 1.46480 \mathrm{E}+00 & 1.59496 \mathrm{E}+00 & 1.90512 \mathrm{E}+00 \\ \text { Program: CDFTBL } \text { Version: } 1.000 & \text { User: } & \text { PauT W. Es1 inger Run ID: } \\ 00620202859 & & & & \end{array}$

Cumulative Probabilities Using Kernel Density Estimation

The density estimate was based on 50 values.

The scale estimate was $1.3115 \mathrm{E}+00$

The kernel bandwidth value was 0.74285

The probability table has 21 pairs of values. 
Table 16. Report File for Example 3: EXAMPLE3.RPT. (sheet 3 of 3)

$\begin{array}{cc}X & \begin{array}{c}\text { Cumulative } \\ \text { Probability }\end{array} \\ -2.9515 E+00 & 0.0000 \\ -1.9806 E+00 & 0.0500 \\ -1.7084 E+00 & 0.1000 \\ -1.5002 E+00 & 0.1500 \\ -1.3219 E+00 & 0.2000 \\ -1.1584 E+00 & 0.2500 \\ -9.9828 E-01 & 0.3000 \\ -8.3467 E-01 & 0.3500 \\ -6.6190 E-01 & 0.4000 \\ -4.7667 E-01 & 0.4500 \\ -2.8259 E-01 & 0.5000 \\ -8.8112 E-02 & 0.5500 \\ 1.0270 E-01 & 0.6000 \\ 2.9297 E-01 & 0.6500 \\ 4.8042 E-01 & 0.7000 \\ 6.6569 E-01 & 0.7500 \\ 8.5211 E-01 & 0.8000 \\ 1.0516 E+00 & 0.8500 \\ 1.2886 E+00 & 0.9000 \\ 1.6242 E+00 & 0.9500 \\ 2.8794 E+00 & 1.0000\end{array}$


Table 17. Input Data File Example 4: EXAMPLE2.DAT.

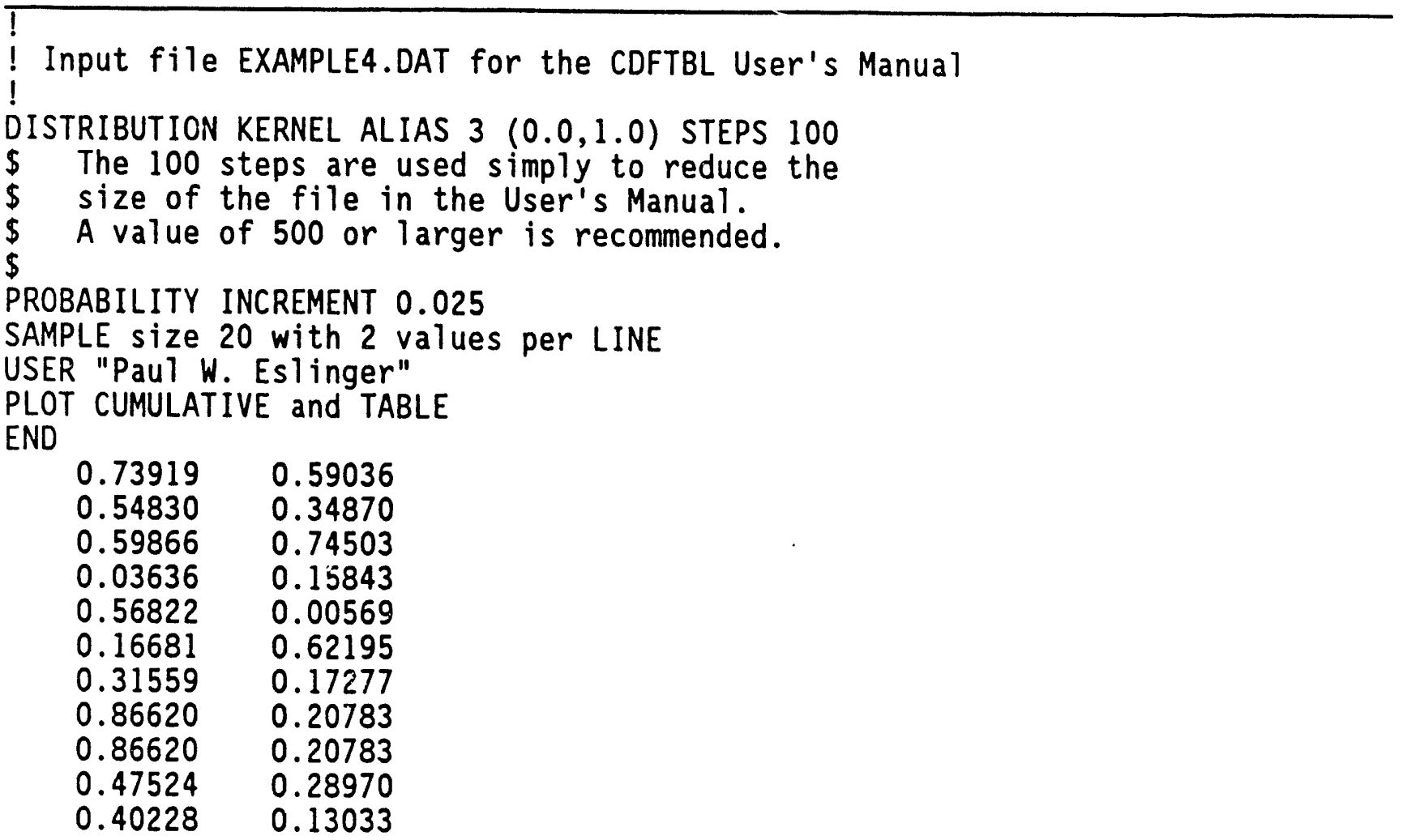


Table 18. Report File for Example 4: EXAMPLE4.RPT. (sheet 1 of 2)

$\overline{1}$

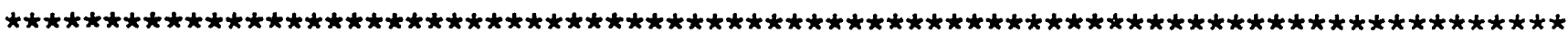

$\star$

\begin{tabular}{|c|c|c|c|c|c|}
\hline $\begin{array}{l}\mathrm{CCCCCC} \\
C C \quad C C \\
C C \\
C C \\
C C \\
C C \quad C C \\
C C C C C\end{array}$ & $\begin{array}{ll}\text { DDDDDDD } \\
\text { DD } & \text { DD } \\
D D & D D \\
D D & D D \\
D D & D D \\
D D & \\
D D & D D \\
\text { DDDDDDD }\end{array}$ & $\begin{array}{l}\text { FFFFFFFFF } \\
\text { FFFFFFFFF } \\
\text { FF } \\
\text { FFFFFF } \\
\text { FF } \\
\text { FF } \\
\text { FF }\end{array}$ & $\begin{array}{l}\text { TTTTTTTT } \\
\text { TTTTTTTT } \\
\text { TT } \\
\text { TT } \\
\text { TT } \\
\text { TT } \\
\text { TT }\end{array}$ & $\begin{array}{lc}\text { BBBBBBBB } \\
\text { BB } \\
\text { BB }\end{array}$ & $\begin{array}{l}\text { LL } \\
\text { LL } \\
\text { LL } \\
\text { LL } \\
\text { LL } \\
\text { LLLLLLLLL } \\
\text { LLLLLLLLL }\end{array}$ \\
\hline
\end{tabular}

CDFTBL $\quad 1.000$

Last Modified on 13 Jun 1990

Cumulative Distribution Function Estimation from a User Supplied Data Set

Statistical Program Developed by Paul W. Eslinger Keyword Input Routines Developed by Dave W. Langford

Current Run ID $=900620203830$ User Name $=$ Paul W. Eslinger

System Date $=06 / 20 / 90$ System Time $=20: 38: 30$

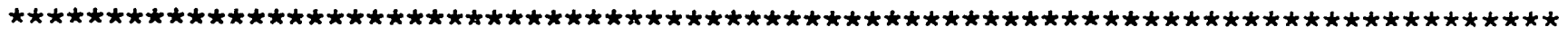

1 Program: CDFTBL Version:1.000 User: Paul W. Eslinger Run ID: 900620203830

Cumulative Probabilities Using Kernel Density Estimation

The density estimate was based on 20 values.

The scale estimate was $3.0698 \mathrm{E}-01$

The kernel bandwidth value was 0.96630

The probability table has 41 pairs of values. 
WHC-EP-0418

Table 18. Report File for Example 4: EXAMPLE4.RPT. (sheet 2 of 2)

$\begin{array}{cc}\text { X } & \text { Cumulative } \\ \text { Probability }\end{array}$


Table 19. Plot File for Example 4: EXAMPLE4.PLT. (sheet 1 of 3)

1 Program: CDFTBL Version: 1.000 User: Paul W. Eslinger Run ID: 900620203830

Cumulative Distribution Function

$-2.90946 E-01$

0.00000

$-2.76262 E-01$

0.00000

$-2.61577 \mathrm{E}-01$

0.00000

$-2.46892 \mathrm{E}-01$

0.00000

$-2.32208 \mathrm{E}-01$

0.00000

$-2.17523 E-01$

0.00000

$-2.02838 \mathrm{E}-01$

0.00000

$-1.88154 \mathrm{E}-01$

0.00000

$-1.73469 E-01$

0.00000

$-1.58784 E-01$

0.00000

$-1.44100 \mathrm{E}-01$

0.00000

$-1.29415 \mathrm{E}-01$

0.00000

$-1.14730 \mathrm{E}-01$

0.00000

$-1.00046 \mathrm{E}-01$

0.00000

$-8.53610 \mathrm{E}-02$

0.00000

$-7.06763 E-02$

0.00000

$-5.59916 E-02$

0.00000

$-4.13069 \mathrm{E}-02$

$-2.66223 E-02$

$-1.19376 \mathrm{E}-02$

0.00000

0.00000

$2.74708 \mathrm{E}-03$

0.00000

$1.74318 \mathrm{E}-02$

0.00948

$3.21164 \mathrm{E}-02$

0.02846

$4.68011 \mathrm{E}-02$

0.04752

$6.14858 \mathrm{E}-02$

0.06662

$7.61705 \mathrm{E}-02$

0.08568

$9.08551 \mathrm{E}-02$

0.10466

$1.05540 \mathrm{E}-01$

0.12346

$1.20224 E-01$

0.14210

$1.34909 \mathrm{E}-01$

0.16061

$1.49594 \mathrm{E}-01$

0.17896

$1.64279 \mathrm{E}-01$

0.19726

$1.78963 E-01$

0.21560

$1.93648 \mathrm{E}-01$

0.23387

0.25205

$2.08333 E-01$

0.27013

2. $23017 \mathrm{E}-01$

0.28799

2.37702E-01

0.30550

2.52387E-01

0.32255

2.67071E-01

0.33915

2.81756E-01

2.96441E-01

$3.11125 \mathrm{E}-01$

3. $25810 \mathrm{E}-01$

3. 40495E-01

3.55179E-01

0.35544

0.37147

0.38744

0.40354

0.41987

$3.69864 \mathrm{E}-01$

0.43646

3. $84549 \mathrm{E}-01$

0.45323

0.47006 
Table 19. Plot File for Example 4: EXAMPLE4.PLT. (sheet 2 of 3)

$\begin{array}{ll}3.99233 \mathrm{E}-01 & 0.48682 \\ 4.13918 \mathrm{E}-01 & 0.50339 \\ 4.28603 \mathrm{E}-01 & 0.51963 \\ 4.43287 \mathrm{E}-01 & 0.53542 \\ 4.57972 \mathrm{E}-01 & 0.55080 \\ 4.72657 \mathrm{E}-01 & 0.56599 \\ 4.87341 \mathrm{E}-01 & 0.58114 \\ 5.02026 \mathrm{E}-01 & 0.59625 \\ 5.16711 \mathrm{E}-01 & 0.61134 \\ 5.31395 \mathrm{E}-01 & 0.62650 \\ 5.46080 \mathrm{E}-01 & 0.64166 \\ 5.60765 \mathrm{E}-01 & 0.65672 \\ 5.75449 \mathrm{E}-01 & 0.67164 \\ 5.90134 \mathrm{E}-01 & 0.68654 \\ 6.04819 \mathrm{E}-01 & 0.70149 \\ 6.19503 \mathrm{E}-01 & 0.71651 \\ 6.34188 \mathrm{E}-01 & 0.73157 \\ 6.48873 \mathrm{E}-01 & 0.74665 \\ 6.63558 \mathrm{E}-01 & 0.76175 \\ 6.78242 \mathrm{E}-01 & 0.77683 \\ 6.92927 \mathrm{E}-01 & 0.79181 \\ 7.07612 \mathrm{E}-01 & 0.80660 \\ 7.22296 \mathrm{E}-01 & 0.82111 \\ 7.36981 \mathrm{E}-01 & 0.83525 \\ 7.51666 \mathrm{E}-01 & 0.84892 \\ 7.66350 \mathrm{E}-01 & 0.86203 \\ 7.81035 \mathrm{E}-01 & 0.87455 \\ 7.95720 \mathrm{E}-01 & 0.88650 \\ 8.10404 \mathrm{E}-01 & 0.89781 \\ 8.25089 \mathrm{E}-01 & 0.90841 \\ 8.39774 \mathrm{E}-01 & 0.91824 \\ 8.54458 \mathrm{E}-01 & 0.92748 \\ 8.69143 \mathrm{E}-01 & 0.93628 \\ 8.83828 \mathrm{E}-01 & 0.94469 \\ 8.98512 \mathrm{E}-01 & 0.95279 \\ 9.13197 \mathrm{E}-01 & 0.96069 \\ 9.27882 \mathrm{E}-01 & 0.96847 \\ 9.42566 \mathrm{E}-01 & 0.97616 \\ 9.57251 \mathrm{E}-01 & 0.98375 \\ 9.71936 \mathrm{E}-01 & 0.99130 \\ 9.86620 \mathrm{E}-01 & 0.99895 \\ 1.00131 \mathrm{E}+00 & 1.00280 \\ 1.01599 \mathrm{E}+00 & 1.00280 \\ 1.03067 \mathrm{E}+00 & 1.00280 \\ 1.04536 \mathrm{E}+00 & 1.00280 \\ 1.06004 \mathrm{E}+00 & 1.00280 \\ 1.07473 \mathrm{E}+00 & 1.00280 \\ 1.08941 \mathrm{E}+00 & 1.00280 \\ 1.10410 \mathrm{E}+00 & 1.00280 \\ 1.11878 \mathrm{E}+00 & 1.00280 \\ 1.13347 \mathrm{E}+00 & 1.00280 \\ 1.14615 \mathrm{E}+00 & 1.00280\end{array}$


Table 19. Plot File for Example 4: EXAMPLE4.PLT. (sheet 3 of 3)

1 Program: CDFTBL Version:1.000 User: Paul W. Eslinger Run ID: 900620203830

Cumulative Probability Table

41

$1.16284 \mathrm{E}+00$

1.00280

$0.00000 E+00$

0.00000

$1.47529 \mathrm{E}-02$

0.02500

$3.40268 \mathrm{E}-02$

$5.32582 \mathrm{E}-02$

7.25625E-02

9.20708E-02

$1.11807 \mathrm{E}-01$

$1.31743 \mathrm{E}-01$

$1.51786 \mathrm{E}-01$

$1.71838 \mathrm{E}-01$

$1.91990 \mathrm{E}-01$

$2.12335 \mathrm{E}-01$

2.33091E-01

$2.54555 \mathrm{E}-01$

2.76852E-01

2.99690E-01

$3.22580 \mathrm{E}-01$

$3.45039 \mathrm{E}-01$

$3.67036 \mathrm{E}-01$

$3.88874 \mathrm{E}-01$

4.10914E-01

$4.33598 \mathrm{E}-01$

$4.57206 \mathrm{E}-01$

$4.81387 \mathrm{E}-01$

0.05000

0.07500

0.10000

0.12500

0.15000

0.17500

0.20000

0.22500

0.25000

0.27500

0.30000

0.32500

0.35000

0.37500

0.40000

0.42500

0.45000

0.47500

0.50000

0.52500

0.55000

0.57500

0.60000

$5.05939 \mathrm{E}-01$

0.62500

0.65000

0.67500

0.70000

0.72500

0.75000

0.77500

0.80000

0.82500

0.85000

0.87500

0.90000

0.92500

0.95000

0.97500

$8.93446 \mathrm{E}-01$

$9.40351 \mathrm{E}-01$

$1.00000 E+00$

1.00000 


\subsection{REFERENCES}

Beran, R., 1977, "Minimum Hellinger Distance Estimates for Parametric Models," The Annals of Statistics, Vol. 5, No. 3, pp. 445-463.

Devroye, L., 1987, A Course in Density Estimation, Birkhauser, Boston, Massachusetts.

Eslinger, P. W., and W. A. Woodward, 1990, "Minimuri Hellinger Distance Estimation for Normal Models," in Journal of Statistical Computation and Simulation.

Epanechnikov, V. A., 1969, "Non-parametric Estimation of a Multivariate Probability Density," Theory of Probability and its Applications, Vol. XIV, No. 1, pp. 153-158.

Lahey, 1987, Reference Manual - Fortran 77 Language System for the Personal Computer, Lahey Computer Systems, Inc., Incline Village, Nevada.

Lewis, P. A., A. S. Goodman, and J. M. Miller, 1969, "A Pseudo-random Number Generator for the System/360," IBM Systems Journal. Vol. 8, No. 2, pp. 136-146.

Mood, A. M., F. A. Graybill, and D. C. Boes, 1974, Introduction to the Theory of Statistics, Third Edition, McGraw-Hill Book Co., New York, New York.

Parzen, E., 1962, "On the Estimation of a Probability Density Function and the Mode," Annals of Mathematical Statistics, V01. 33, pp. 1065-1076.

Runchal, A. K. and B. Sagar, 1989, PORFLO-3: A Mathematical Model for Fluid Flow, Heat, and Mass Transport in Variably Saturated Geologic Media, Users Manual, Version 1.0, WHC-EP-0041, Westinghouse Hanford Company, Richland, Washington.

Serfling, R. J., 1980, Approximation Theorems of Mathematical Statistics, John Wiley and Sons, New York, New York.

Strait, P. T., 1989, A First Course in Probability and Statistics with Applications, Second Edition, Harcourt Brace Jonanovich, San Diego, California. 
WHC-EP-0418

This page intentionally left blank. 
WHC-EP-0418

APPENDIX A

SOURCE CODE LISTING 
WHC-EP-0418

This page intentionally left blank. 
WHC-EP-0418

\section{APPENDIX A}

\section{SOURCE CODE LISTING}

This appendix contains a source code listing (Table A-1). The source code is listed as if it were ready for processing by the Cray UPDATE processor. The differences between this method and the usual FORTRAN compiler methods are (1) all of the source is contained in a single file, (2) items that would be 'INCLUDE' or 'INSERT' decks are identified by the '*COMDECK name', (3) items that would be separate FORTRAN subroutines or files are identified by '*DECK name', and (4) when '*CALL name' is encountered, it means to insert the COMDECK with that given name at the same location.

The listing given uses a version of subroutine IDENC, which is designed for the Lahey (Lahey 1987) FORTRAN 77 compiler. Table A-2 is a separate version of the subroutine (IDENC.VAX) that runs a VAX under the VMS operating system.

Table A-1. Source Code Listing. (sheet 1 of 62)

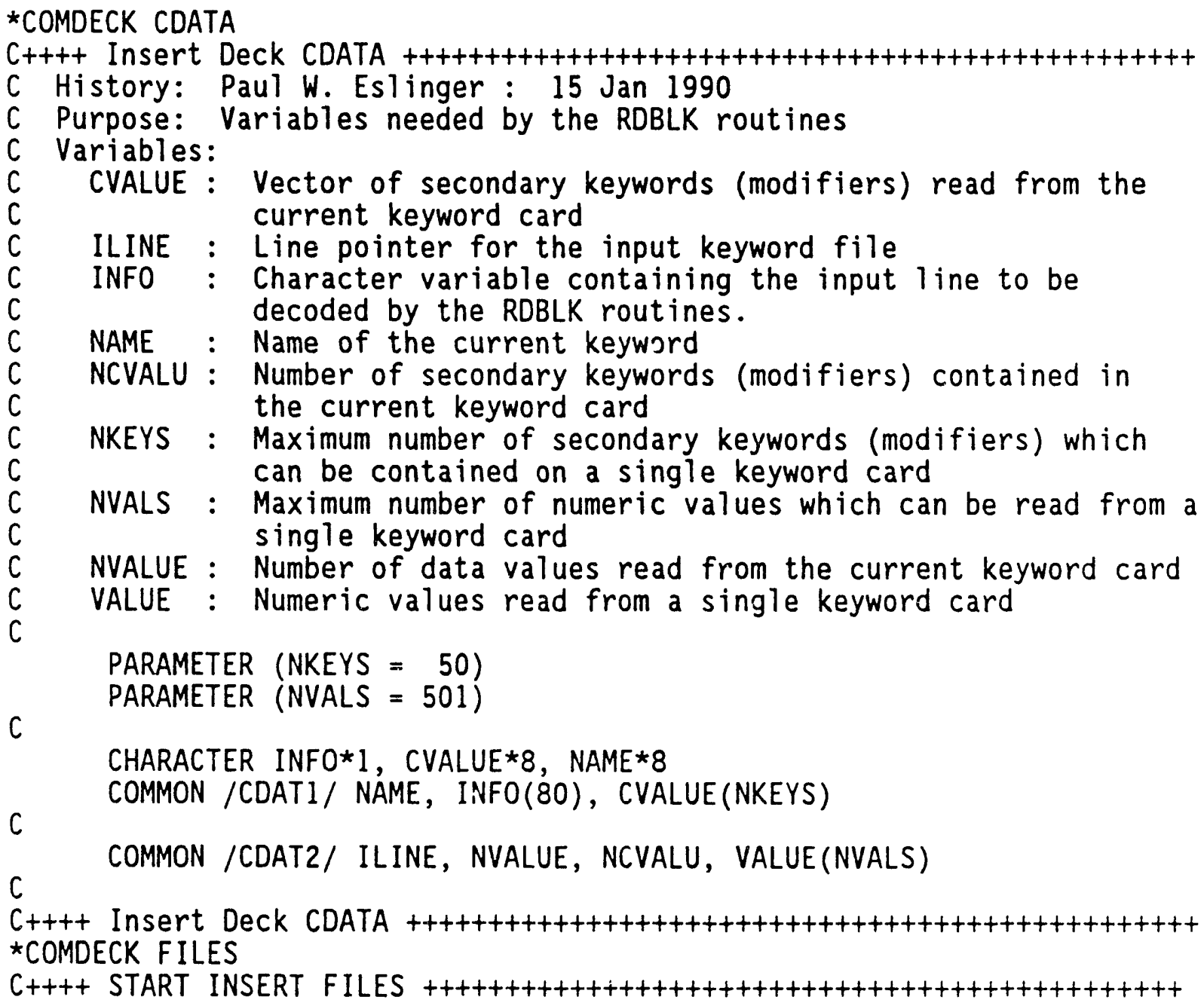


Table A-1. Source Code Listing. (sheet 2 of 62)

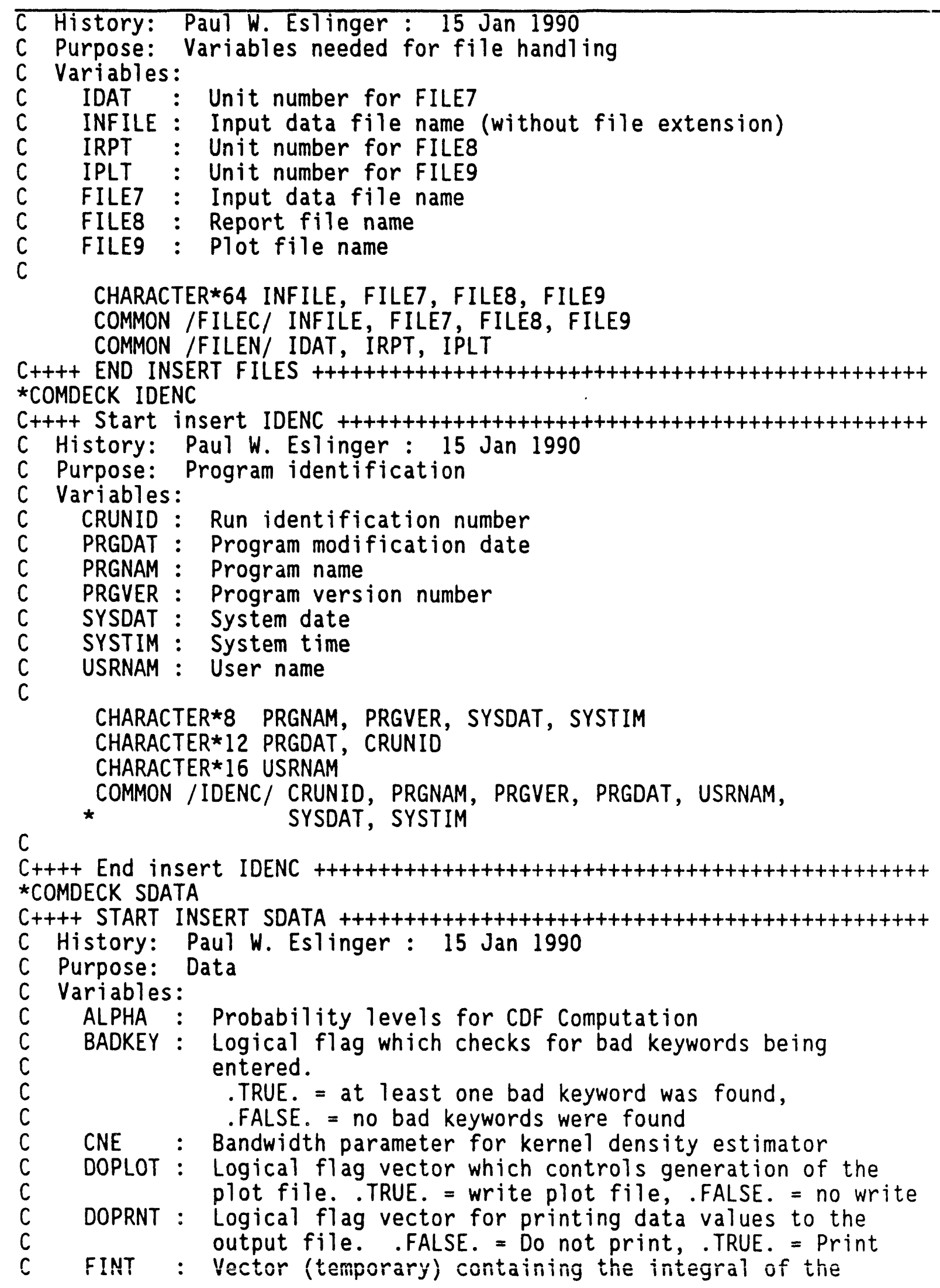


Table A-1. Source Code Listing. (sheet 3 of 62)

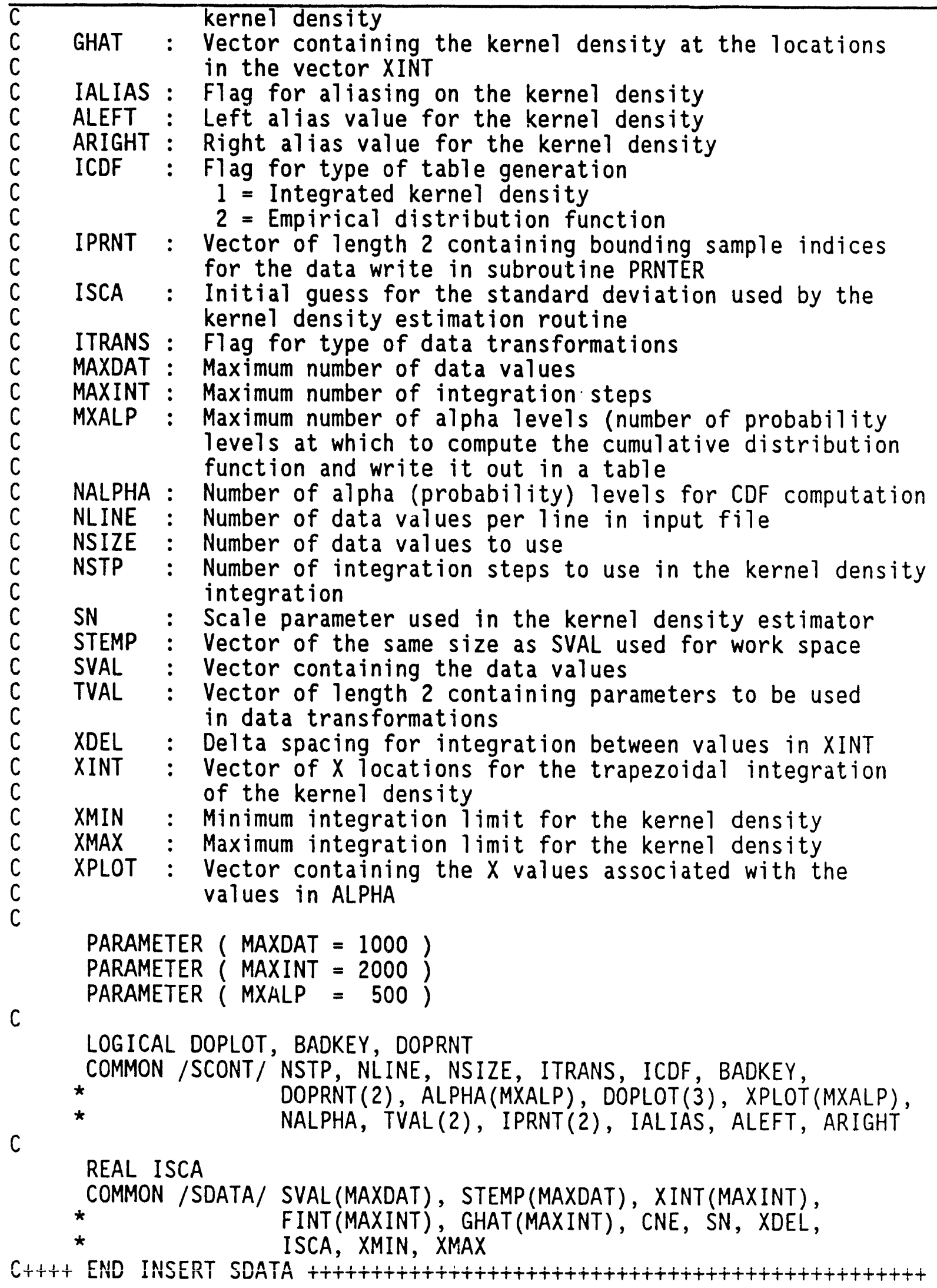


WHC-EP-0418

Table A-1. Source Code Listing. (sheet 4 of 62)

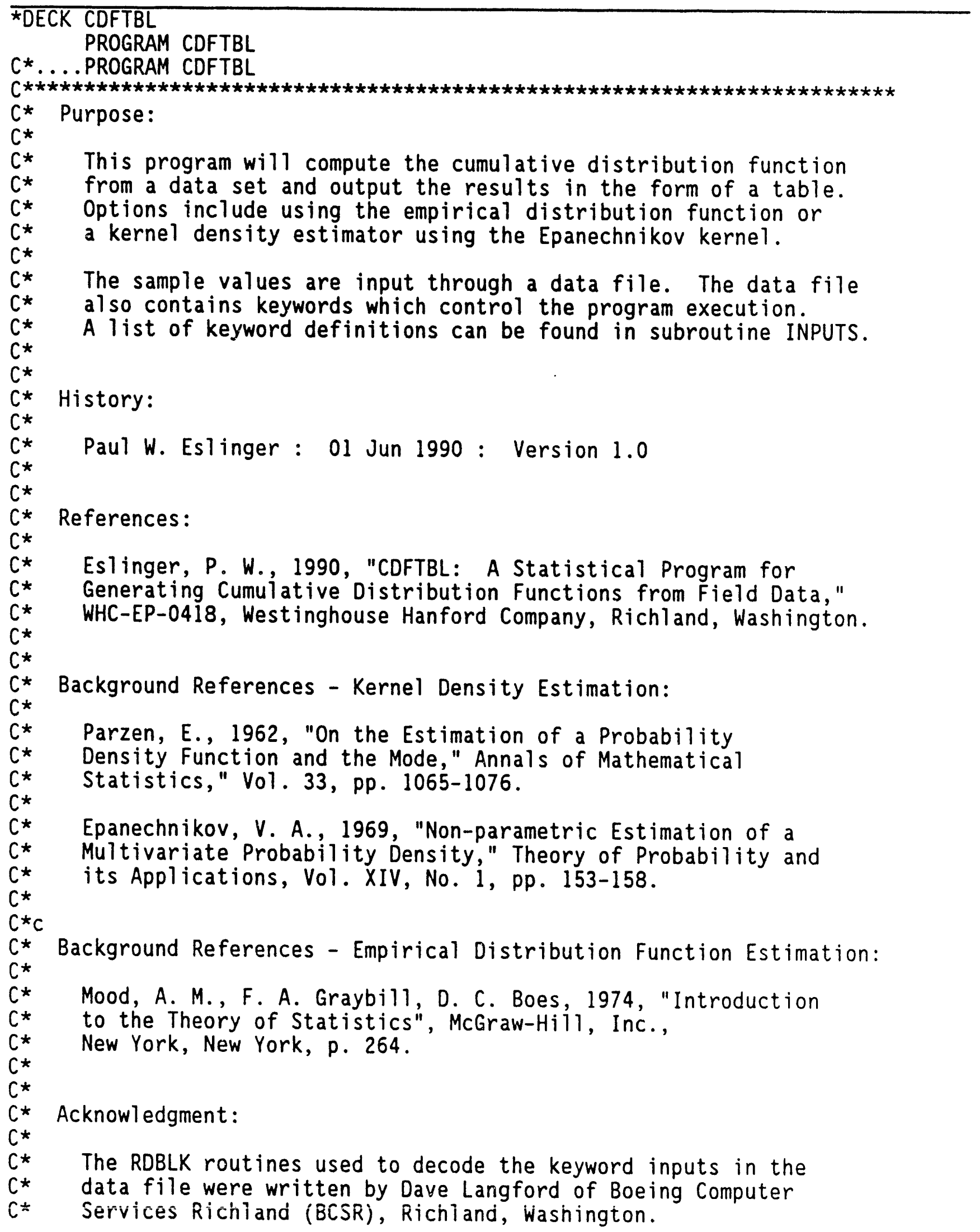


Table A-1. Source Code Listing. (sheet 5 of 62)

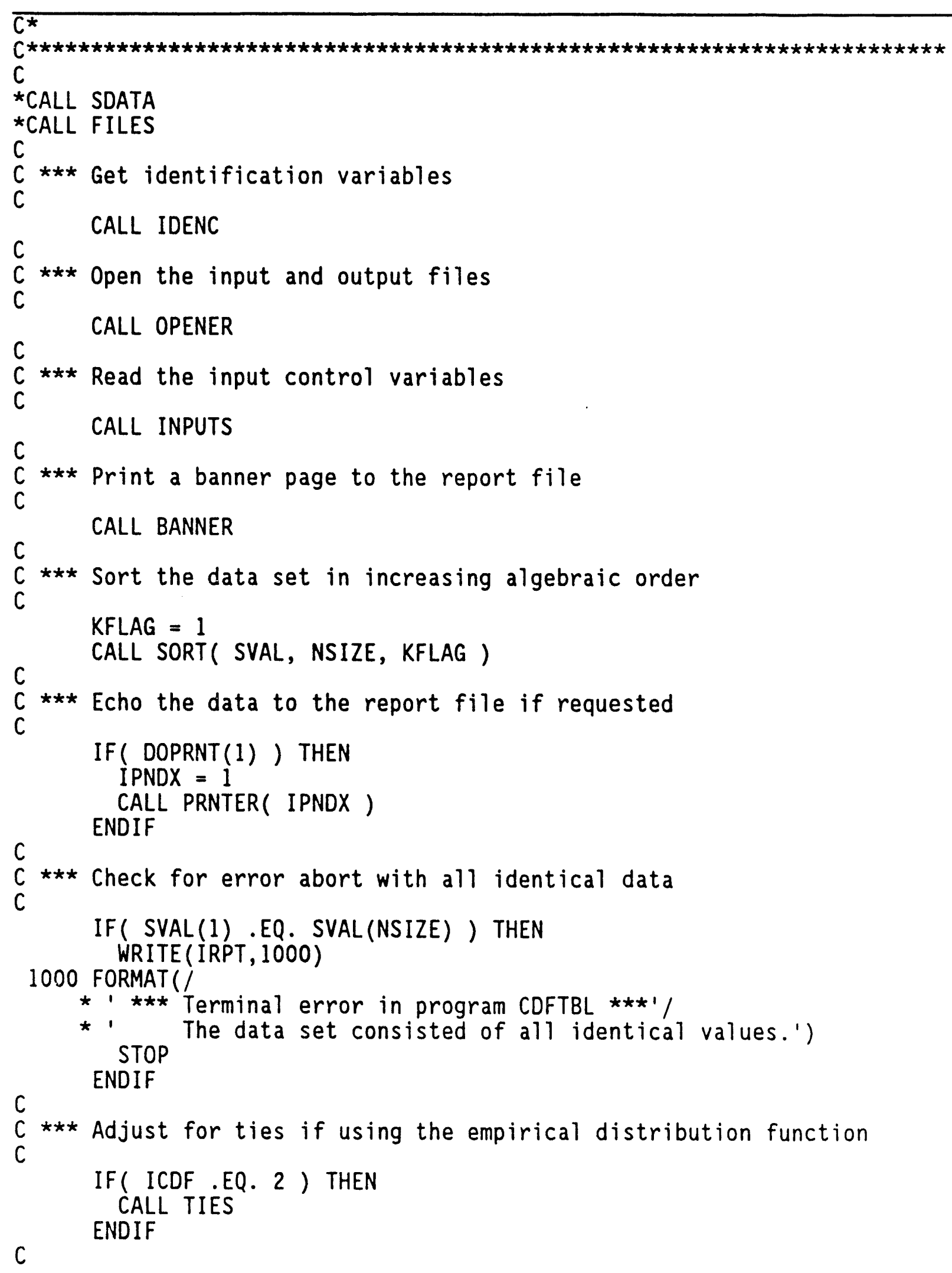


Table A-1. Source Code Listing. (sheet 6 of 62)

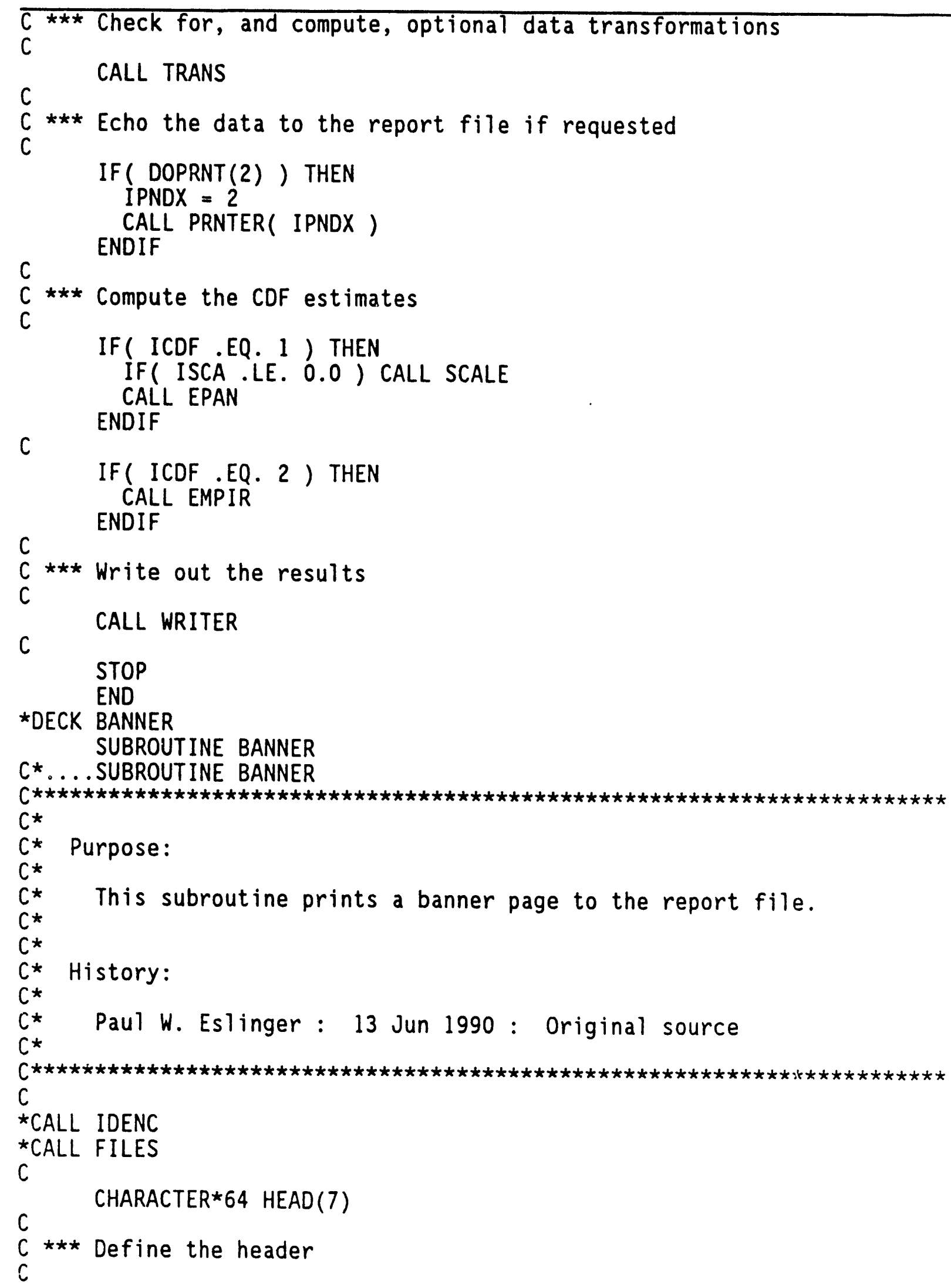


Table A-1. Source Code Listing. (sheet 7 of 62)

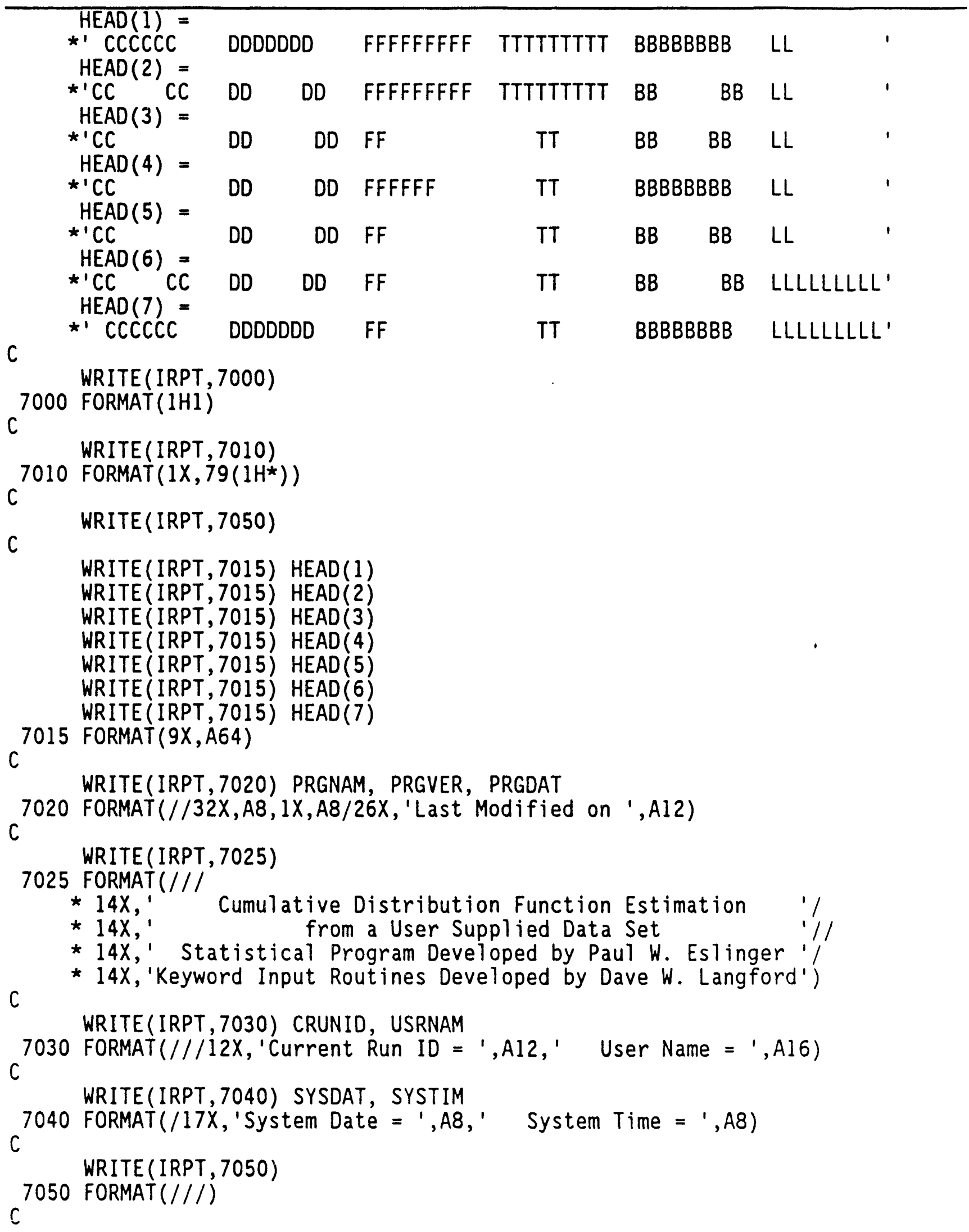


Table A-1. Source Code Listing. (sheet 8 of 62)

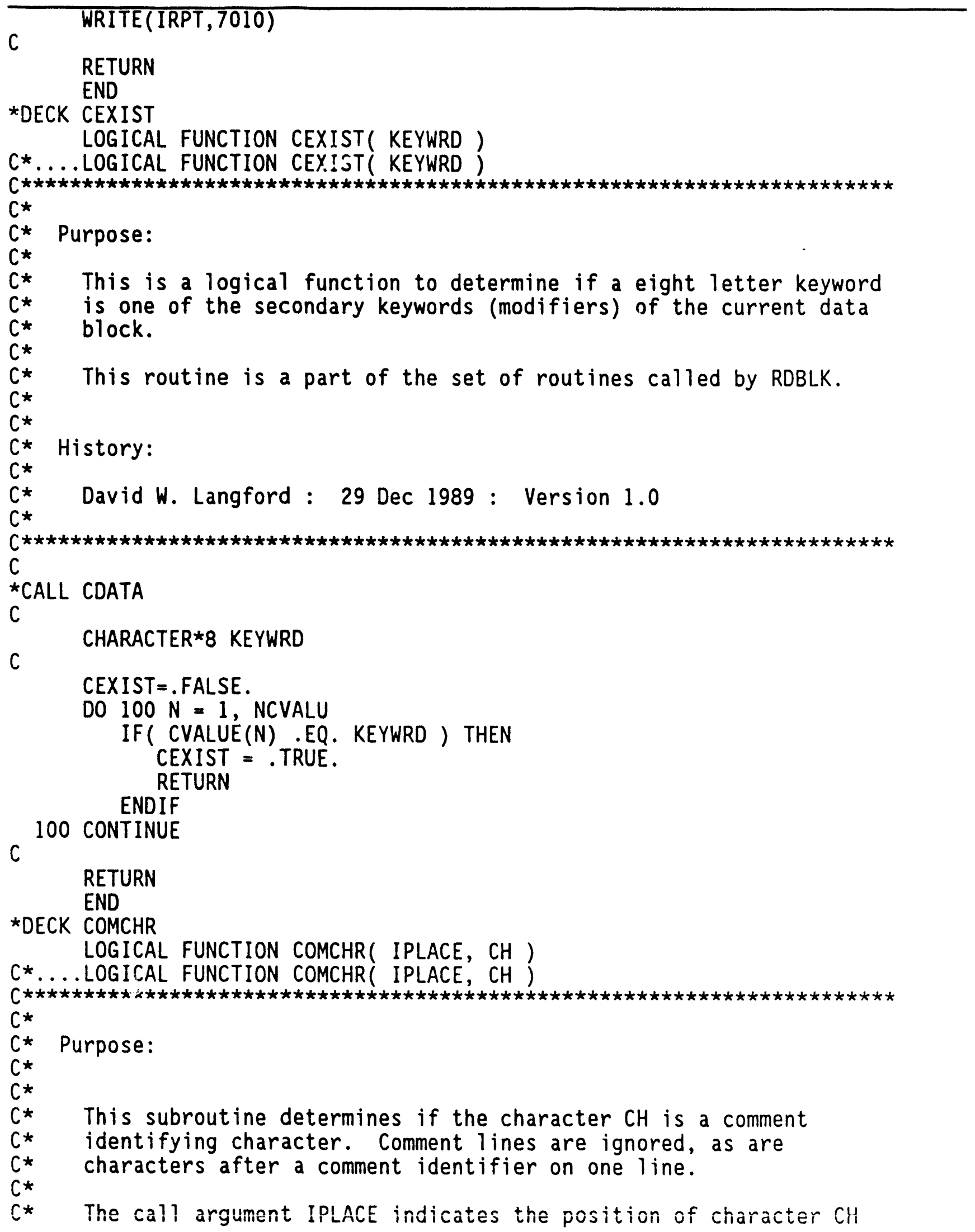


Table A-1. Source Code Listing. (sheet 9 of 62)

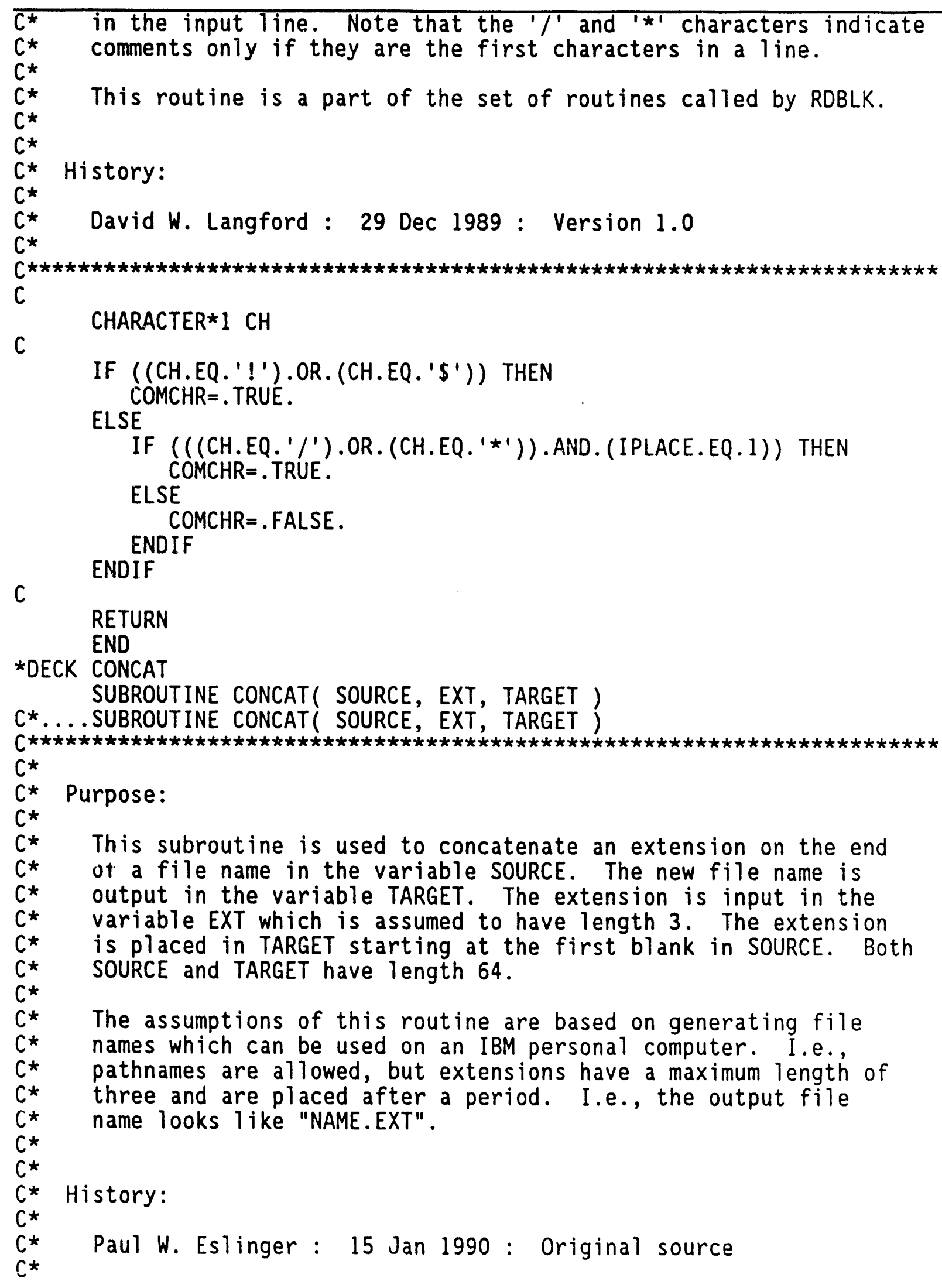


WHC-EP-0418

Table A-1. Source Code Listing. (sheet 10 of 62)

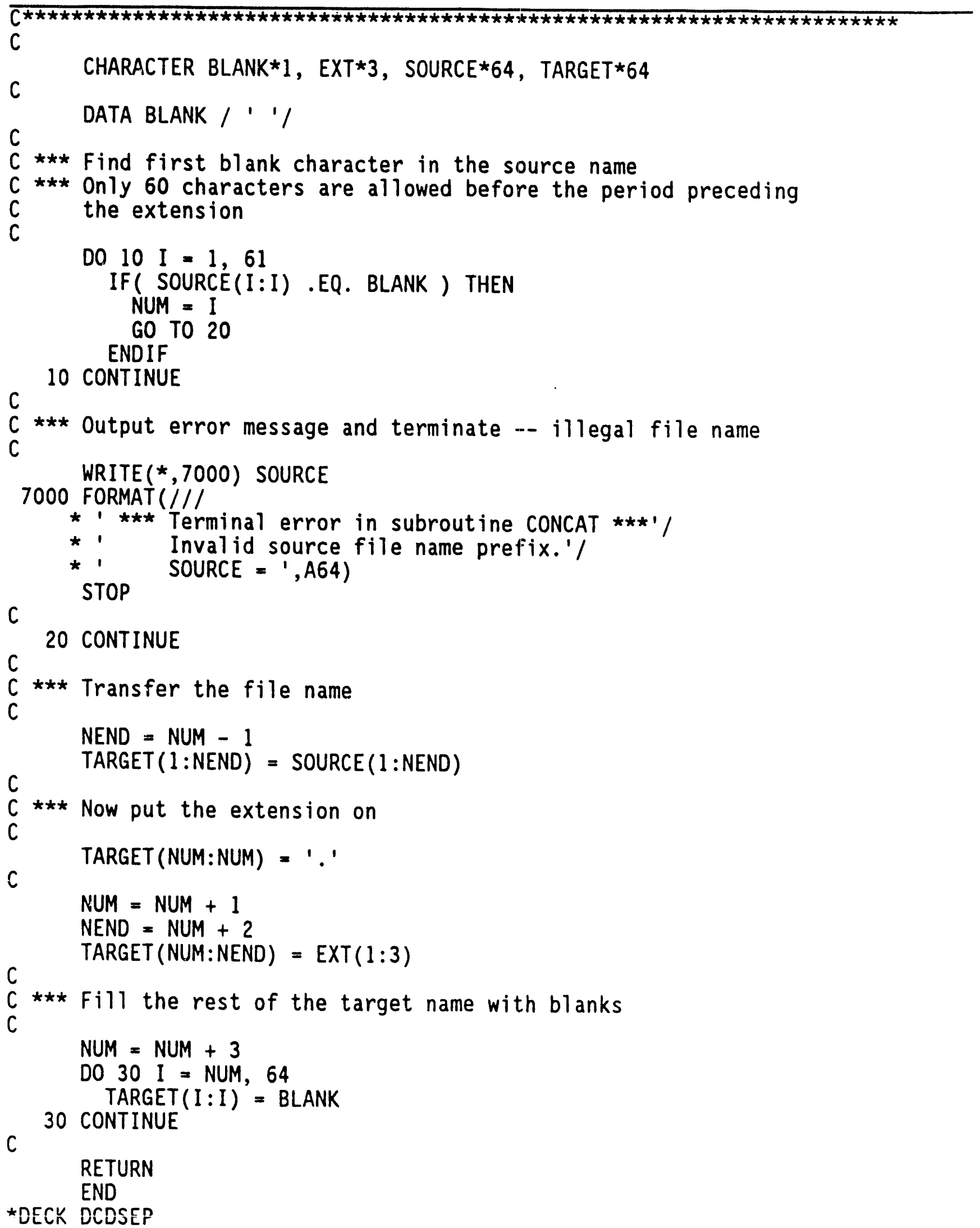


WHC-EP-0418

Table A-1. Source Code Listing. (sheet 11 of 62)

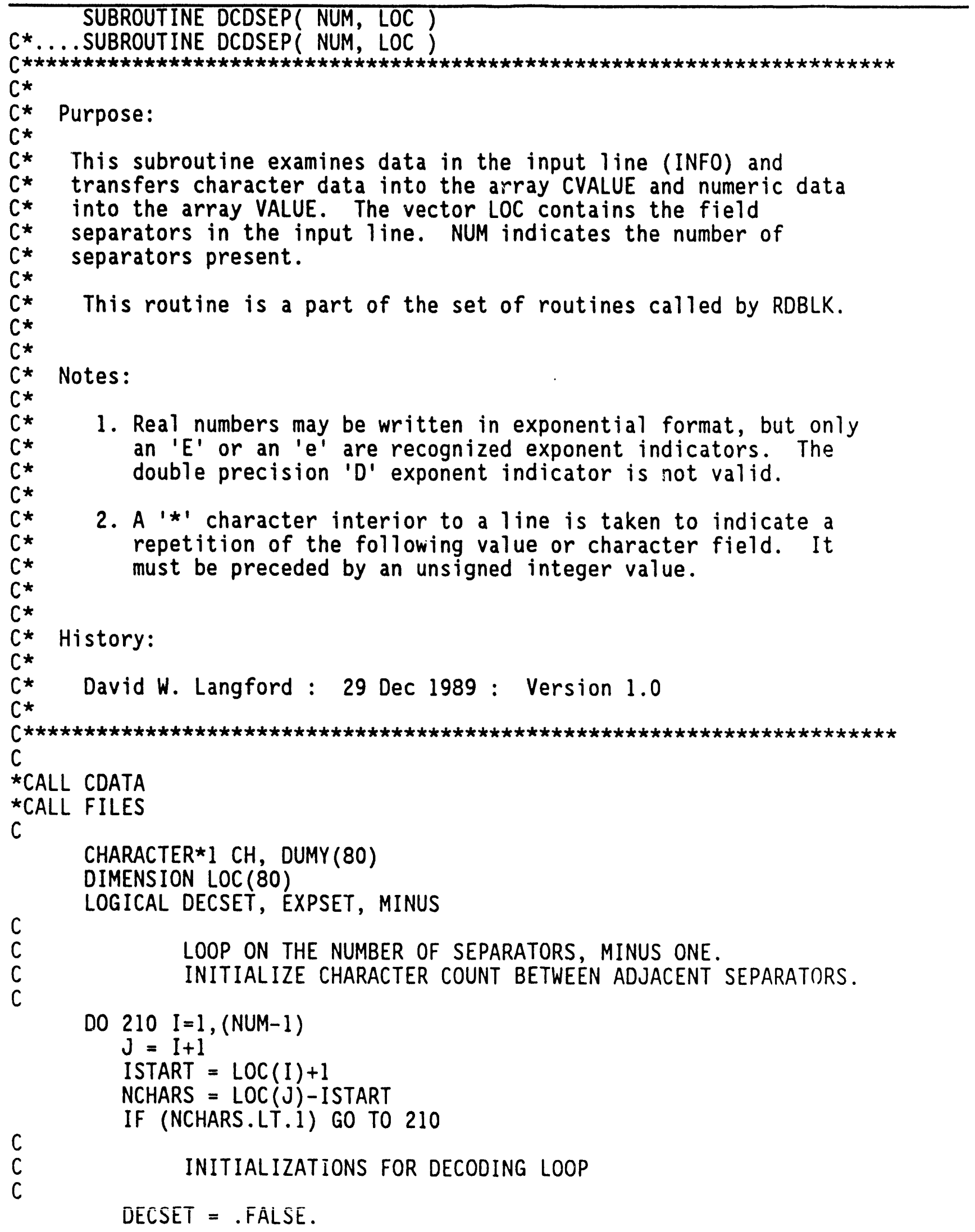


Table A-1. Source Code Listing. (sheet 12 of 62)

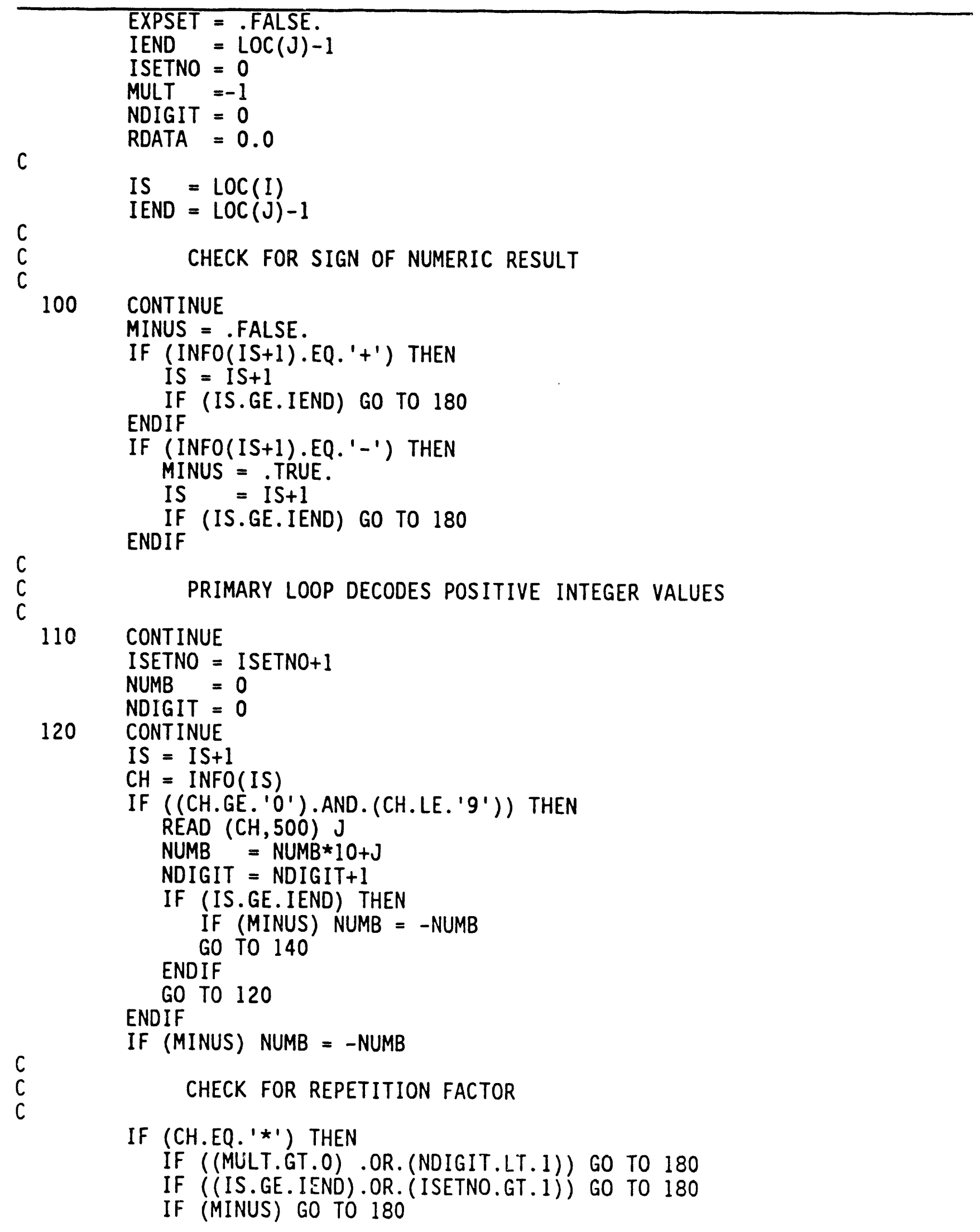


Table A-1. Source Code Listing. (sheet 13 of 62)

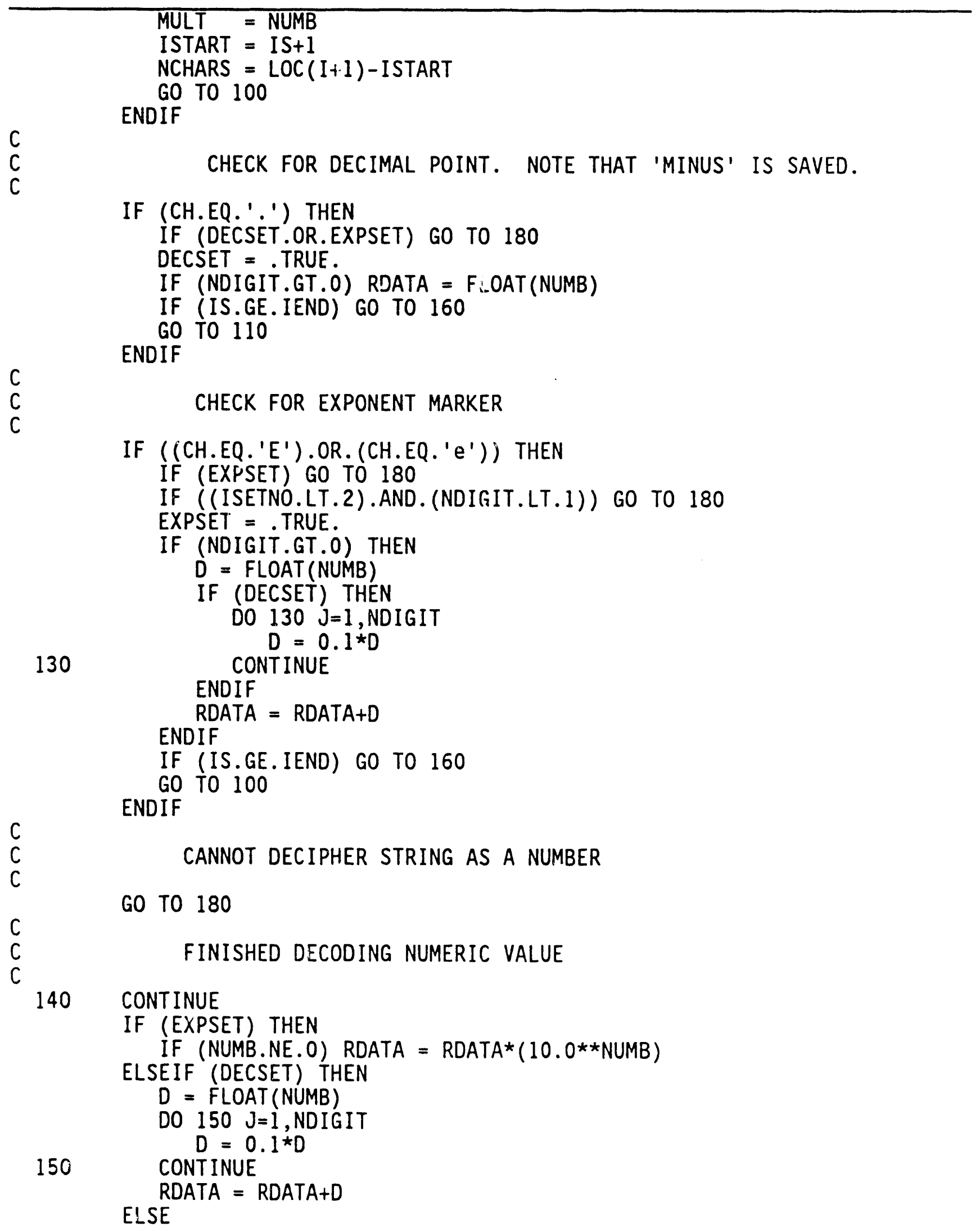


Table A-1. Source Code Listing. (sheet 14 of 52)

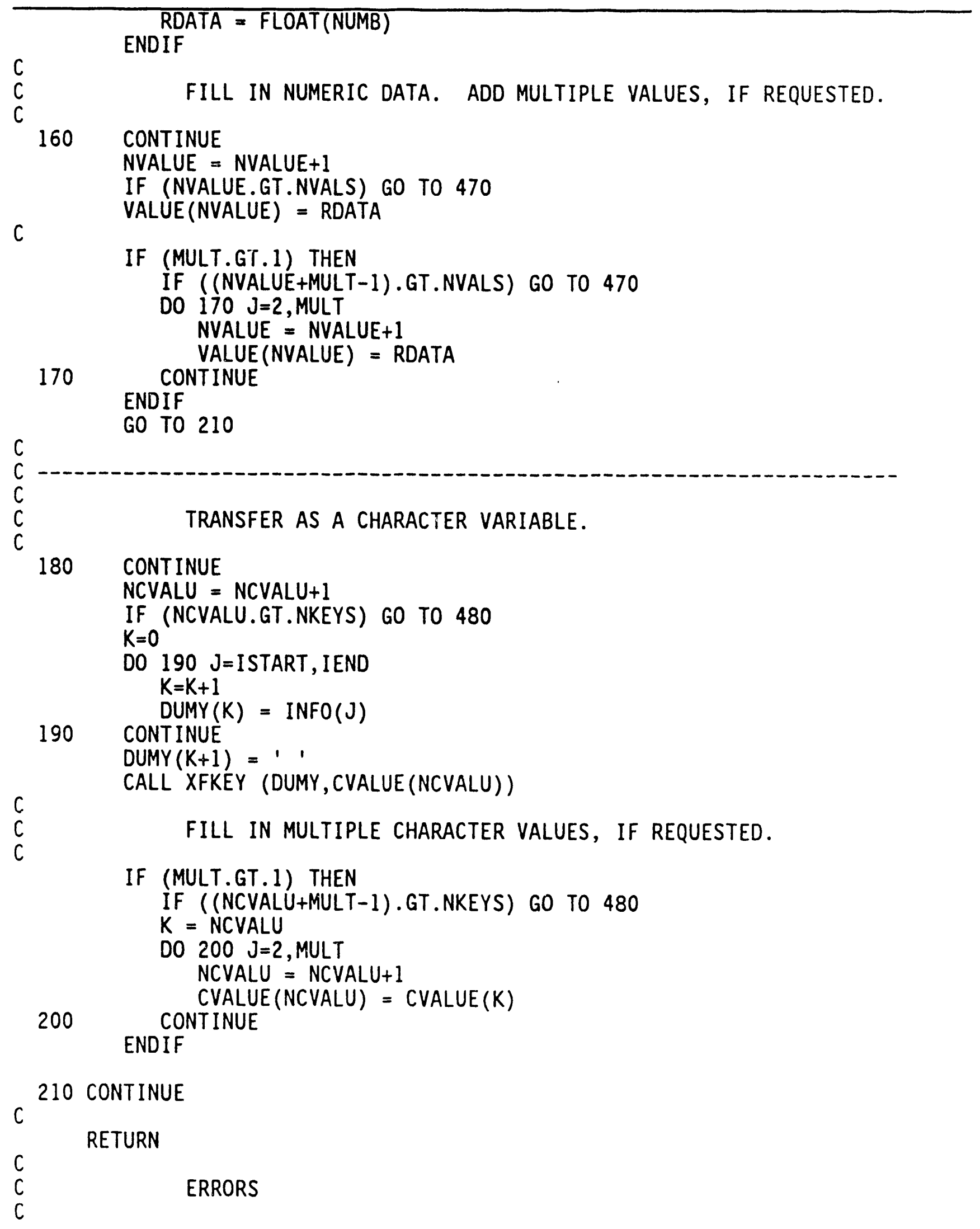


Table A-1. Source Code Listing. (sheet 15 of 62)

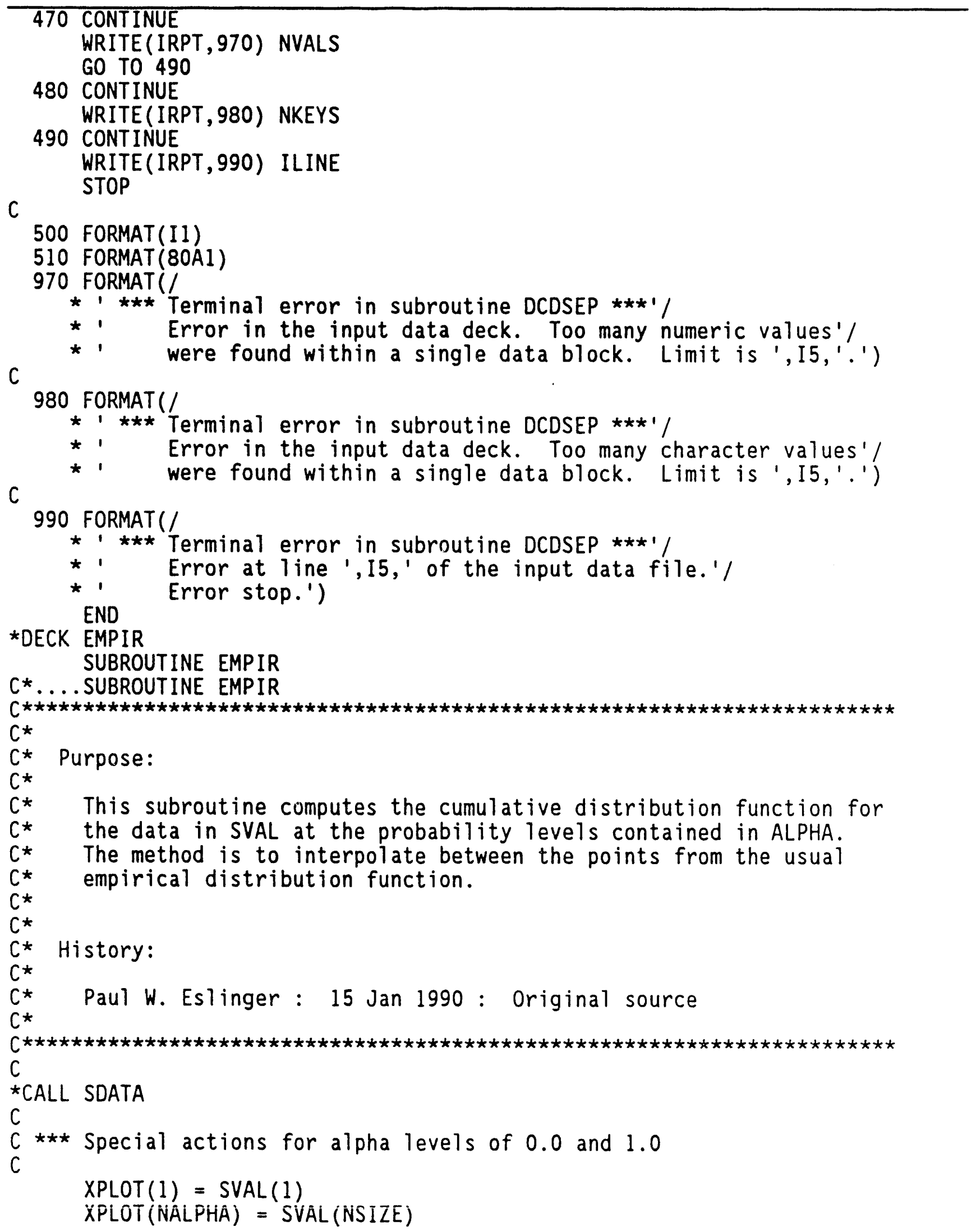


Table A-1. Source Code Listing. (sheet 16 of 62)

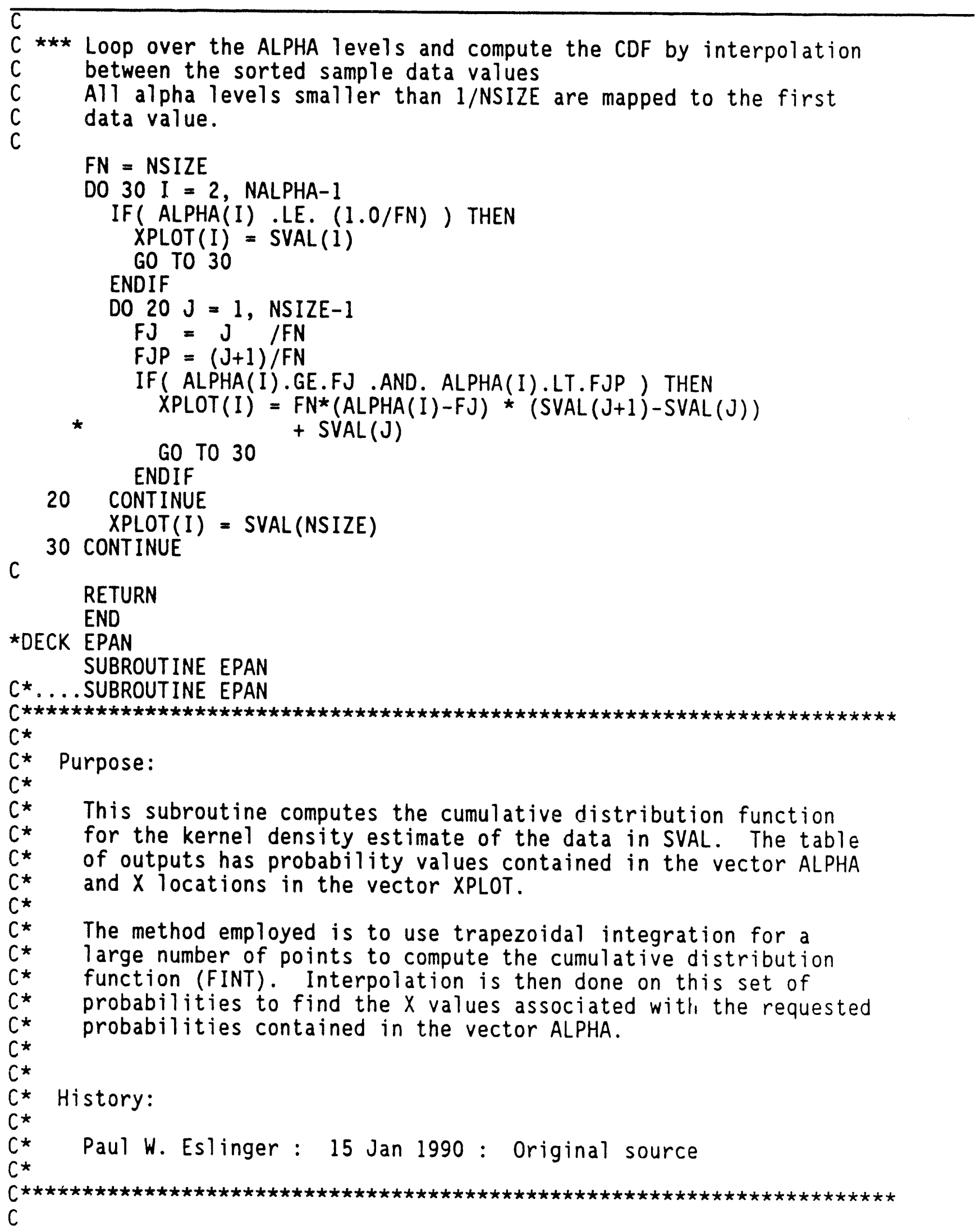


Table A-1. Source Code Listing. (sheet 17 of 62)

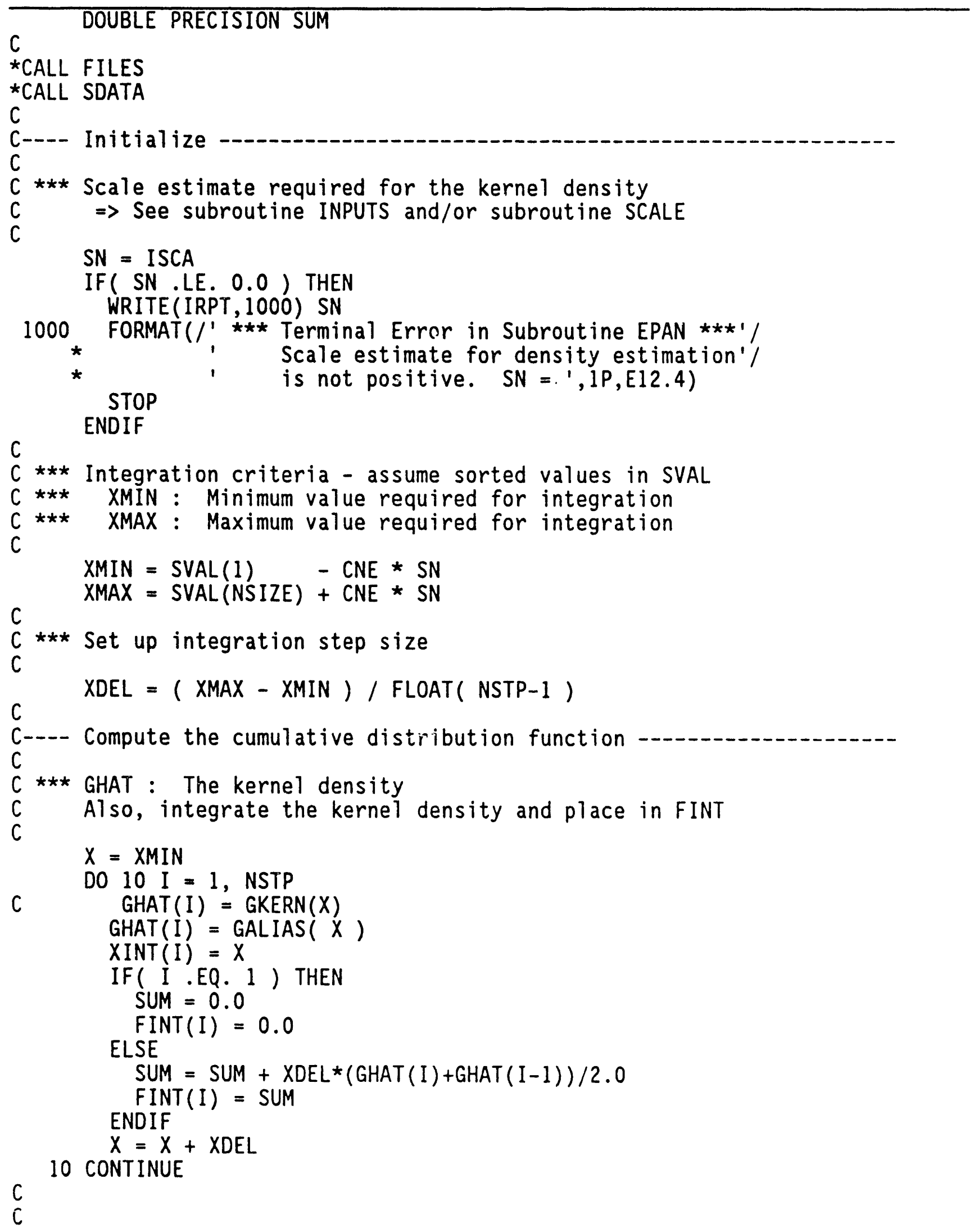


$W H C-E P-0418$

Table A-1. Source Code Listing. (sheet 18 of 62)

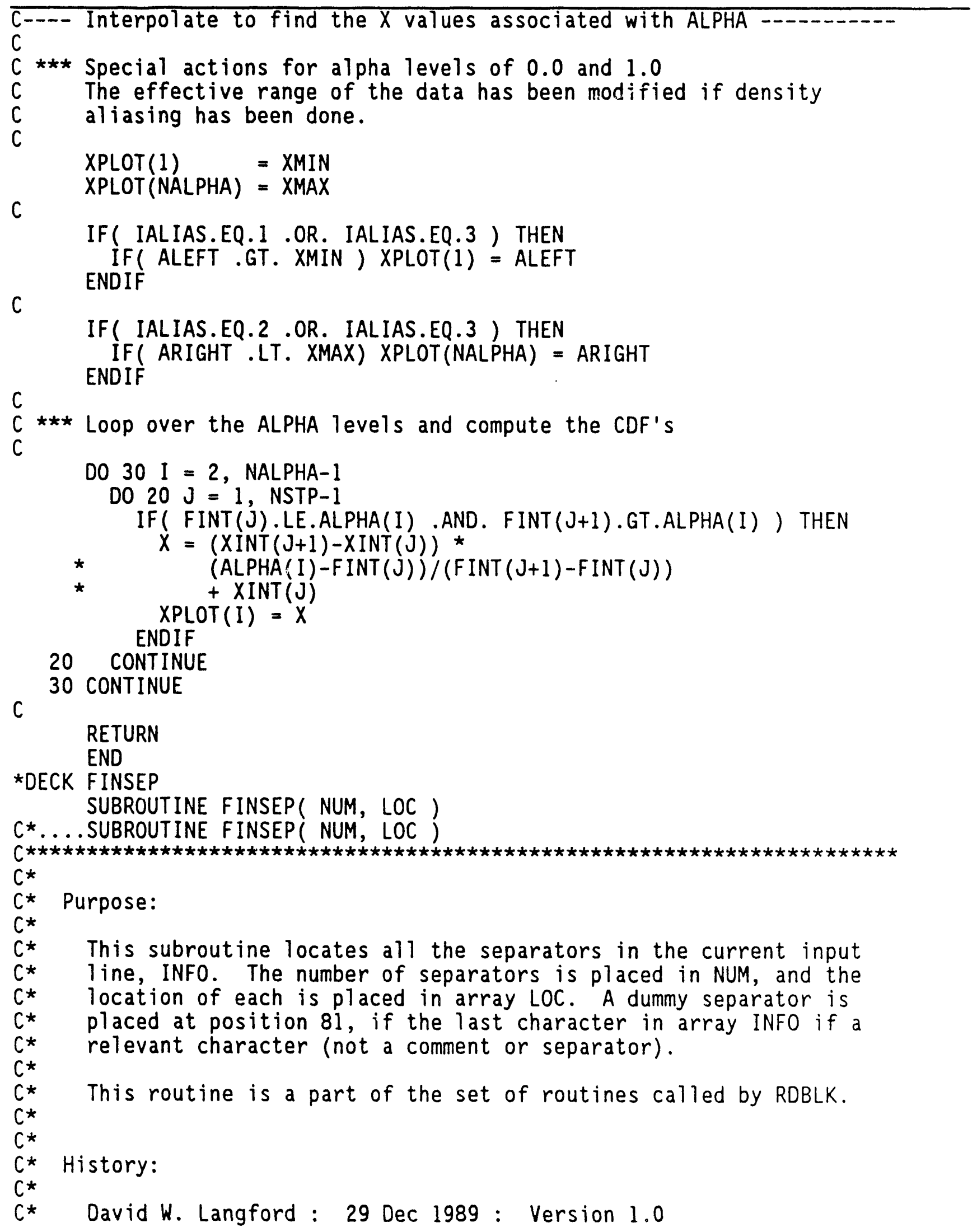


Table A-1. Source Code Listing. (sheet 19 of 62)

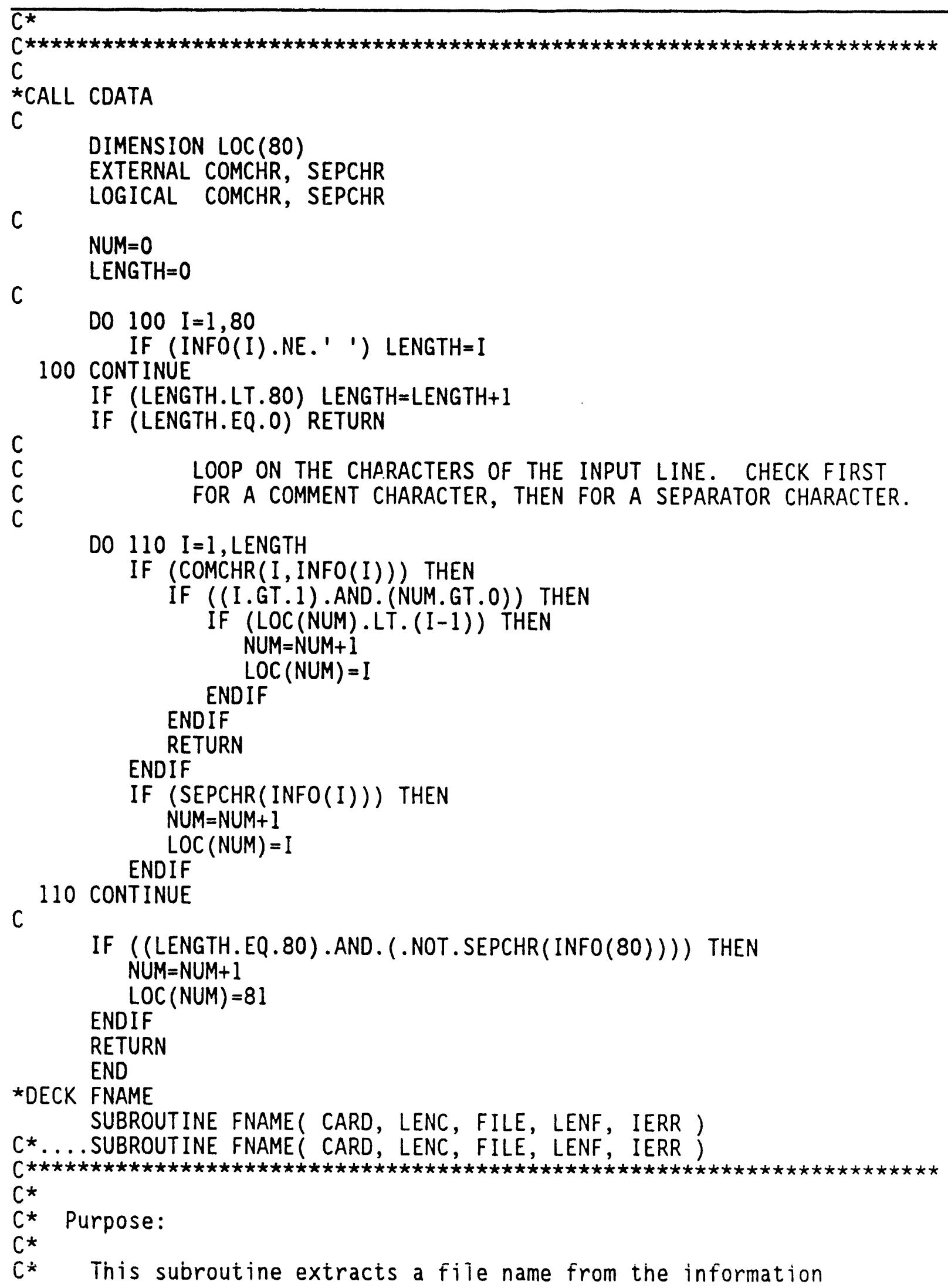


Table A-1. Source Code Listing. (sheet 20 of 62)

contained in the character vector CARD. The file name must be enclosed in double apostrophes and cannot contain more than LENF characters. This subroutine only reads CARD until two apostrophes are found. Any characters after the second apostrophe are ignored.

Call List Variables:

CARD : Input (character) vector from which to extract the file name. CARD is considered as a CHARACTER*1 vector of length LENC.

LENC : Input (integer) giving the maximum number of characters in CARD.

FILE : Output (character) array containing the file name which was extracted from CARD. FILE is considered as a CHARACTER 1 vector of length LENF. FILE is blank filled before any file name extraction is performed.

LENF : Input (integer) giving the maximum number of characters in the file name FILE.

IERR : Output (integer) error flag.

$0=$ Normal termination

$1=$ There were not two apostrophes in CARD. A blank file name will be returned.

2 = Two adjacent apostrophes were located. A blank file name will be returned.

$3=$ The file name would contain more than LENF characters. A blank file name is returned.

History:

Paul W. Eslinger : 29 Dec 1989 : Version 1.0

$C^{\star}$

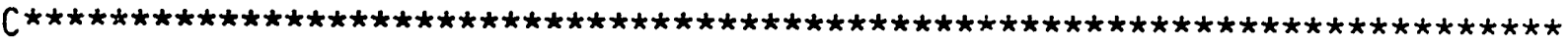

C

INTEGER LENC, LENF, IERR

CHARACTER*I CARD(LENC), FILE(LENF), APOS, BLANK

C

DATA APOS / $" 1 /$, BLANK / $/$

$C \star \star \star \star$ Set the error flag and blank fill the file name

IERR $=0$

DO $10 I=1$, LENF

FILE(I) = BLANK

10 CONTINUE

$C$

C ${ }^{* * *}$ Locate the apostrophes bracketing the file name

$I 1=0$ 
WHC-EP-0418

Table A-1. Source Code Listing. (sheet 21 of 62)

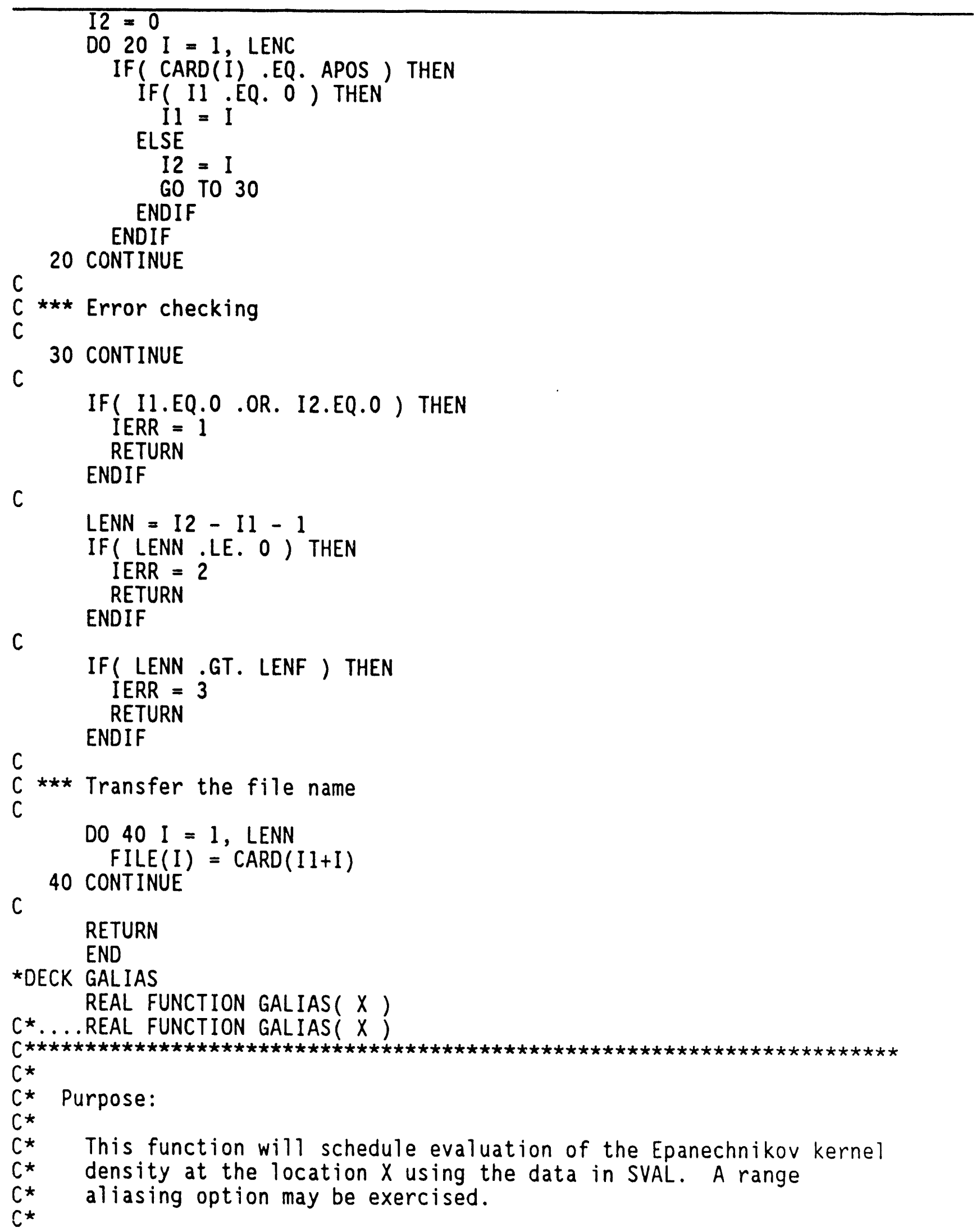


Table A-1. Source Code Listing. (sheet 22 of 62)

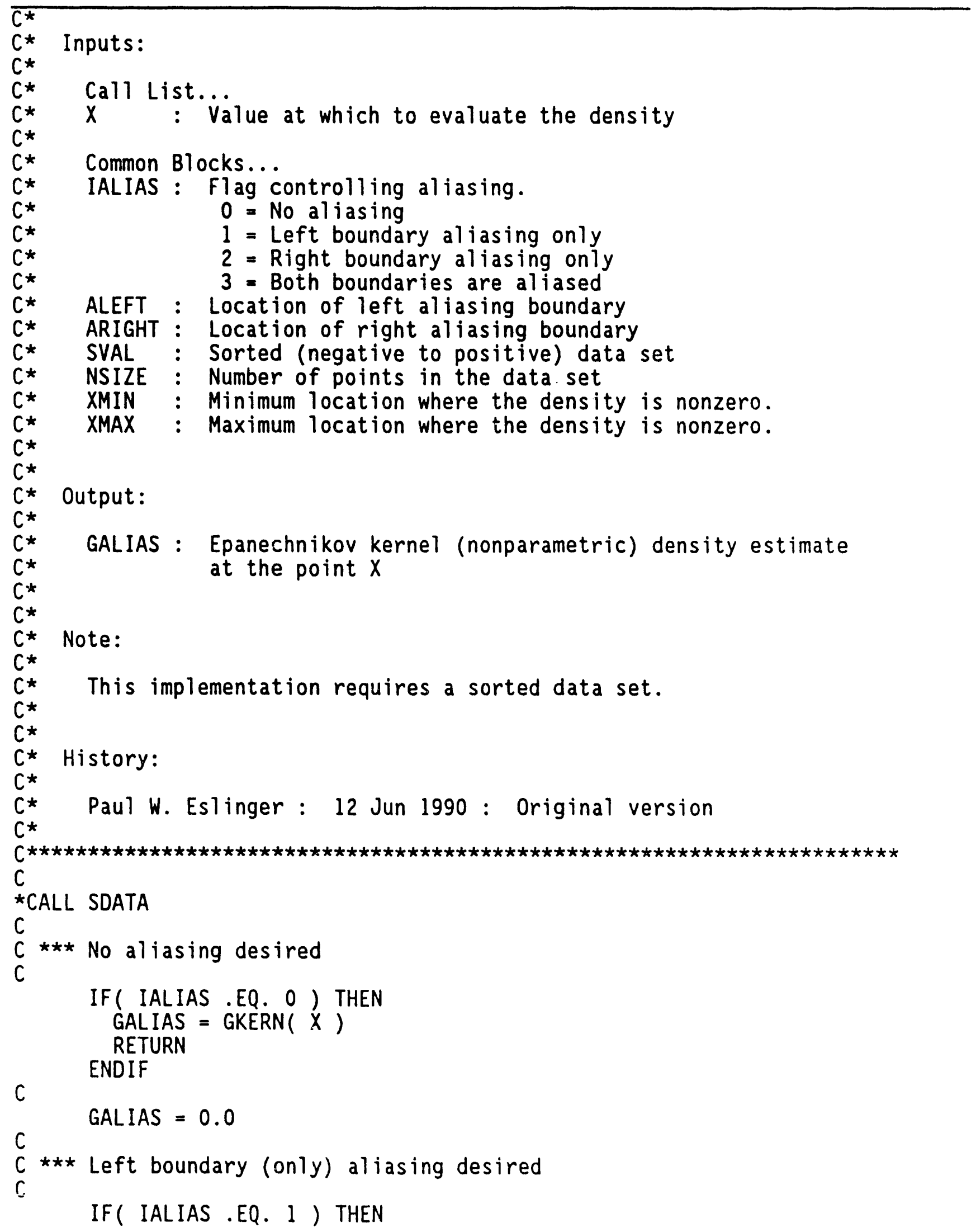


Table A-1. Source Code Listing. (sheet 23 of 62)

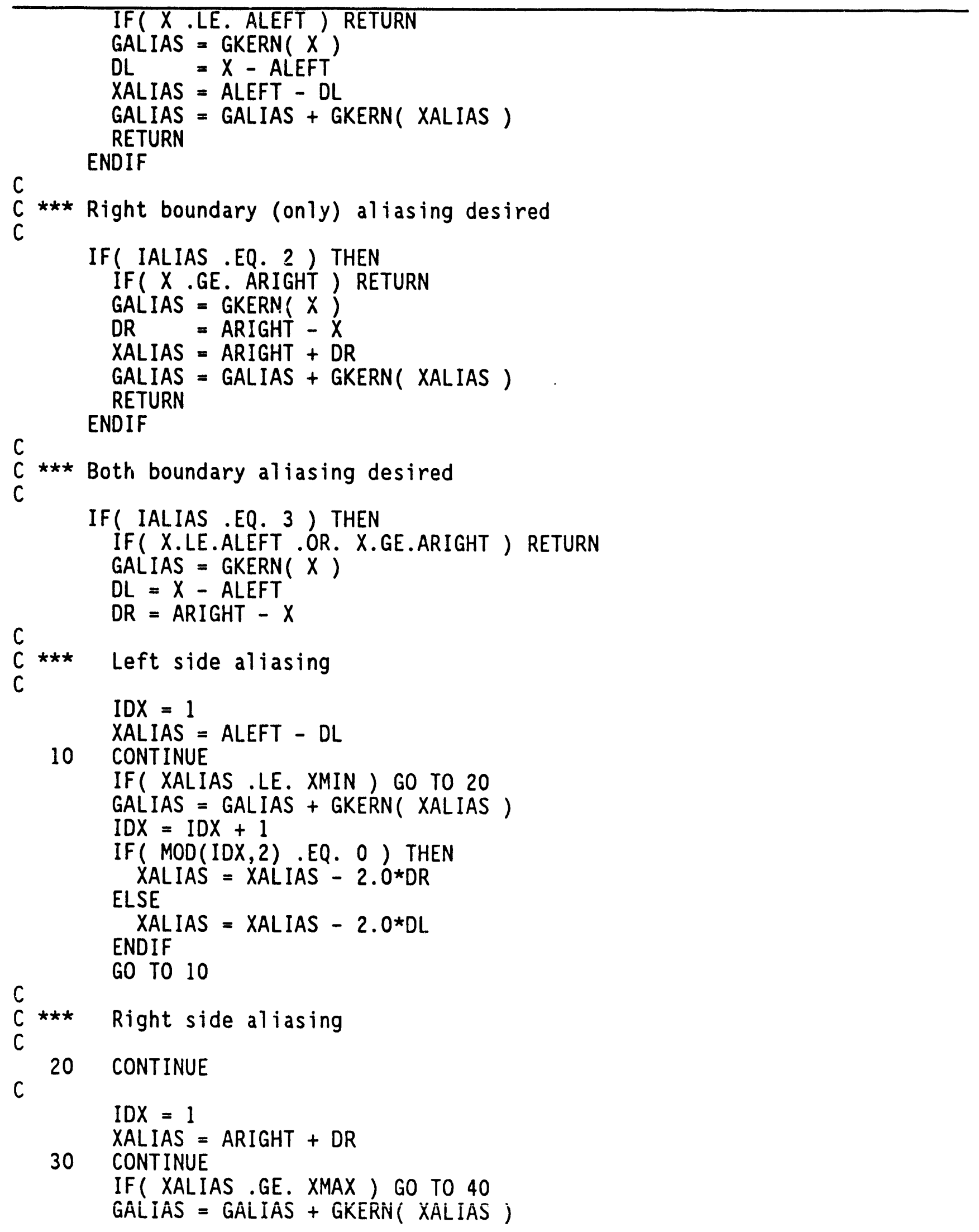


Table A-1. Source Code Listing. (sheet 24 of 62)

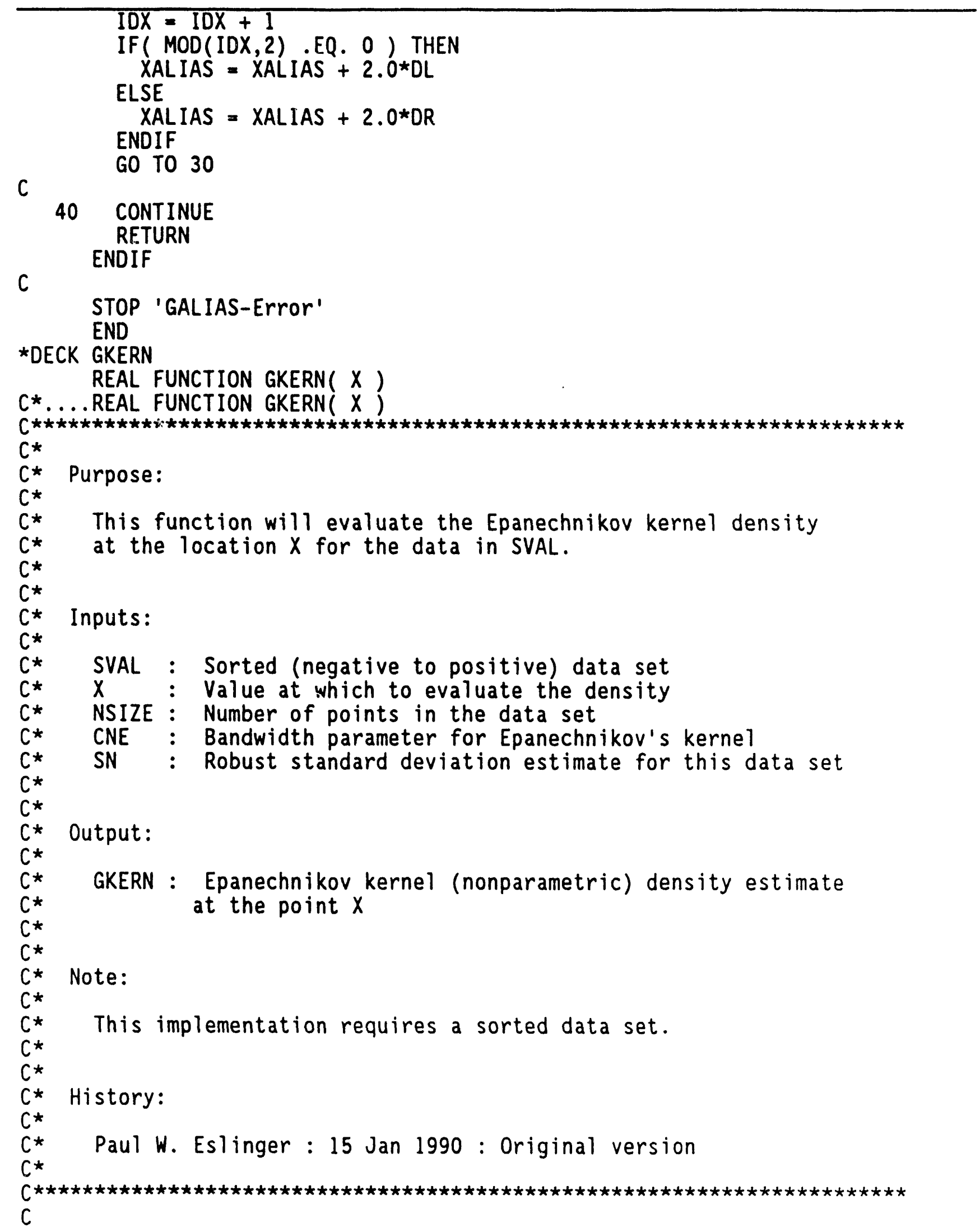


Table A-1. Source Code Listing. (sheet 25 of 62)

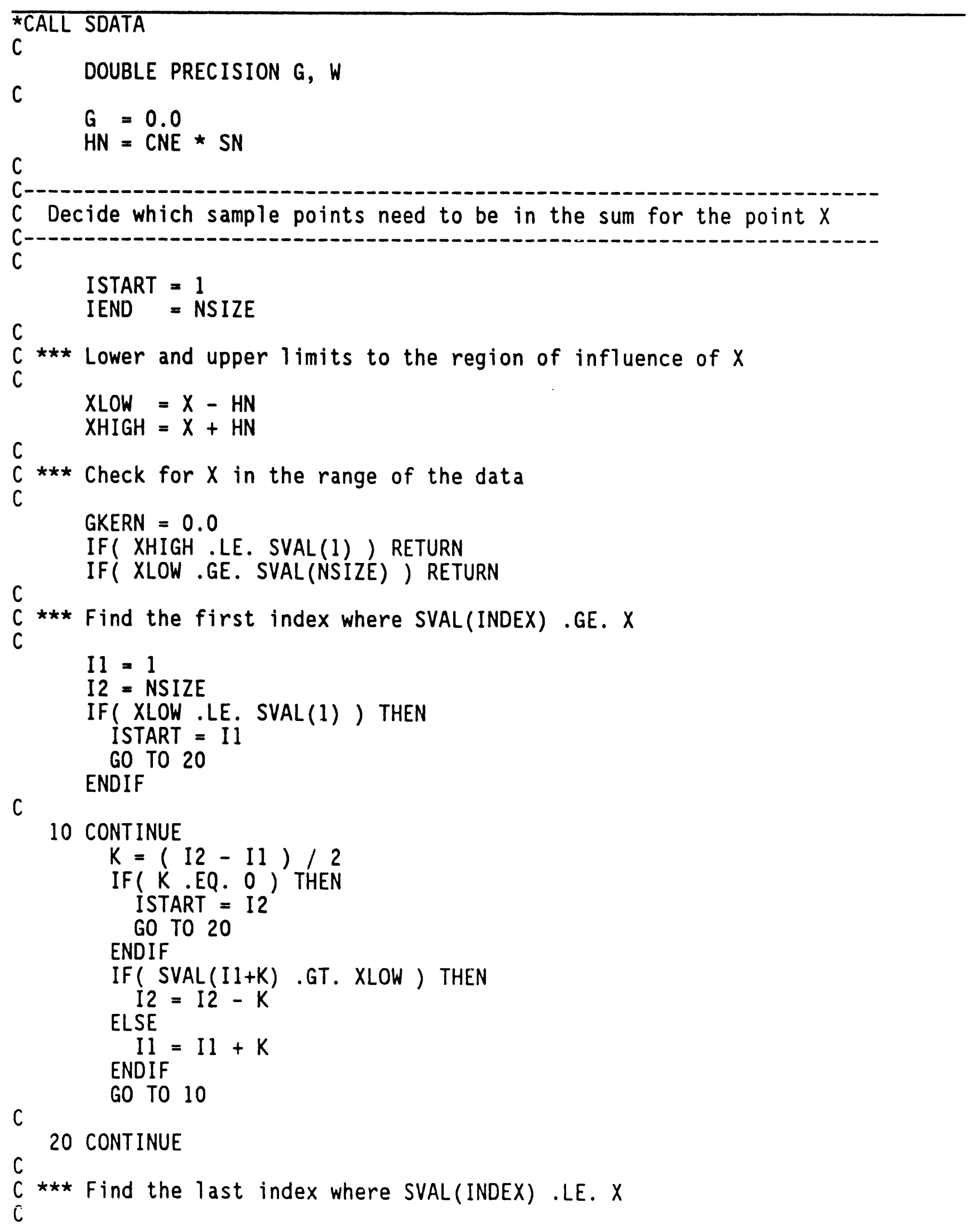


WHC-EP-0418

Table A-1. Source Code Listing. (sheet 26 of 62)

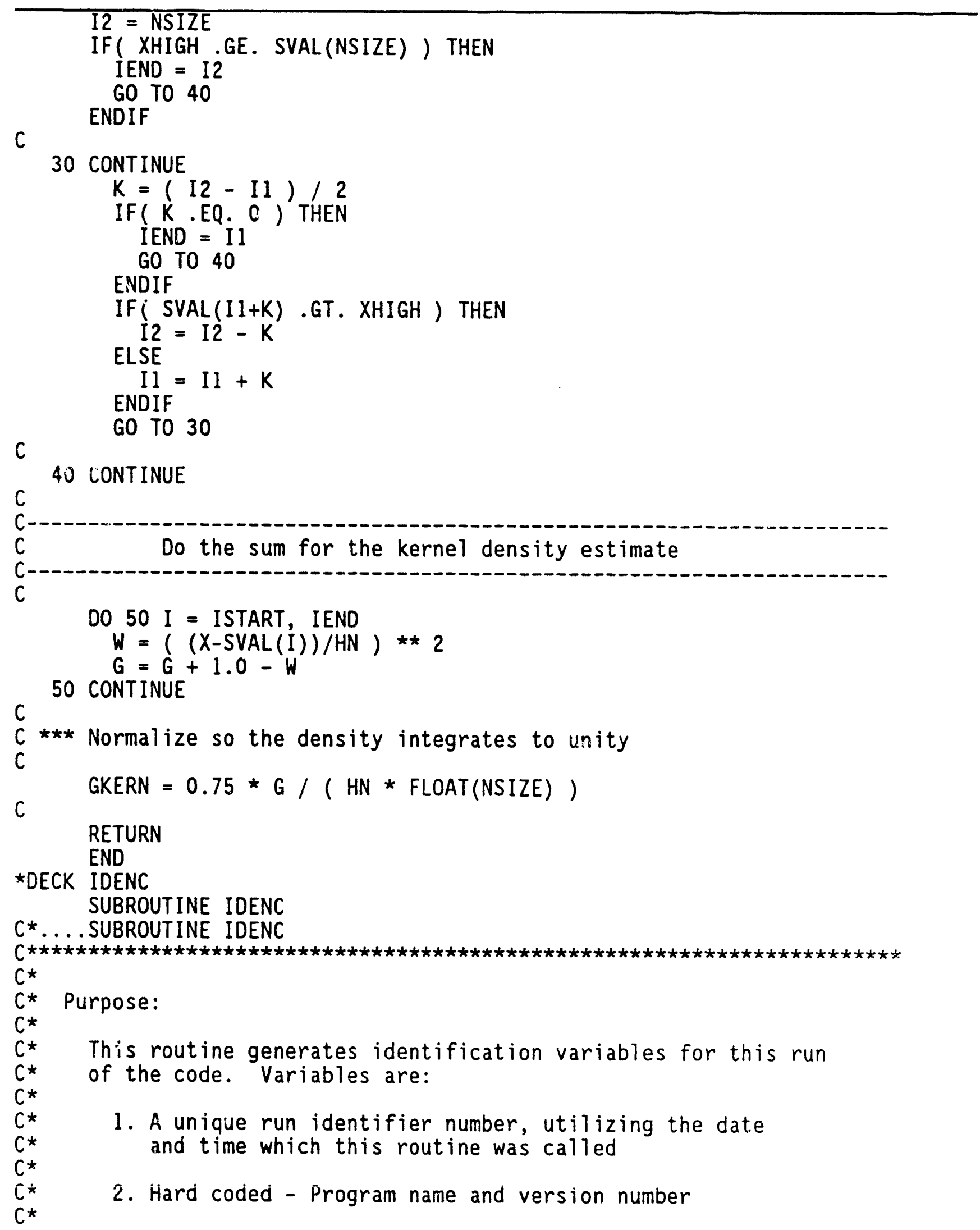


Table A-1. Source Code Listing. (sheet 27 of 62)

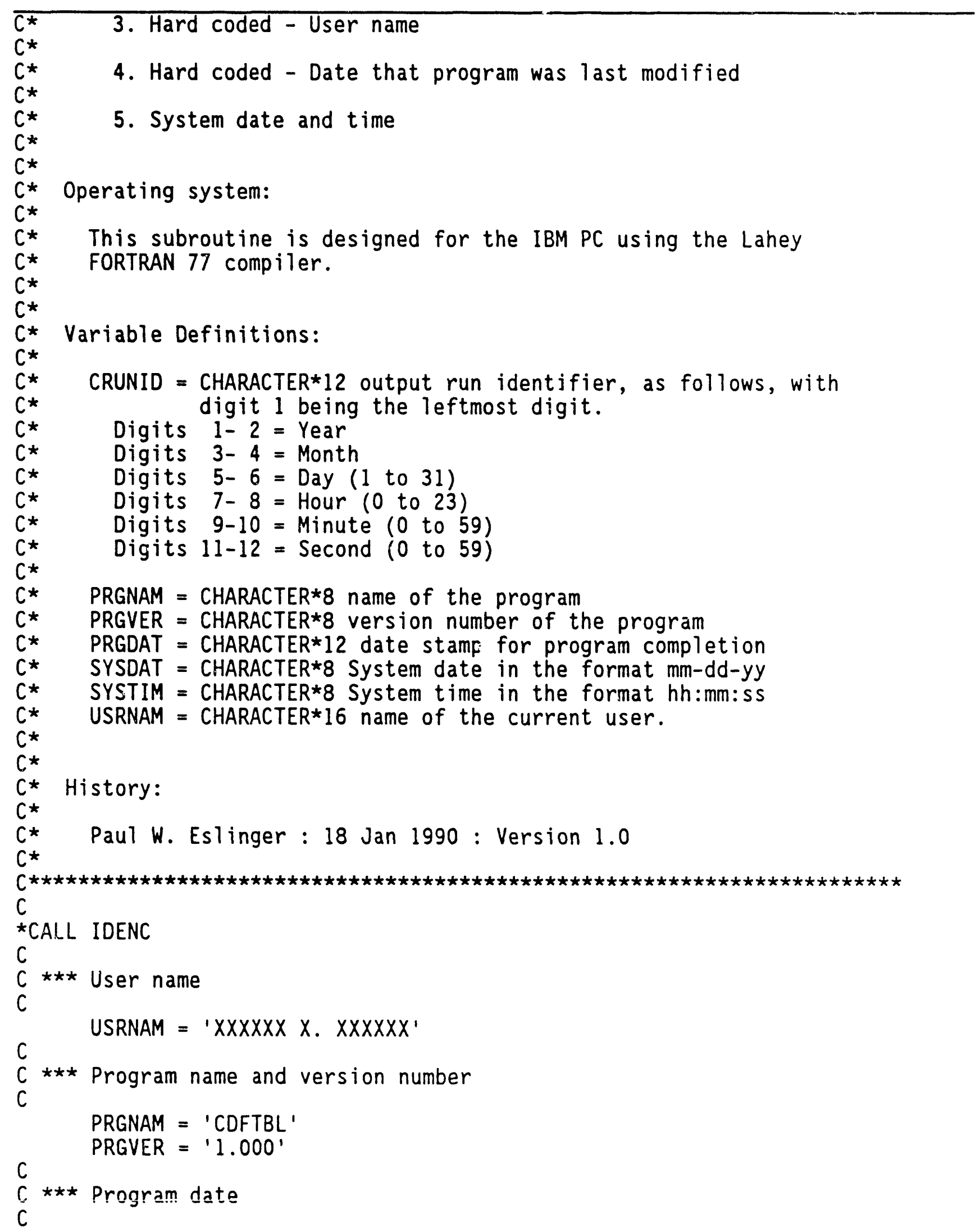


Table A-1. Source Code Listing. (sheet 28 of 62)

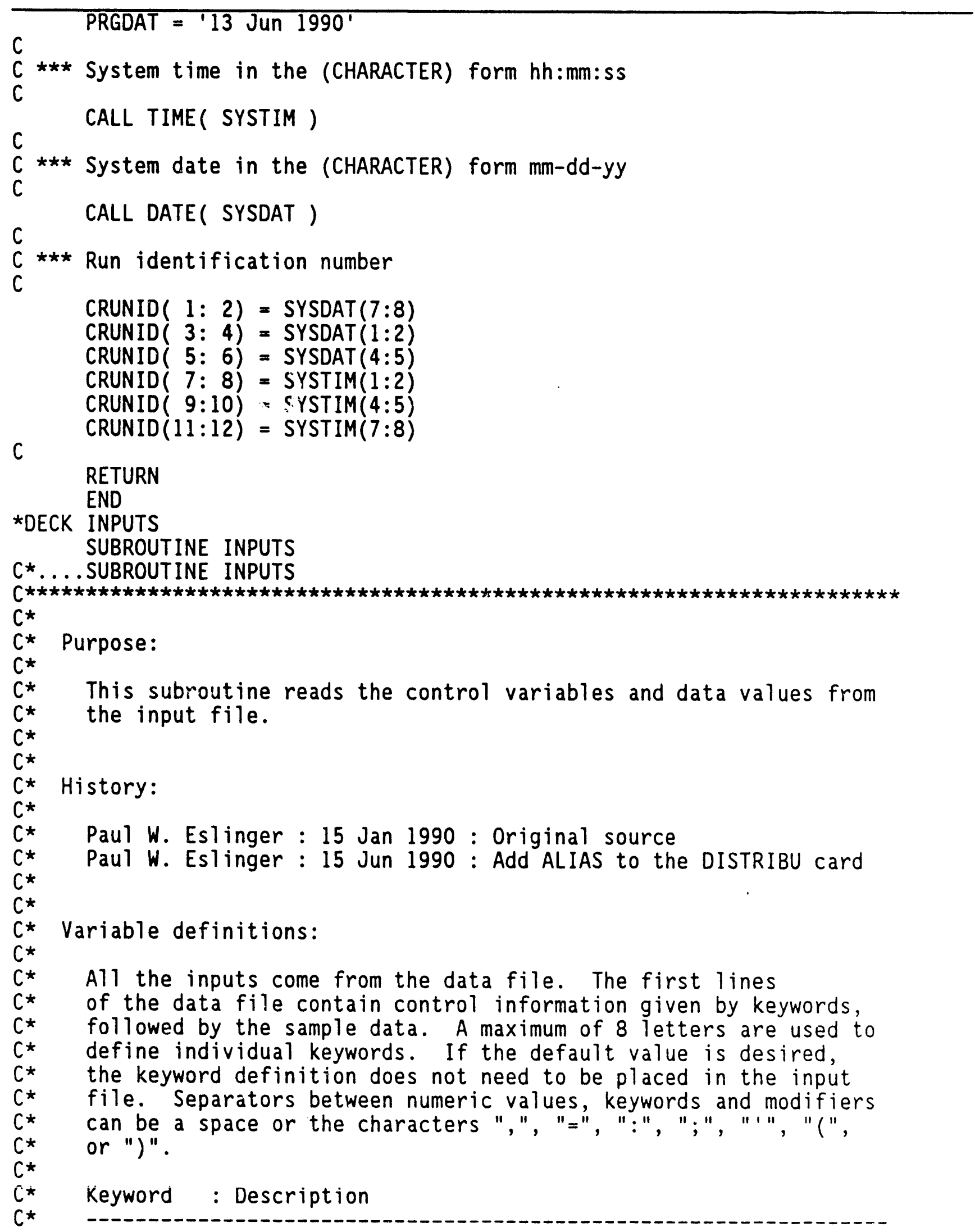


Table A-1. Source Code Listing. (sheet 29 of 62)

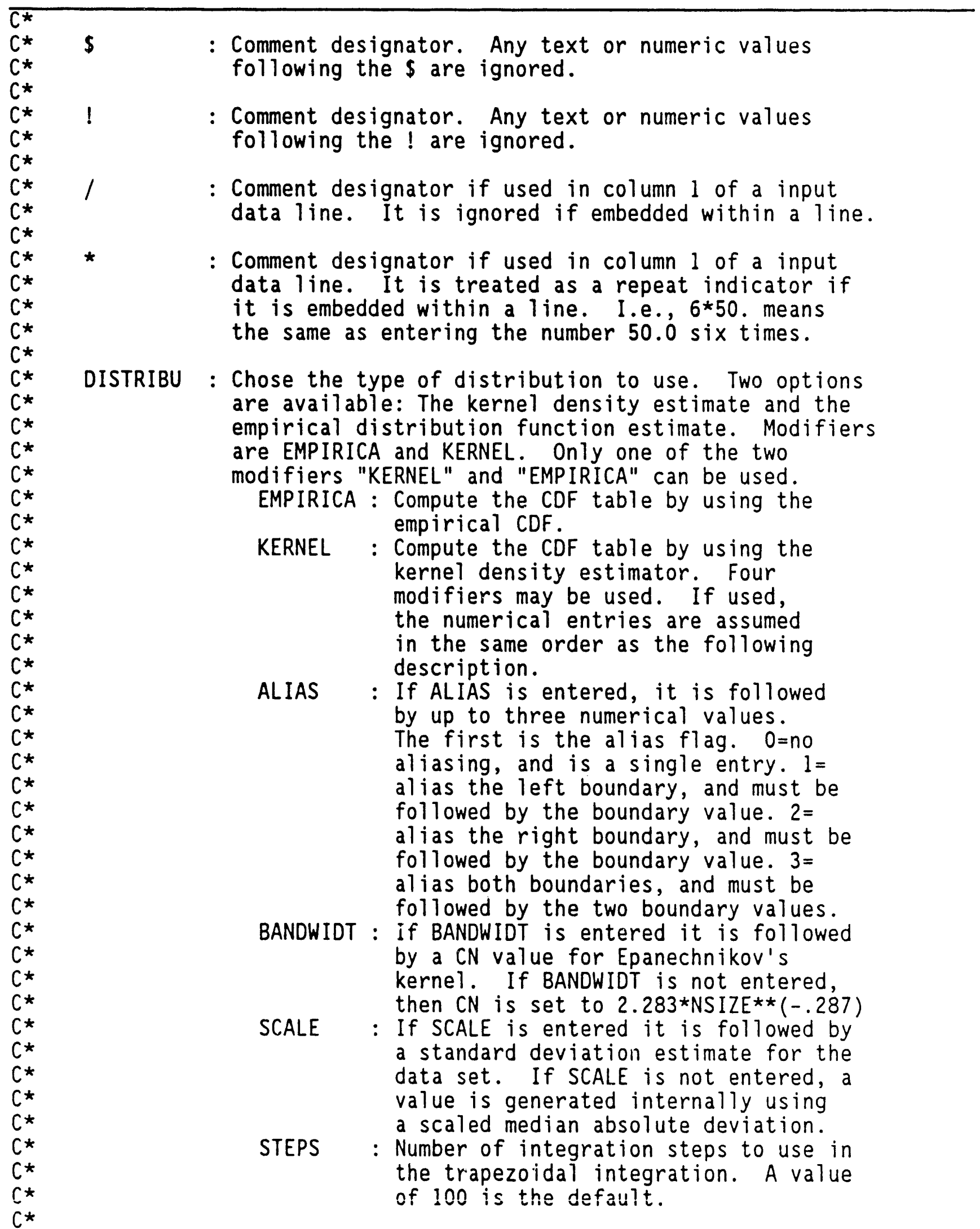


Table A-1. Source Code Listing. (sheet 30 of 62)

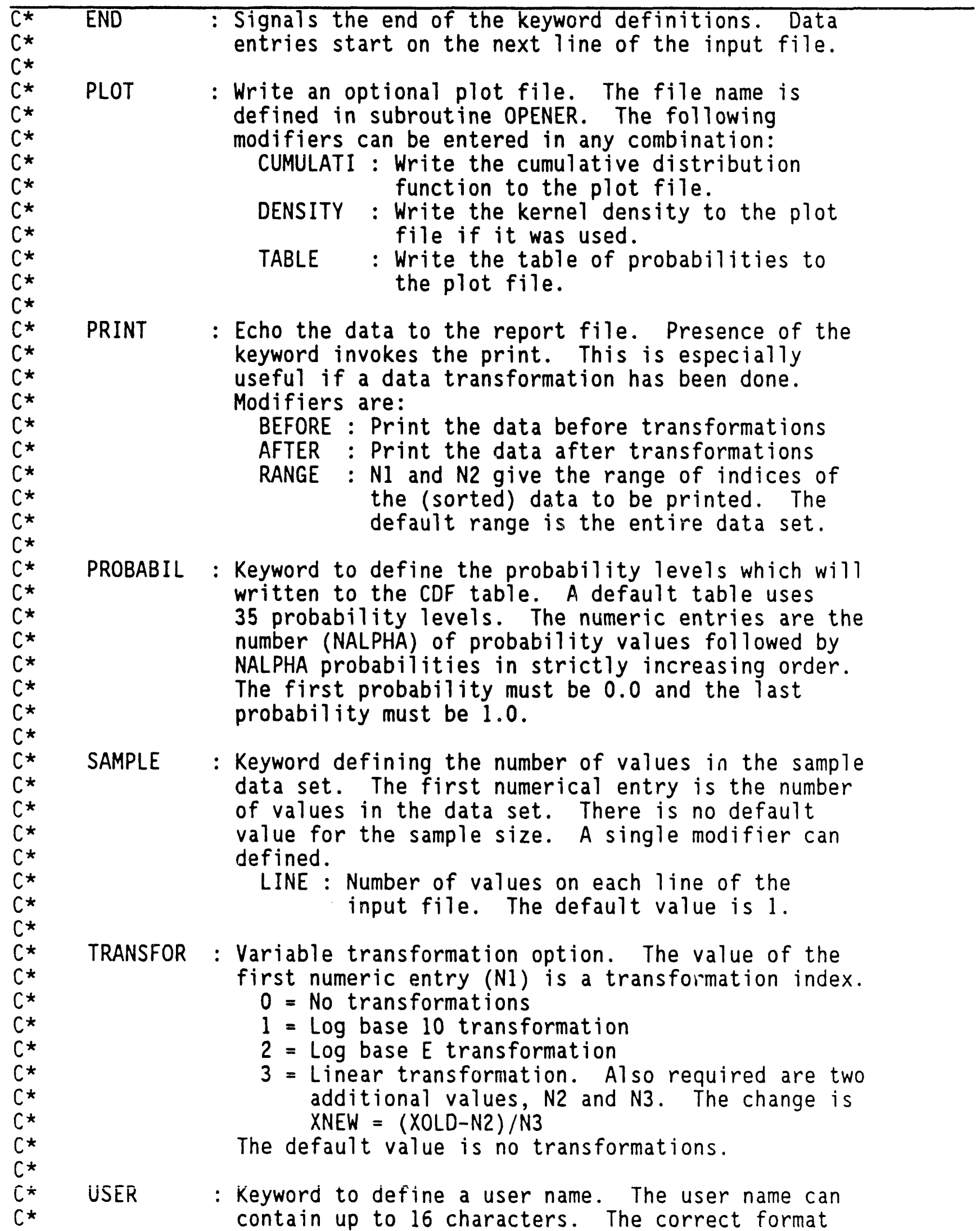


Table A-1. Source Code Listing. (sheet 31 of 62)

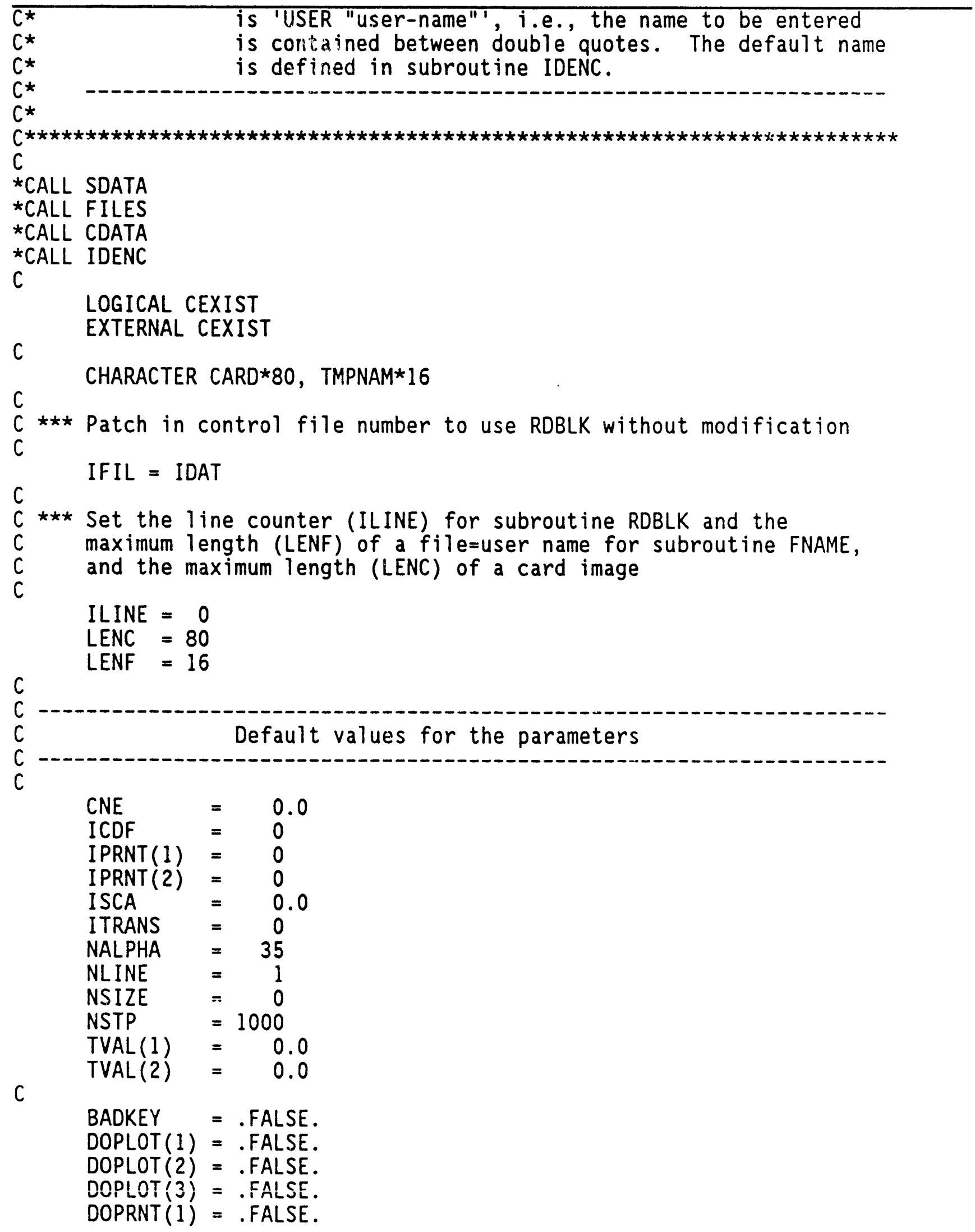


Table A-1. Source Code Listing. (sheet 32 of 62)

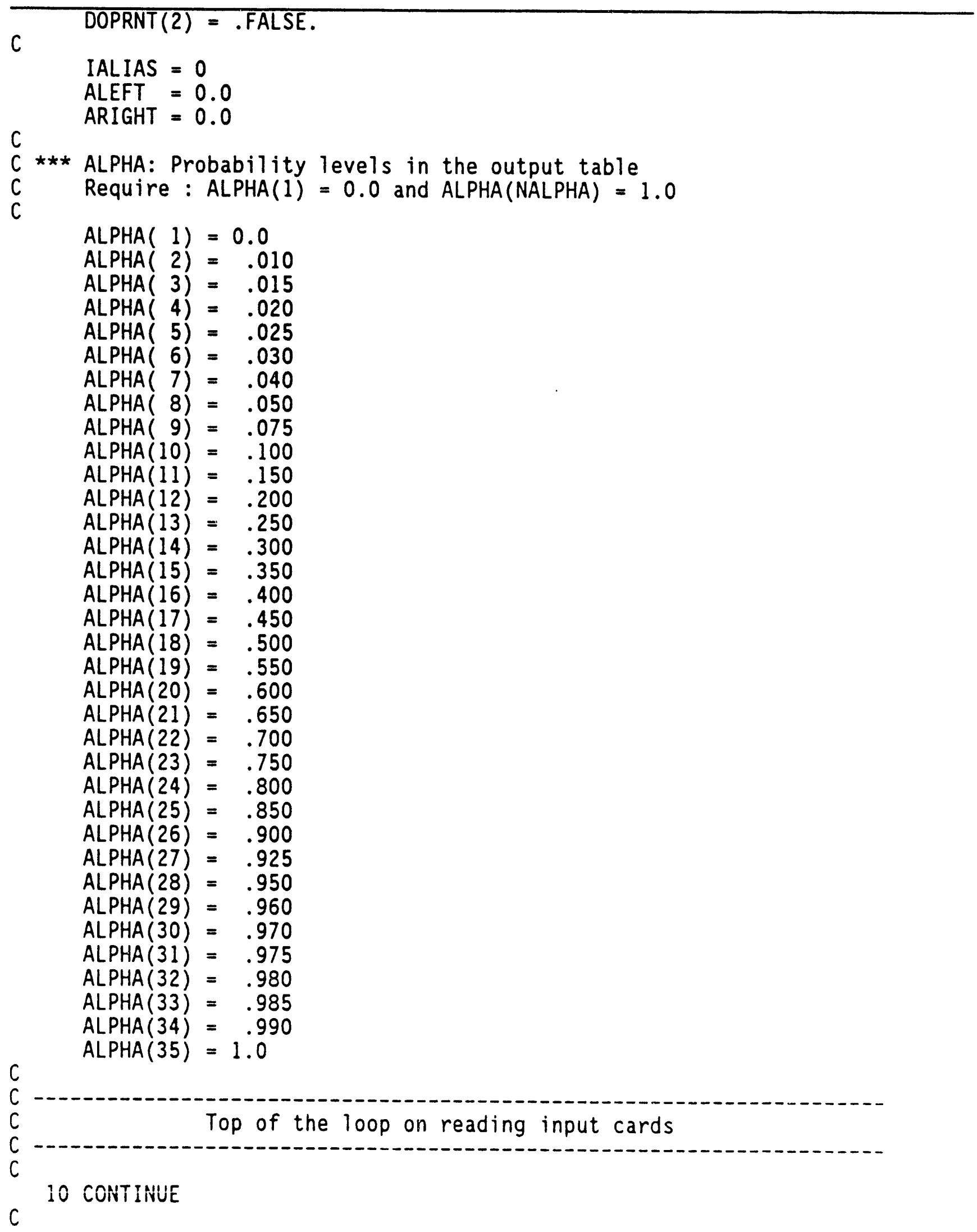


Table A-1. Source Code Listing. (sheet 33 of 62)

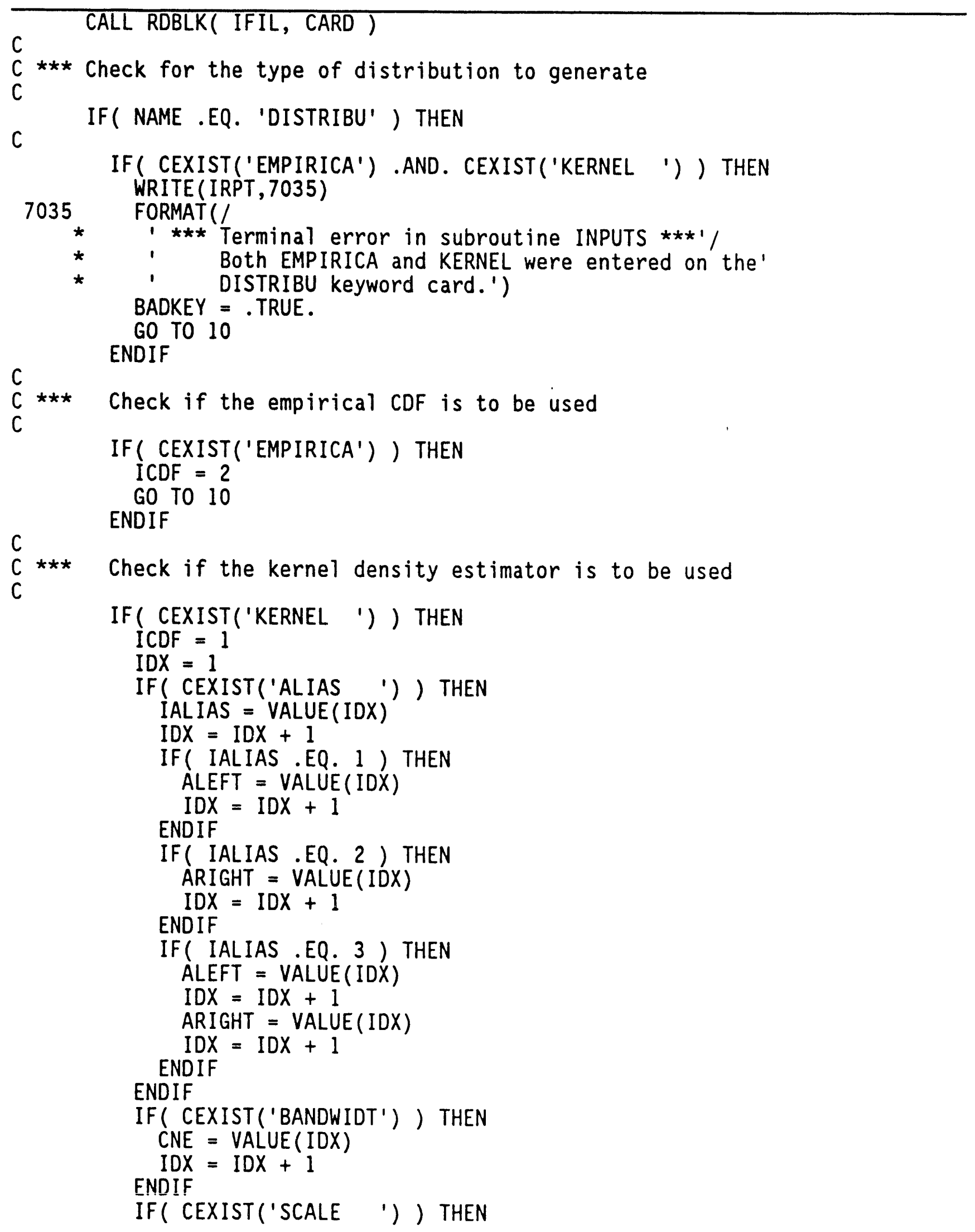


$C$

$C \star \star \star$ Set the error flag and blank fill the file name

C

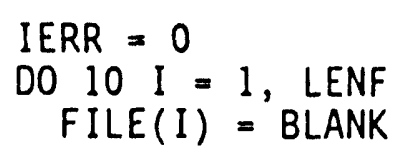

C

$C \star \star \star$ Locate the apostrophes bracketing the file name

I] $=0$

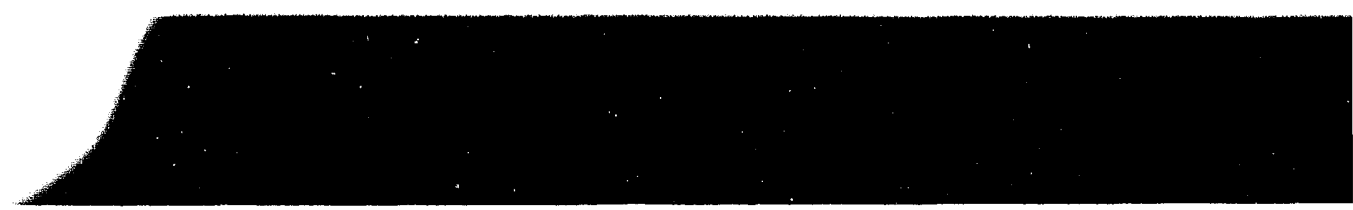

WHC-EP-0418

Table A-1. Source Code Listing. (sheet 34 of 62)

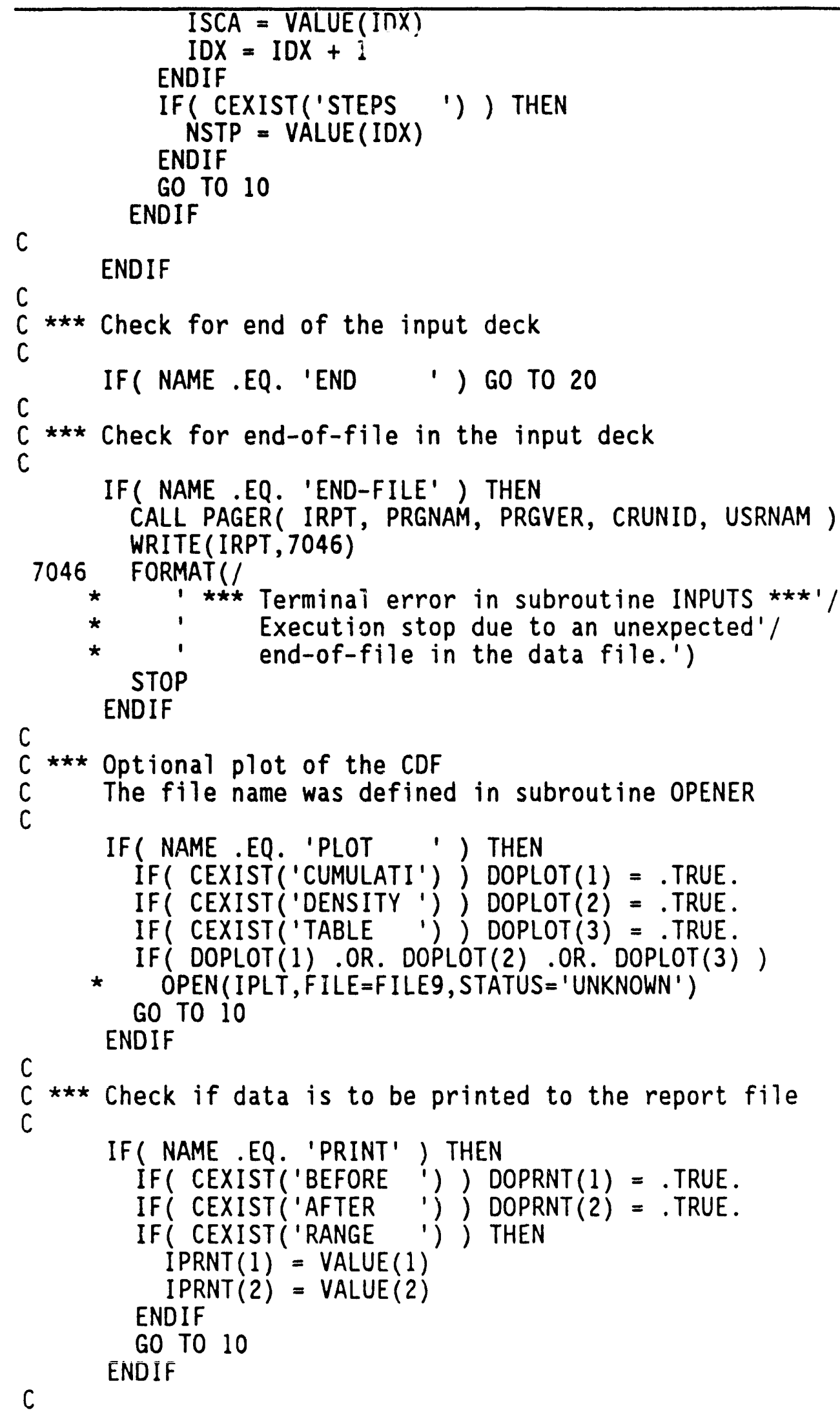


Table A-1. Source Code Listing. (sheet 35 of 62)

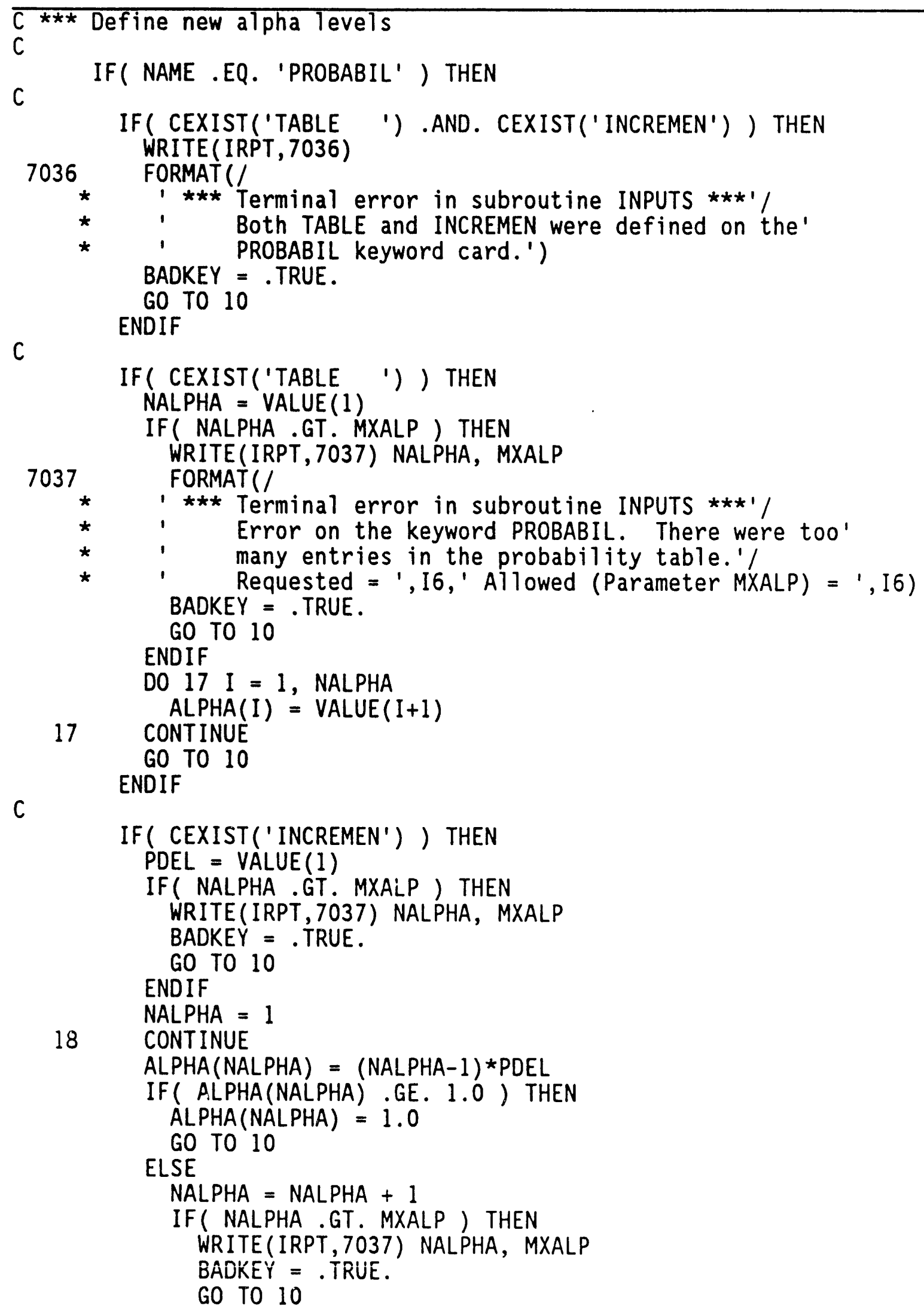


Table A-1. Source Code Listing. (sheet 36 of 62)

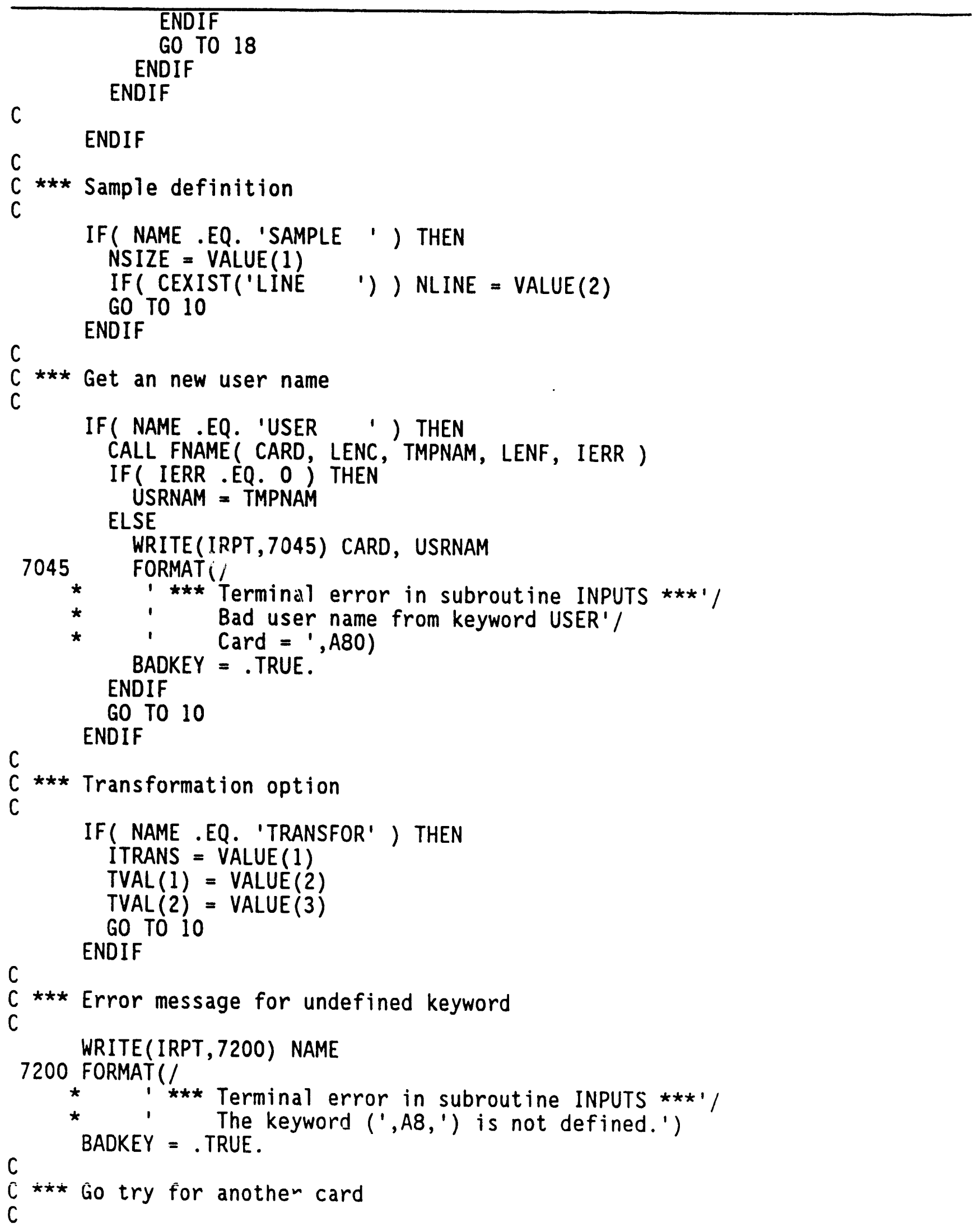


Table A-1. Source Code Listing. (sheet 37 of 62)

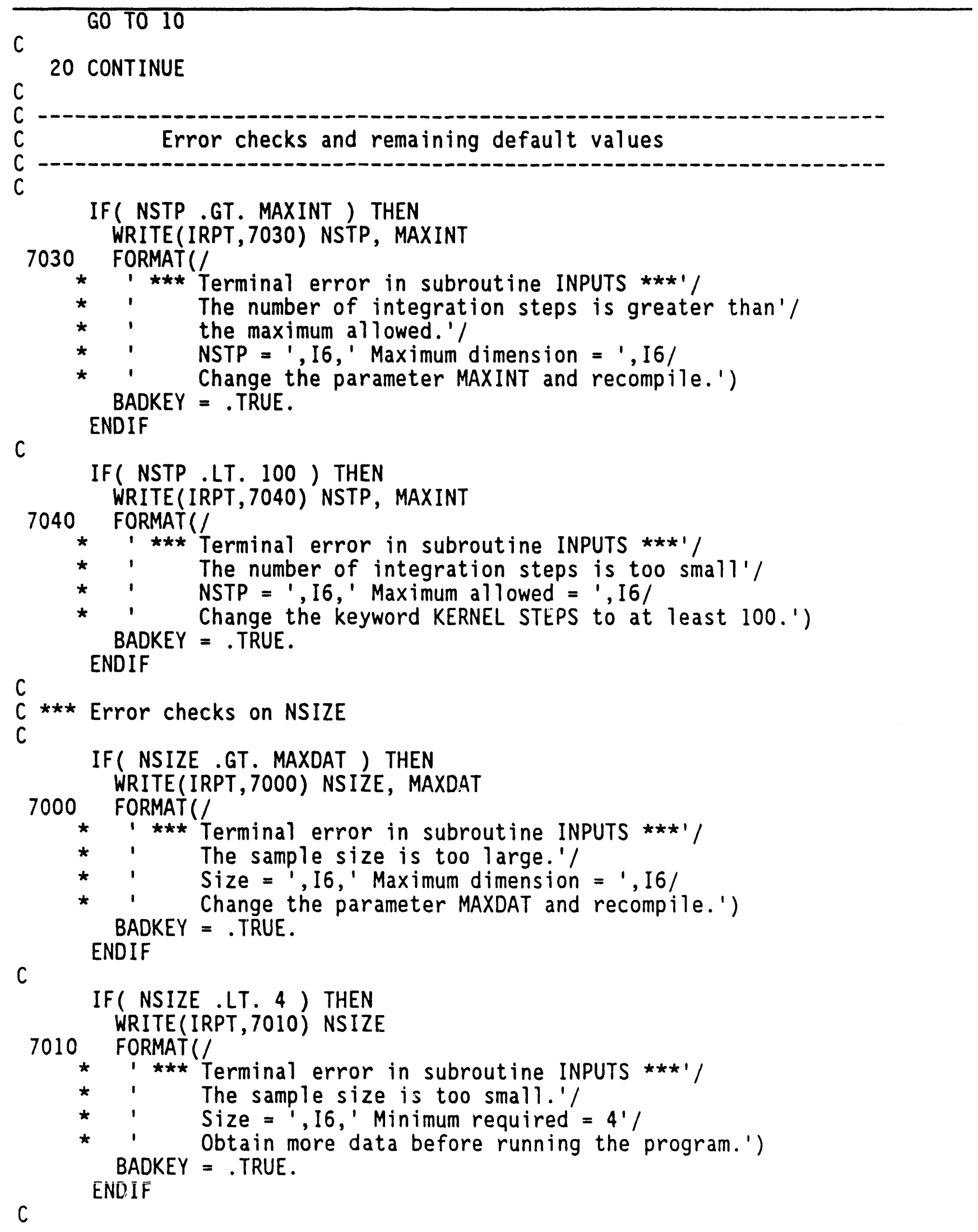


Table A-1. Source Code Listing. (sheet 38 of 62)

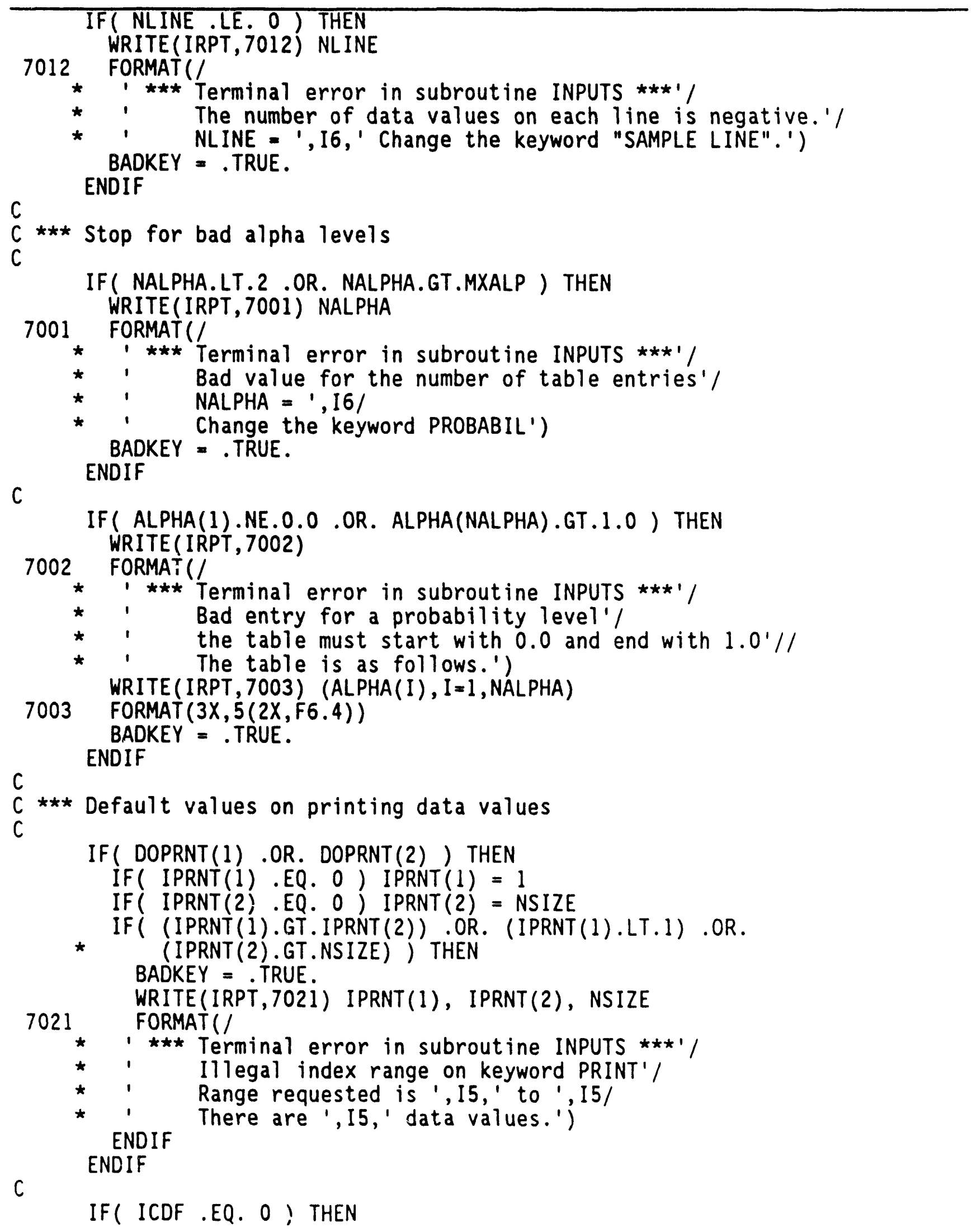


Table A-1. Source Code Listing. (sheet 39 of 62)

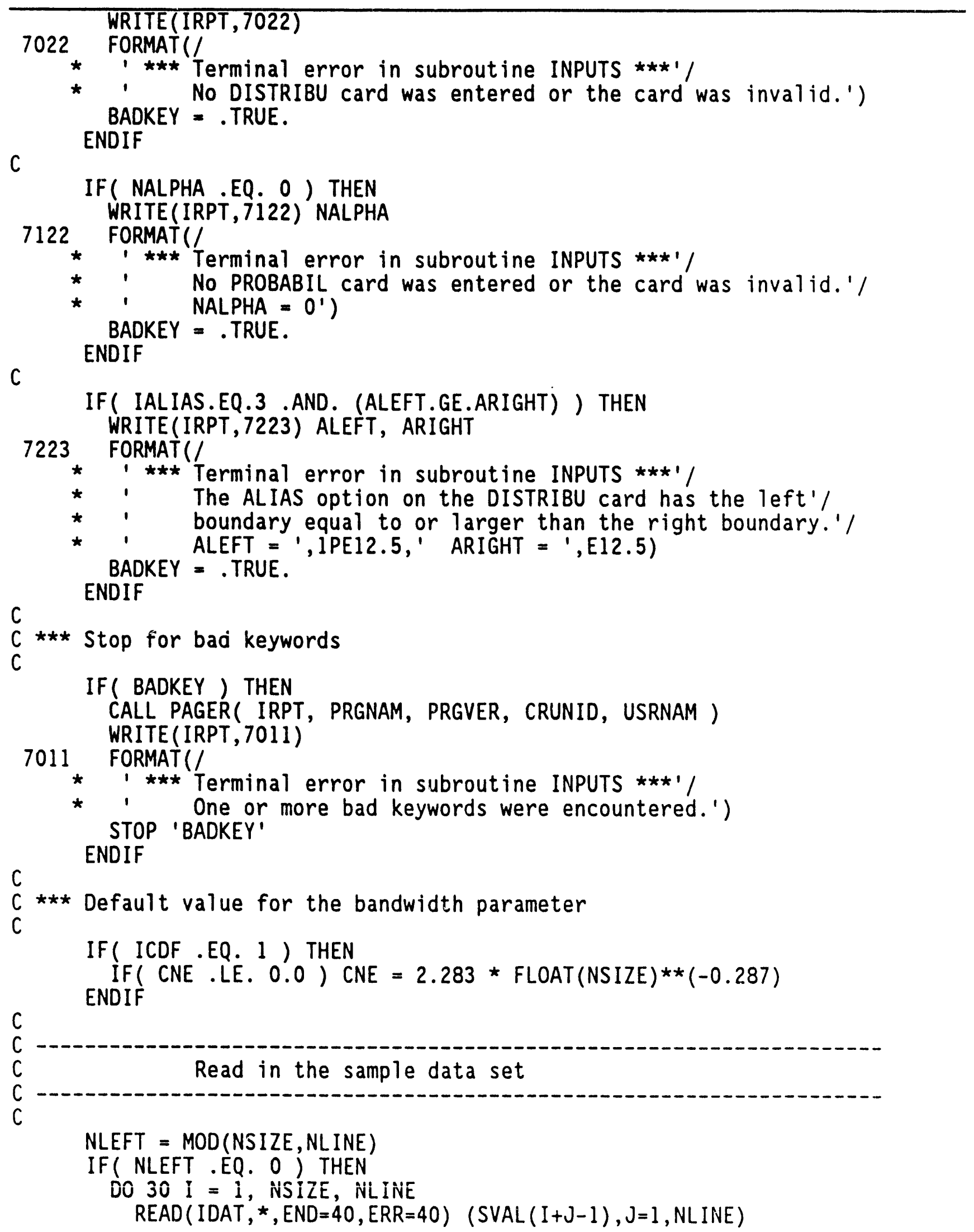


WHC-EP-0418

Table A-1. Source Code Listing. (sheet 40 of 62)

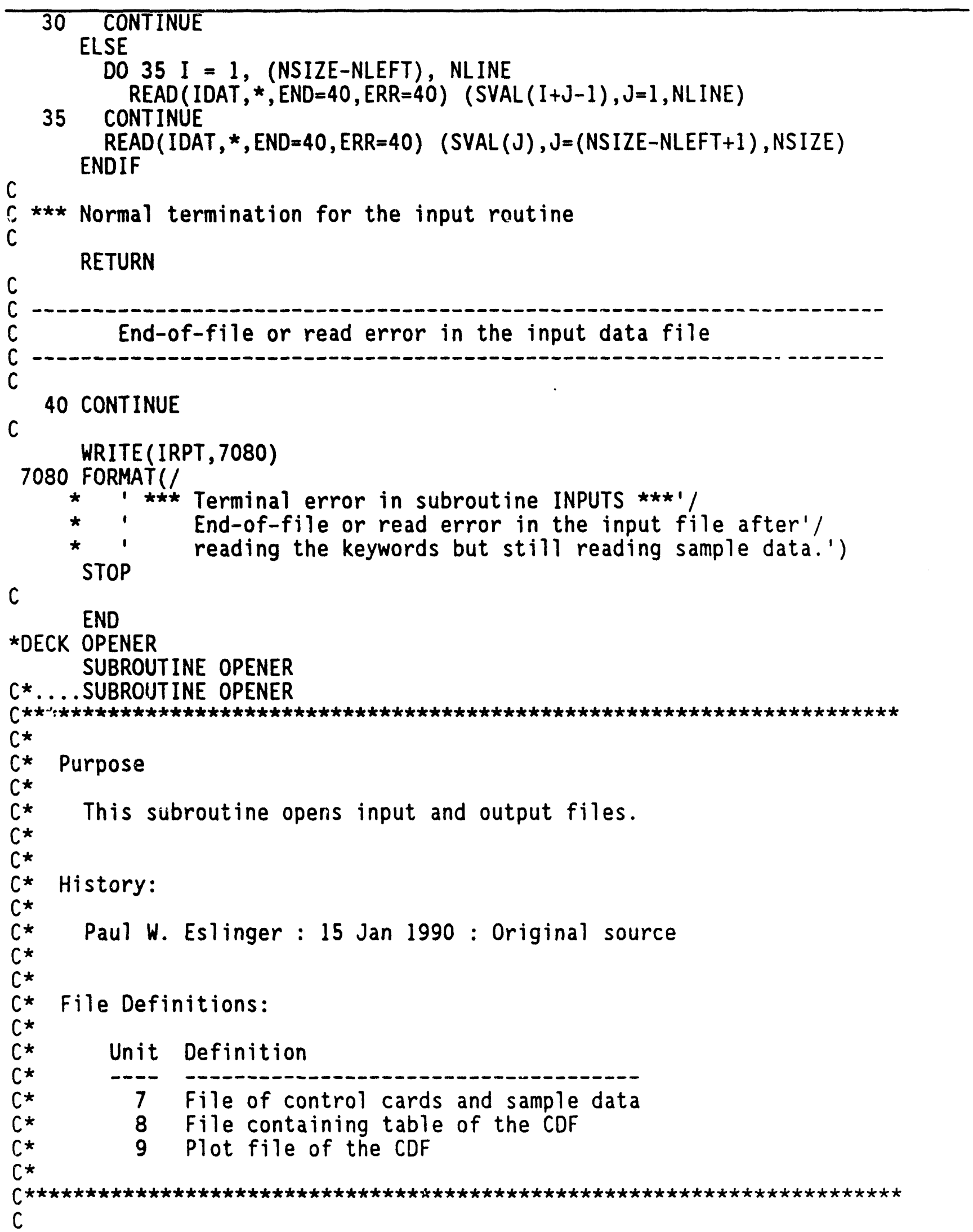


Table A-1. Source Code Listing. (sheet 41 of 62)

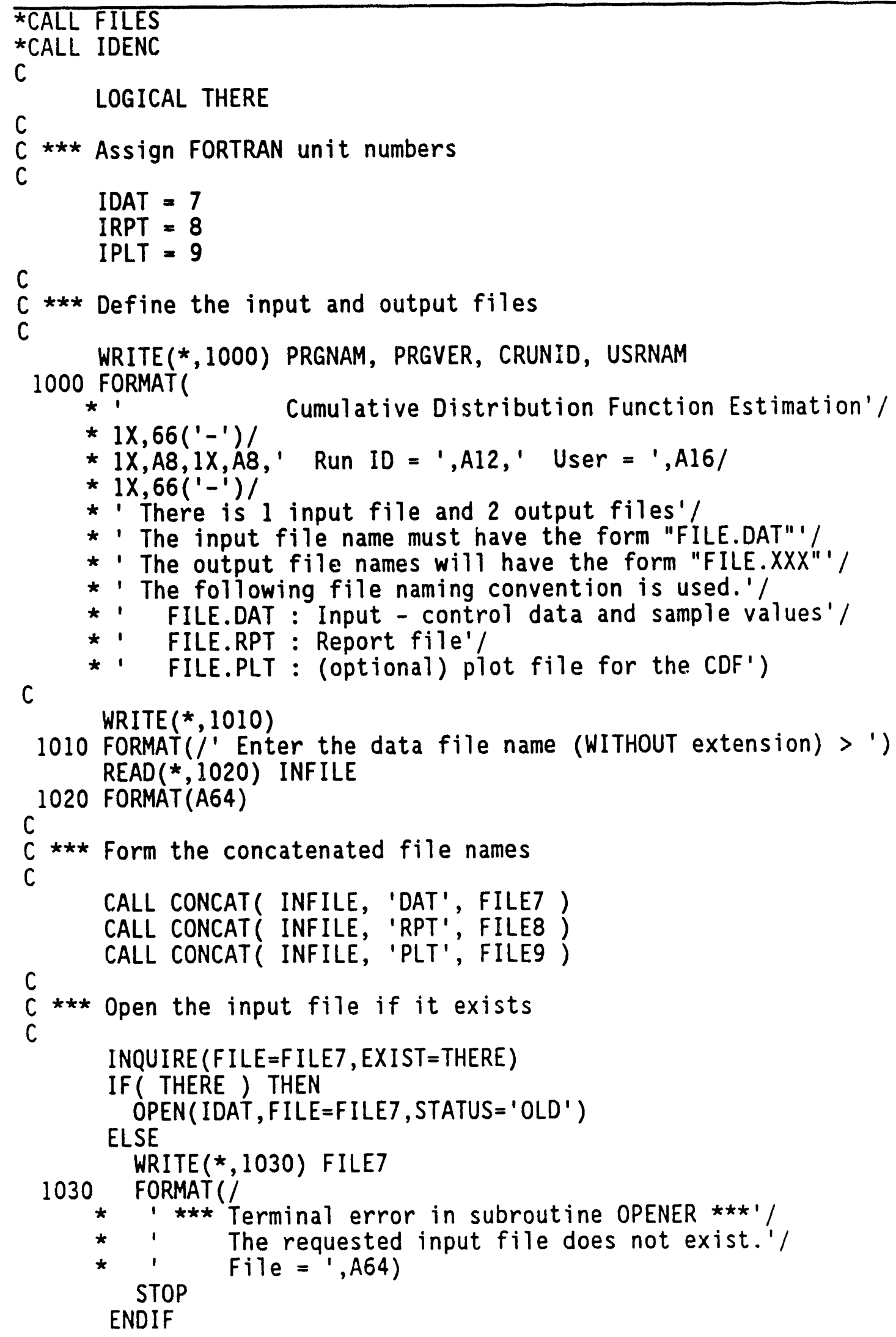


Table A-1. Source Code Listing. (sheet 42 of 62)

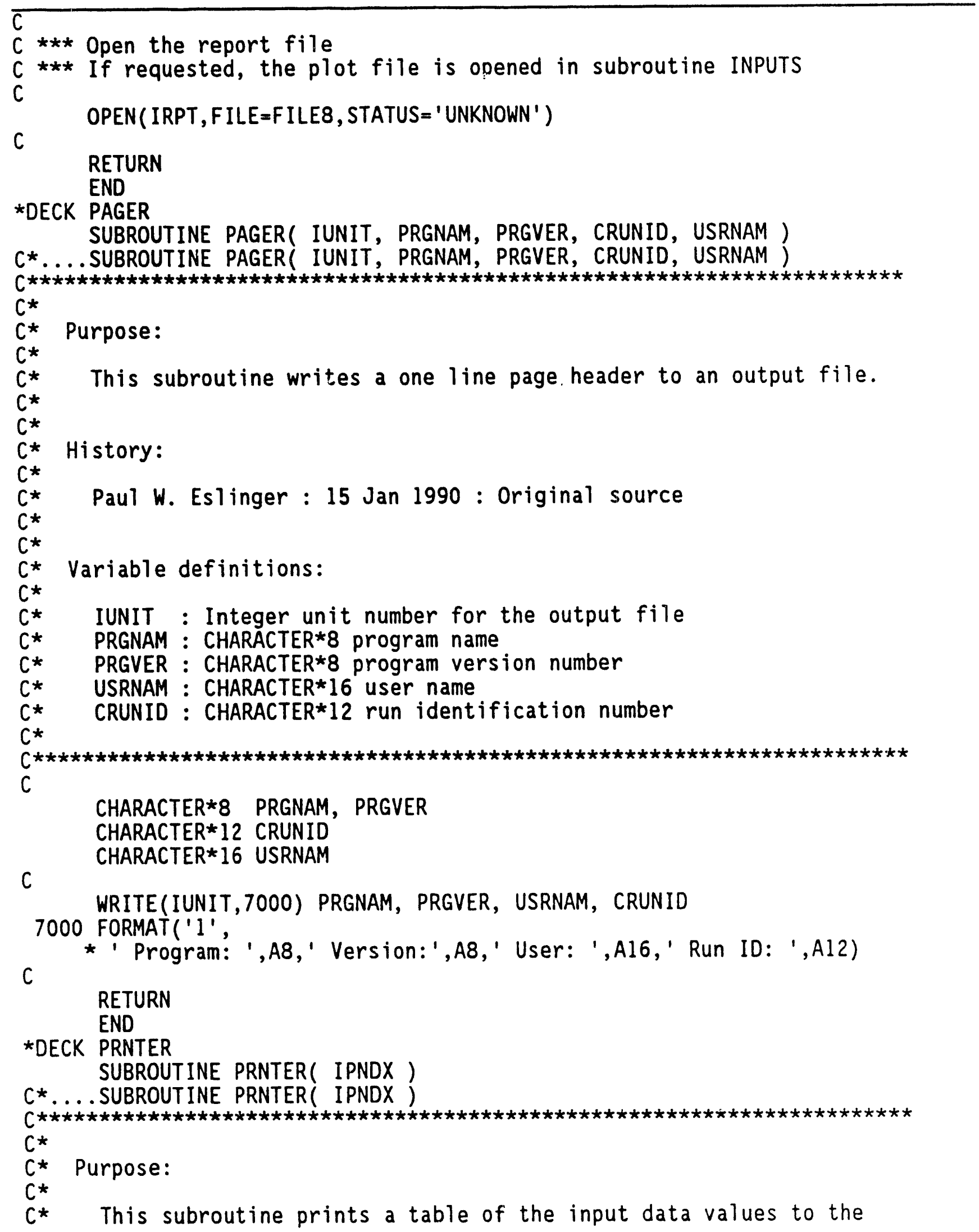


WHC-EP-0418

Table A-1. Source Code Listing. (sheet 43 of 62)

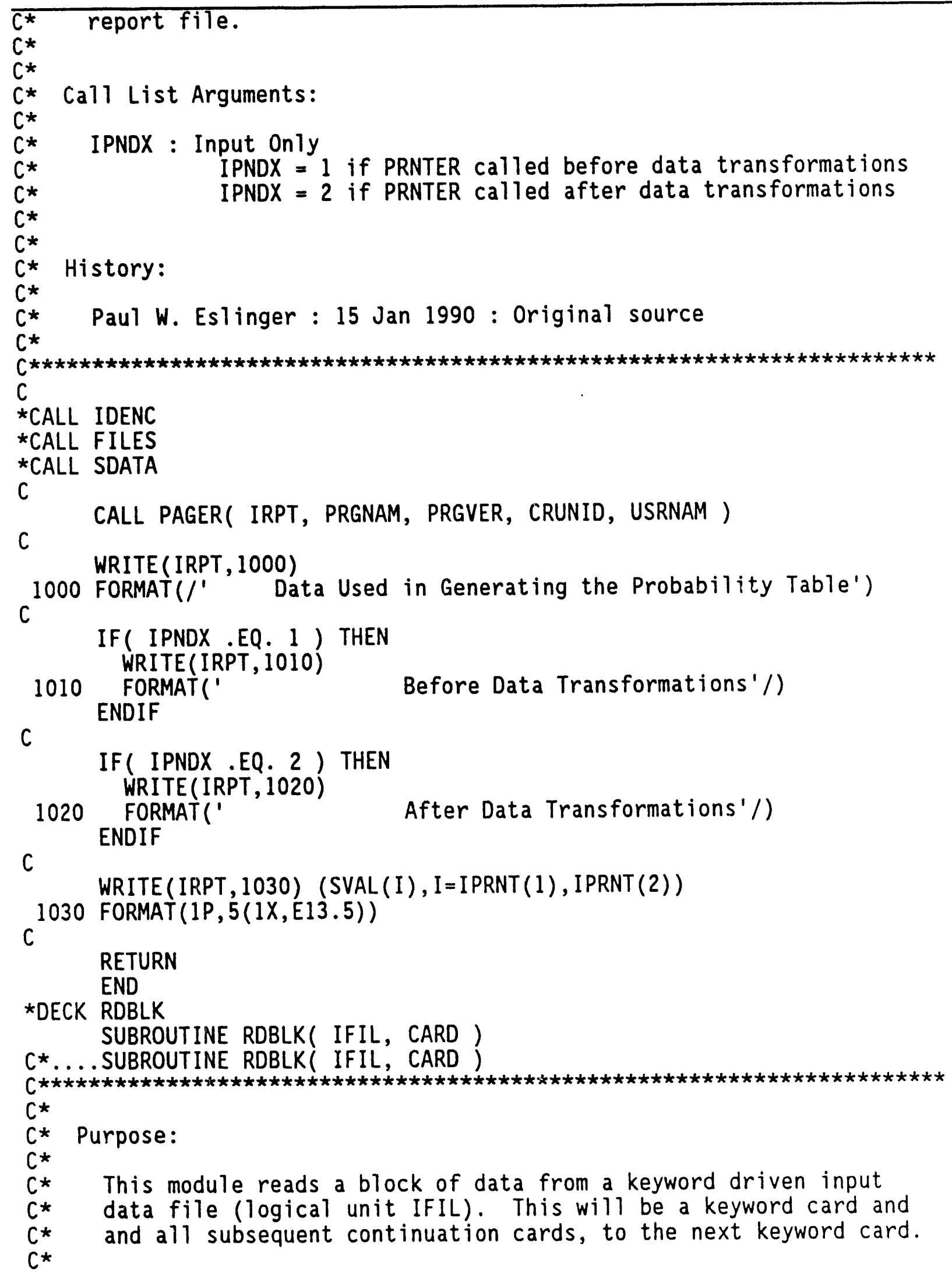




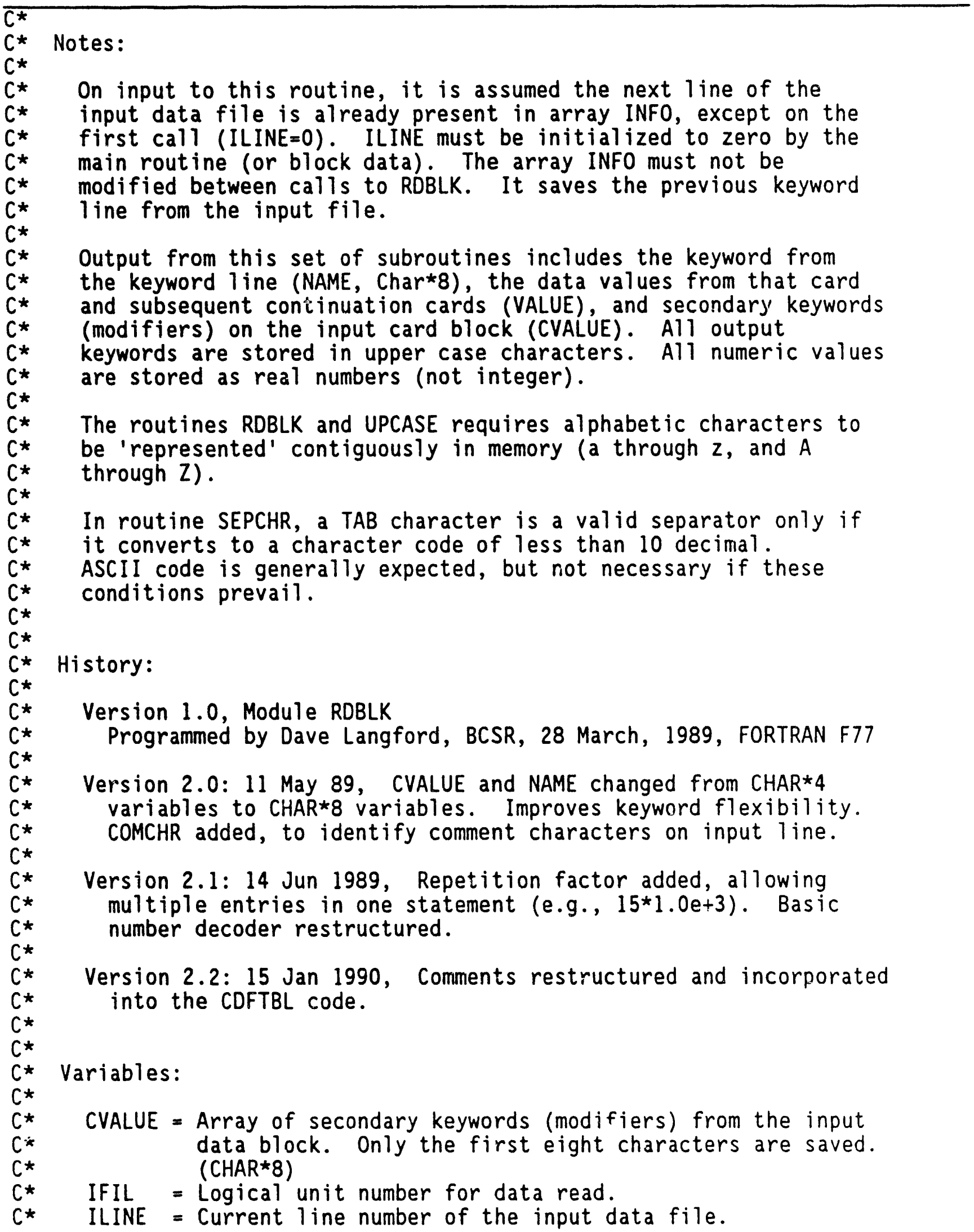


Table A-1. Source Code Listing. (sheet 45 of 62)

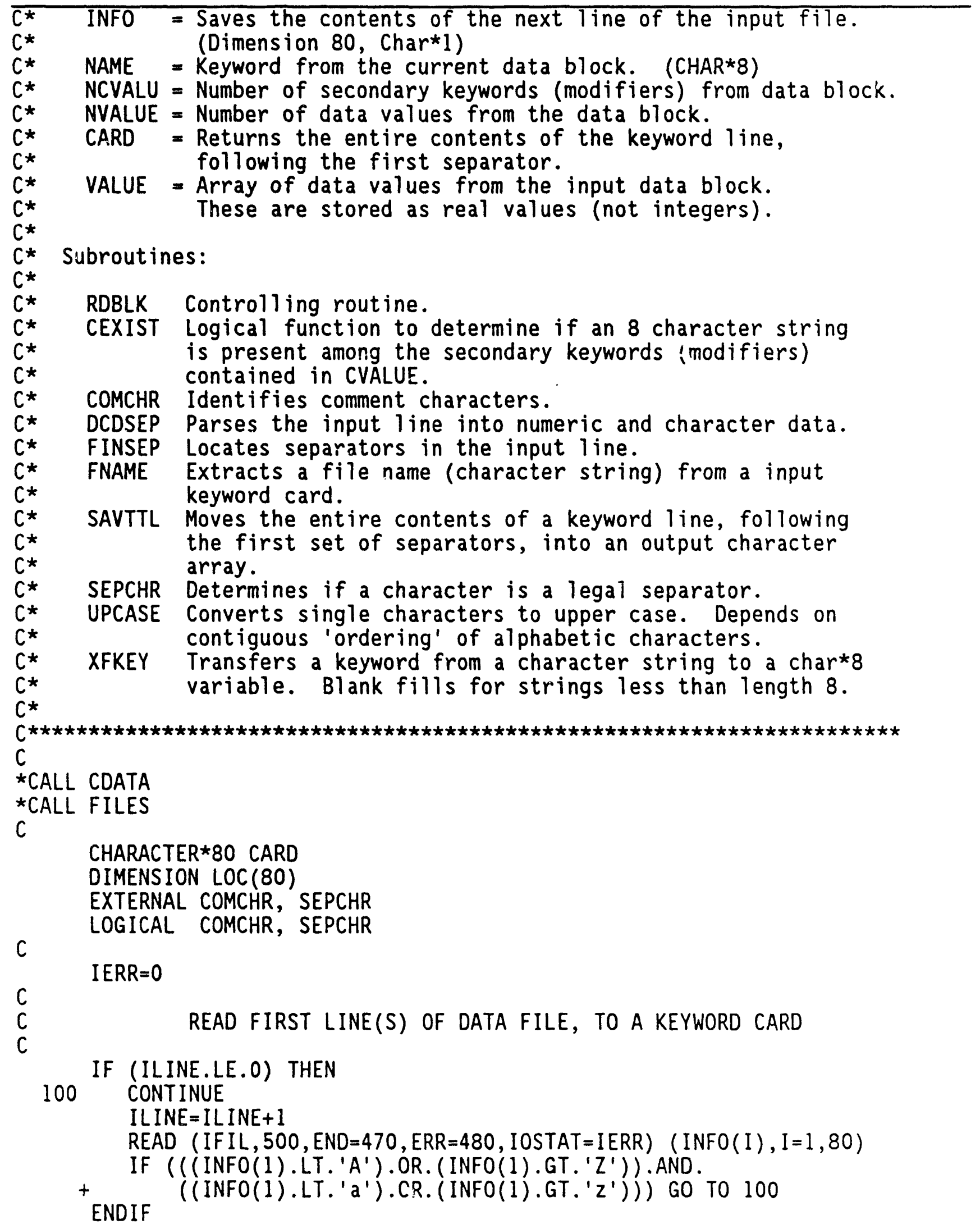


Table A-1. Source Code Listing. (sheet 46 of 62)

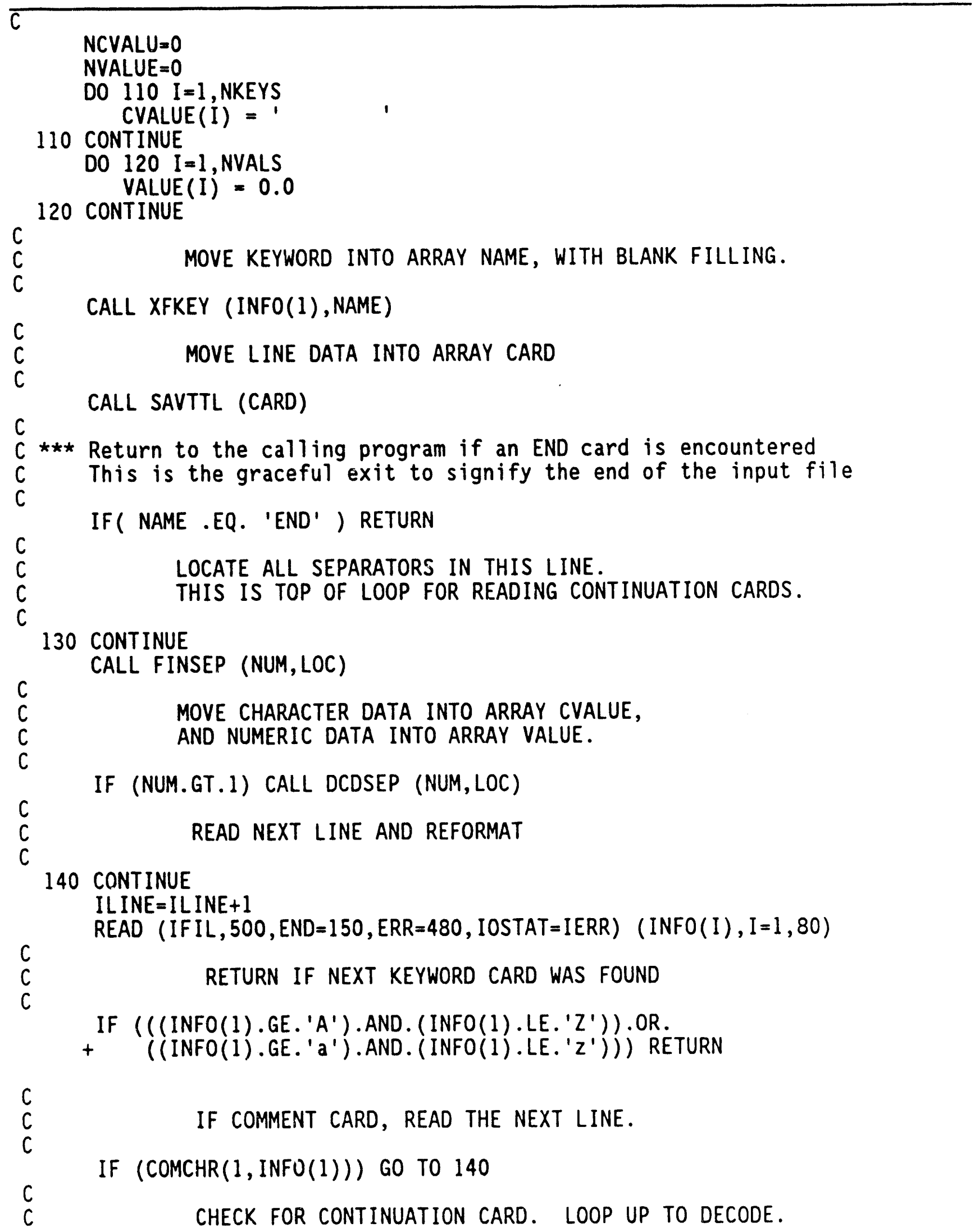


Table A-1. Source Code Listing. (sheet 47 of 62 )

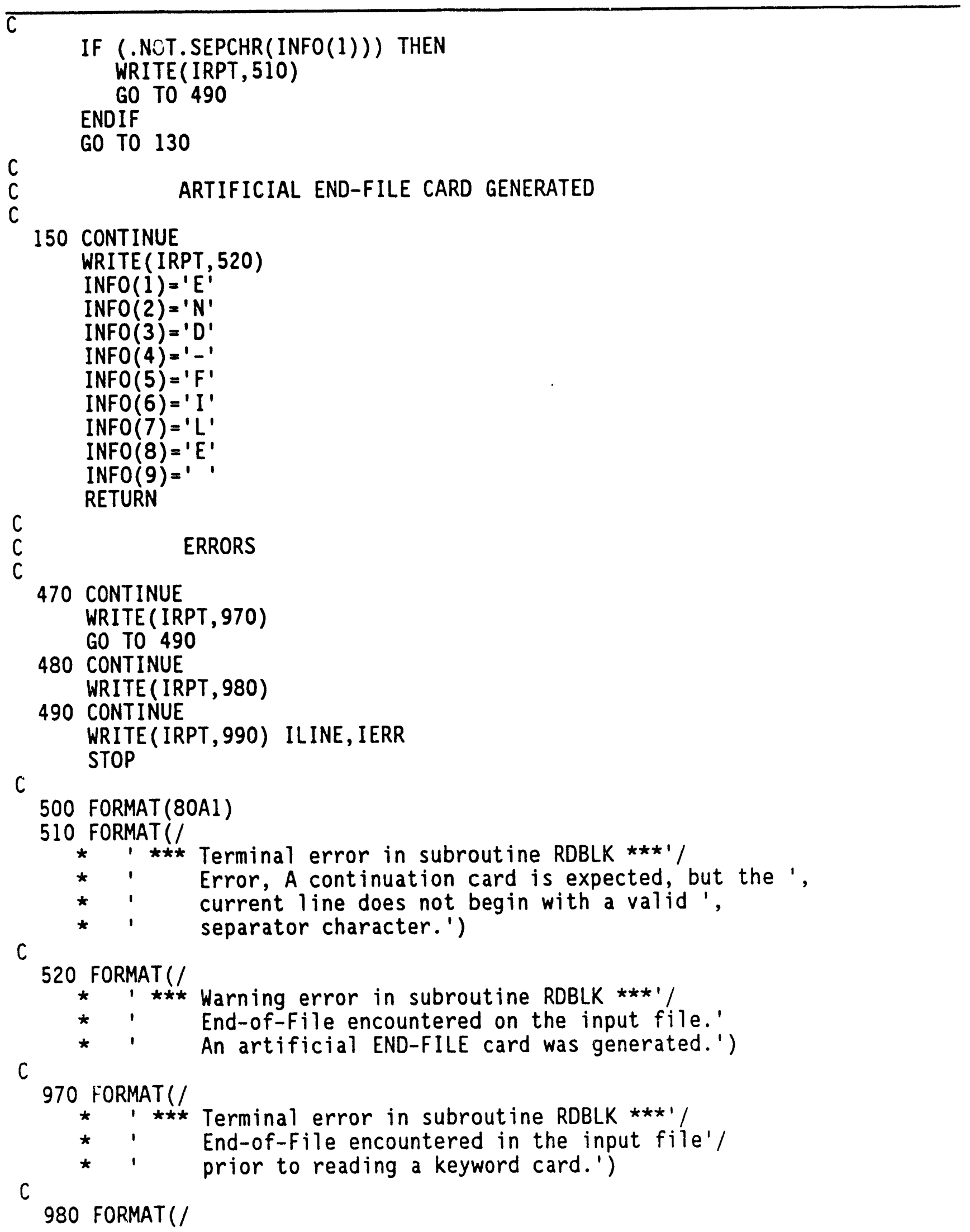


Table A-1. Source Code Listing. (sheet 48 of 62)

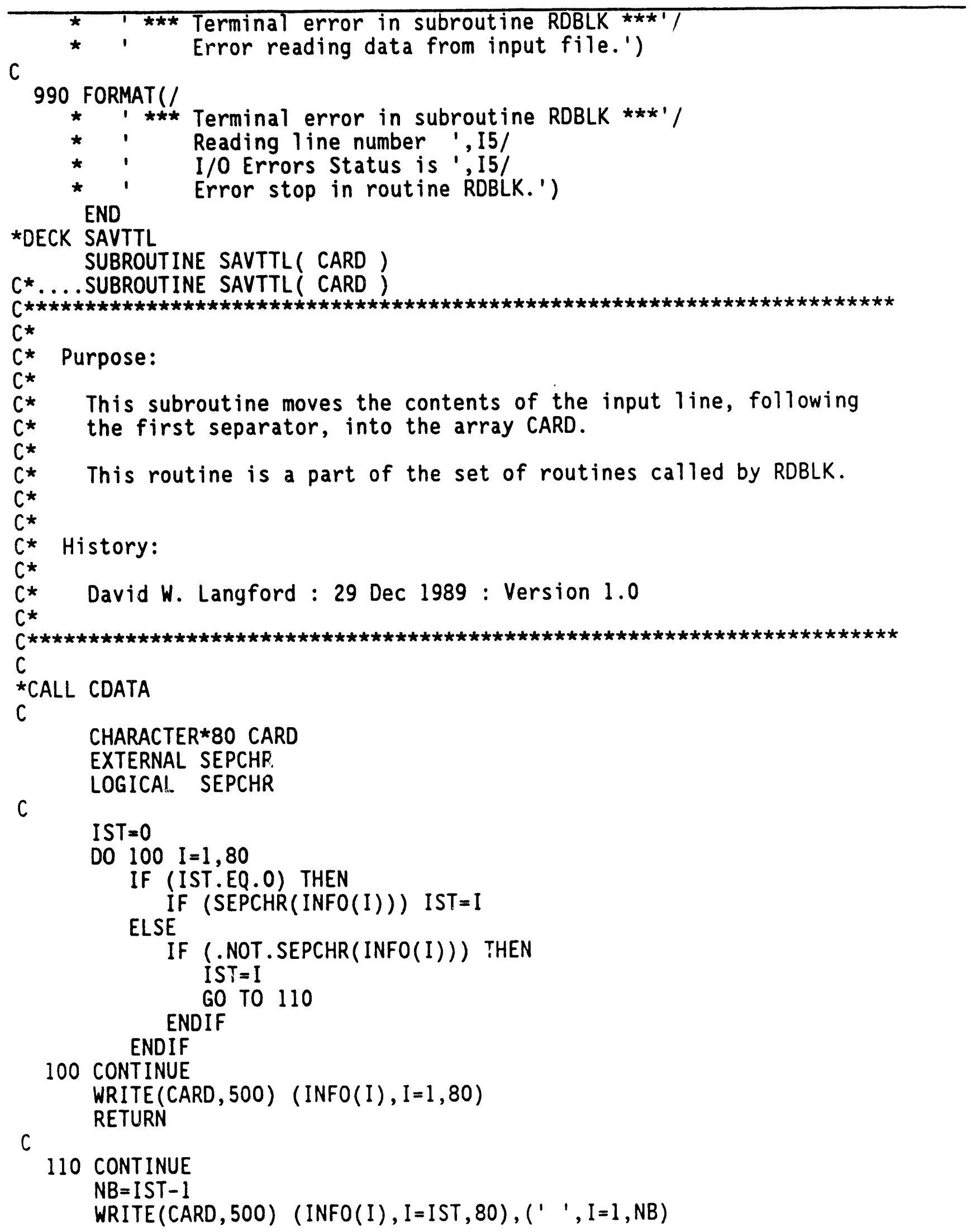


WHC-EP-0418

Table A-1. Source Code Listing. (sheet 49 of 62)

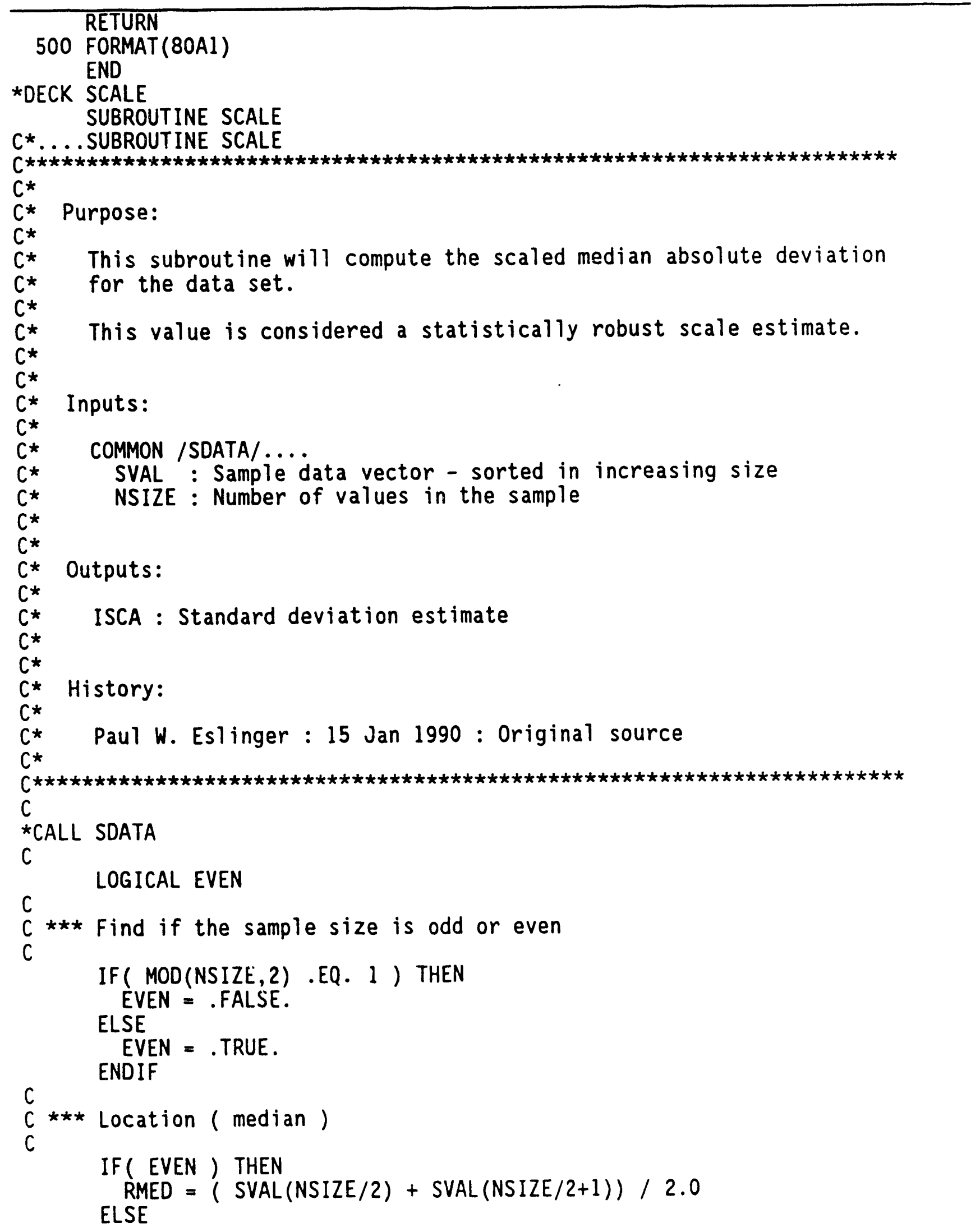


Table A-1. Source Code Listing. (sheet 50 of 62)

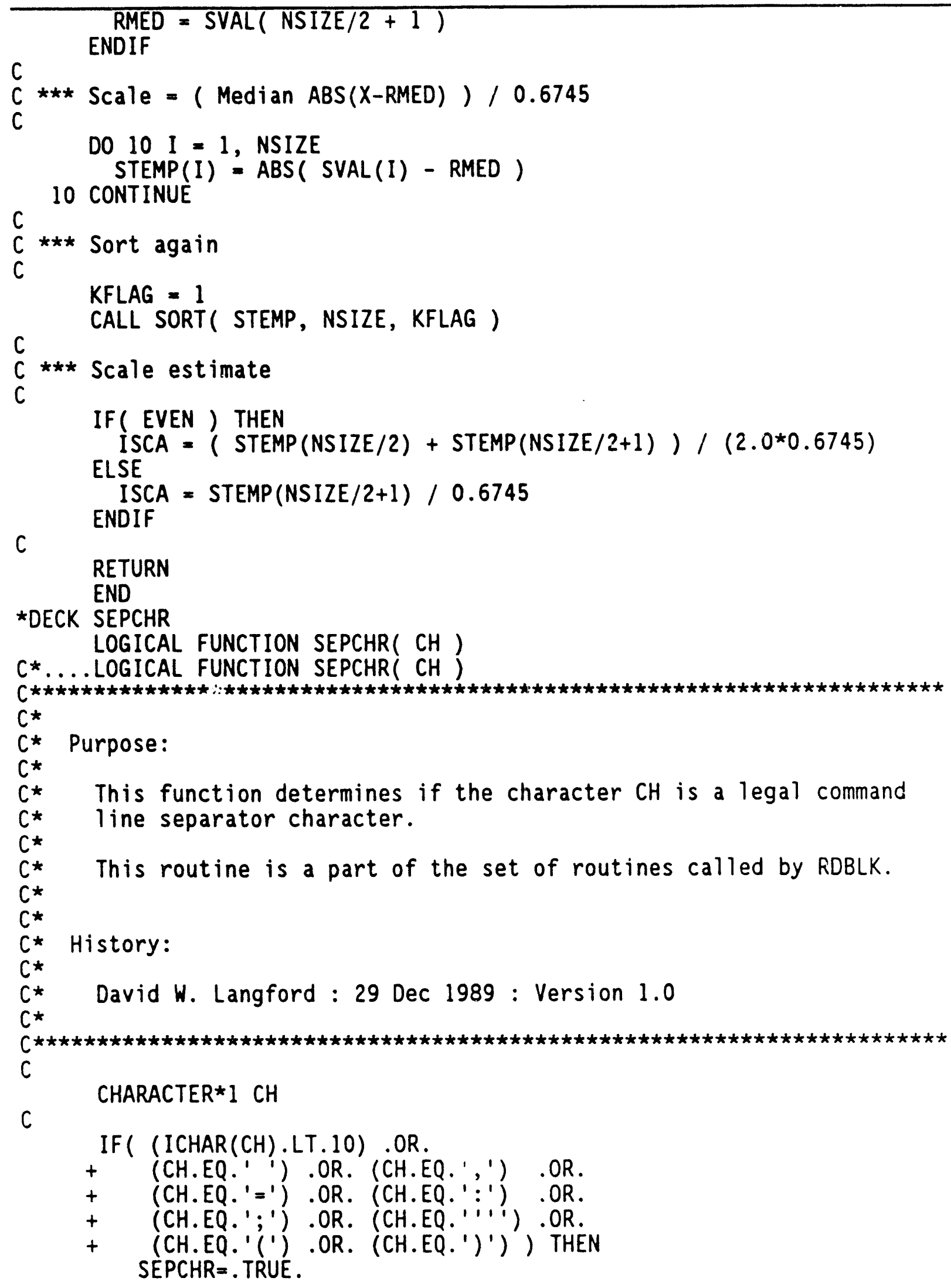


WHC-EP-0418

Table A-1. Source Code Listing. (sheet 51 of 62)

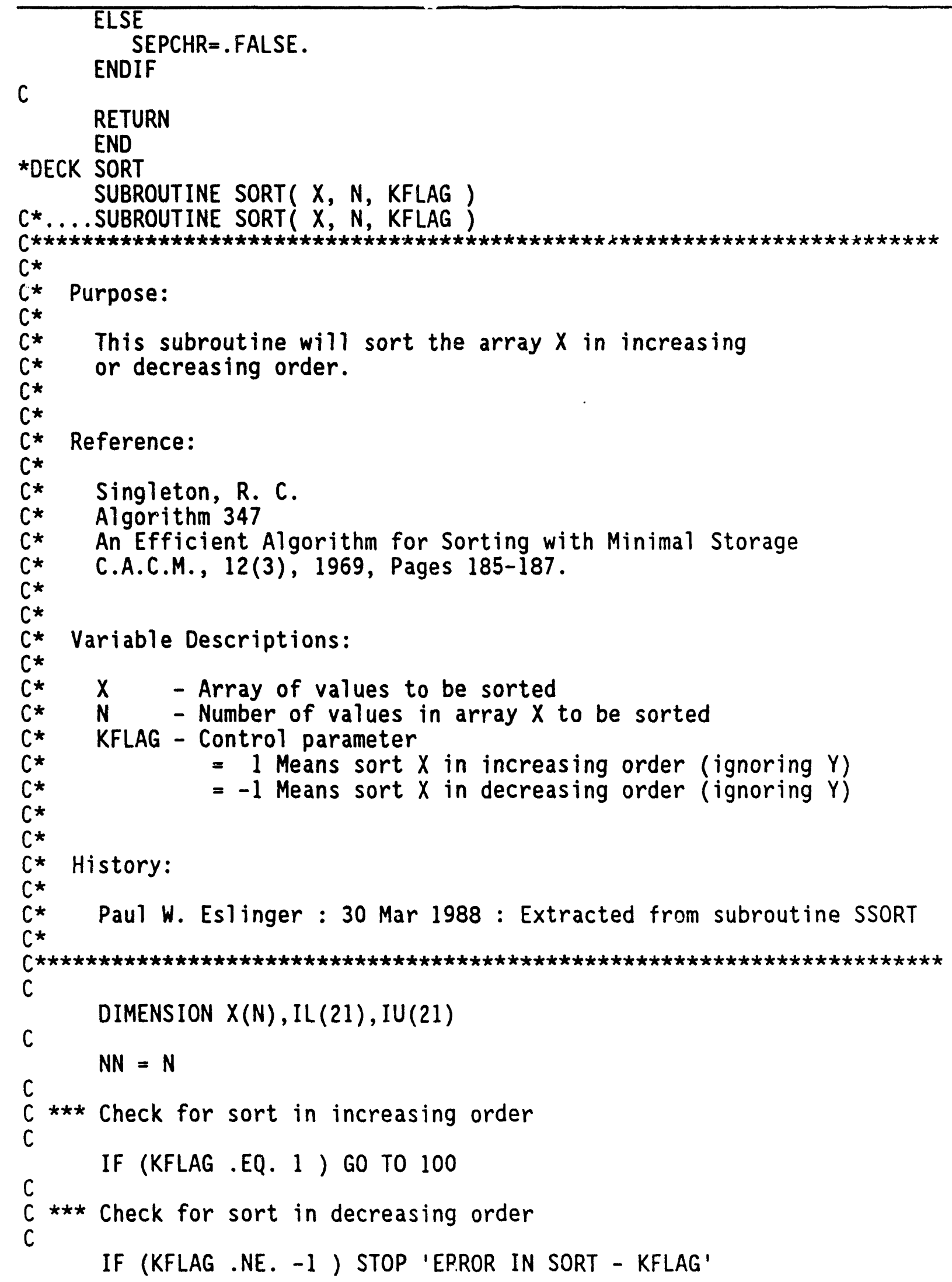


Table A-1. Source Code Listing. (sheet 52 of 62)

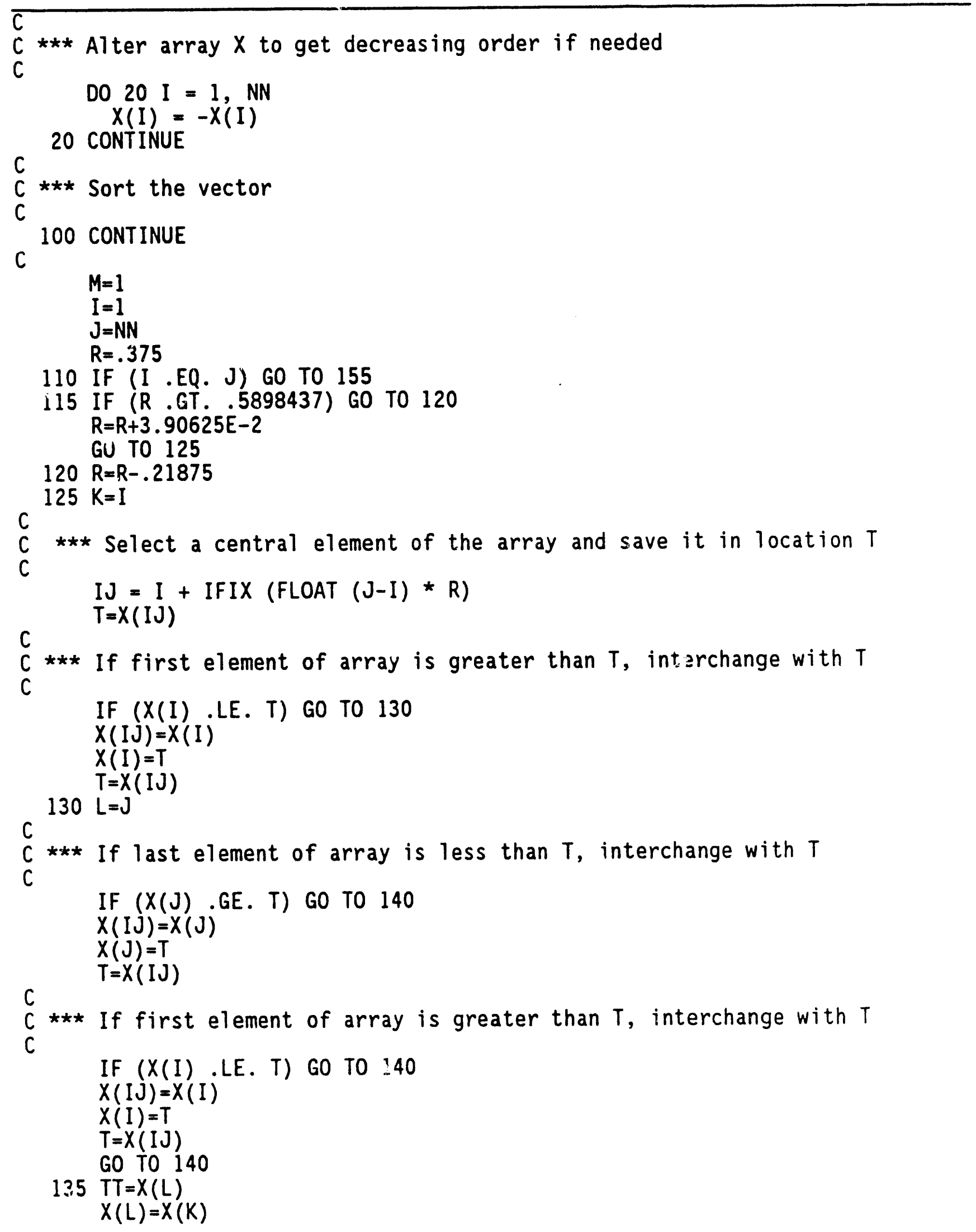


Table A-1. Source Code Listing. (sheet 53 of 62)

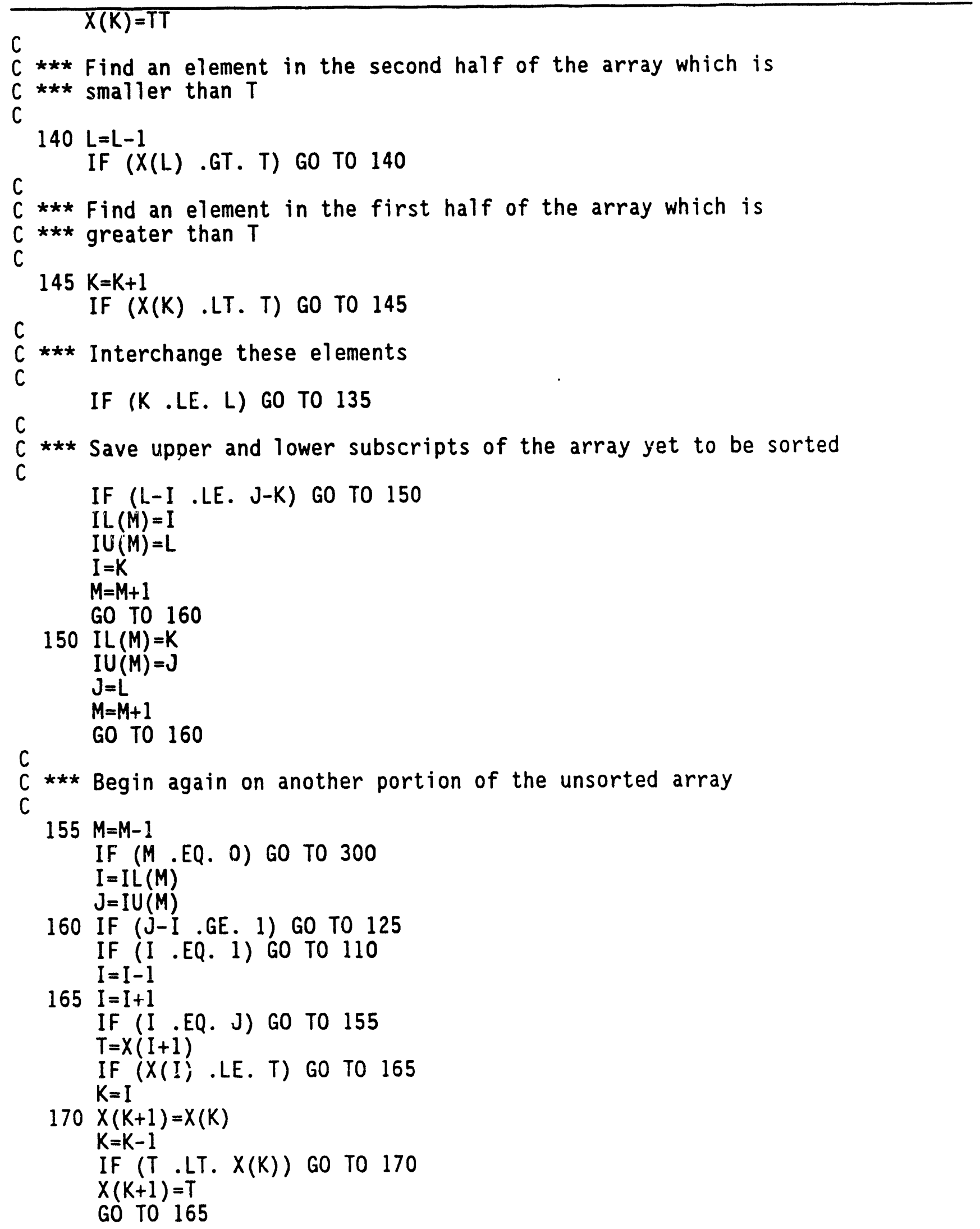


Table A-1. Source Code Listing. (sheet 54 of 62)

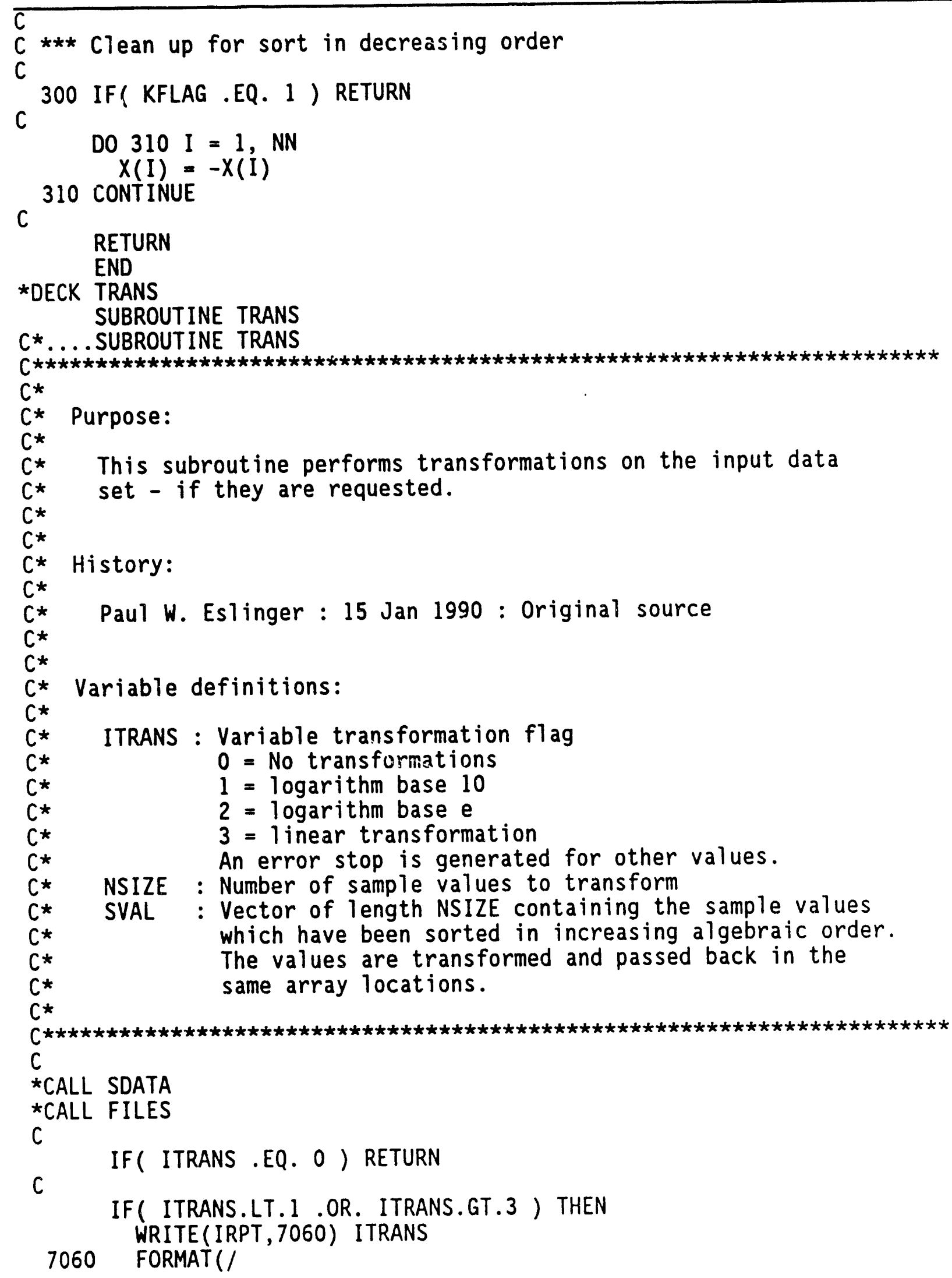


WHC-EP-0418

Table A-1. Source Code Listing. (sheet 55 of 62)

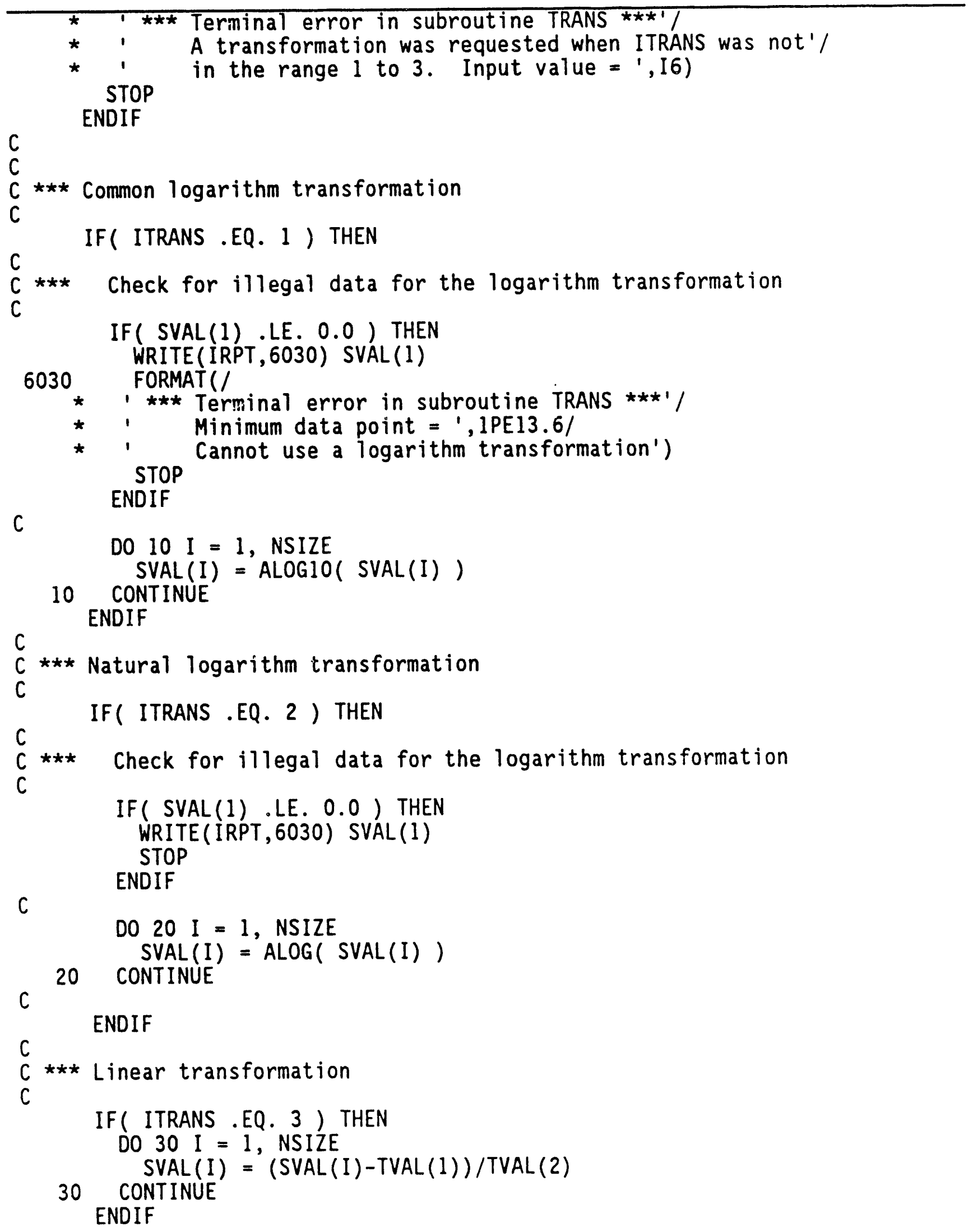


WHC-EP-0418

Table A-1. Source Code Listing. (sheet 56 of 62)

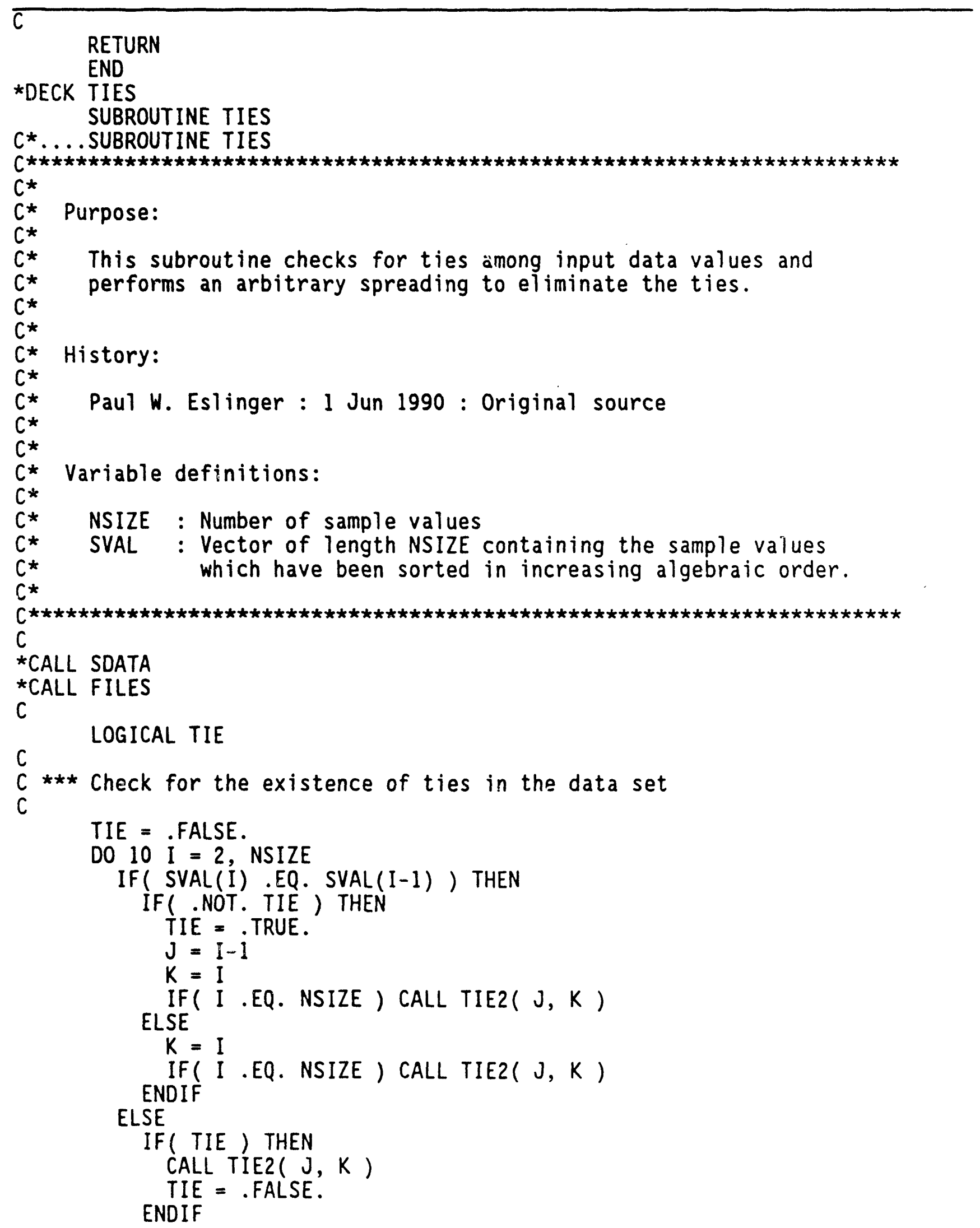


Table A-1. Source Code Listing. (sheet 57 of 62)

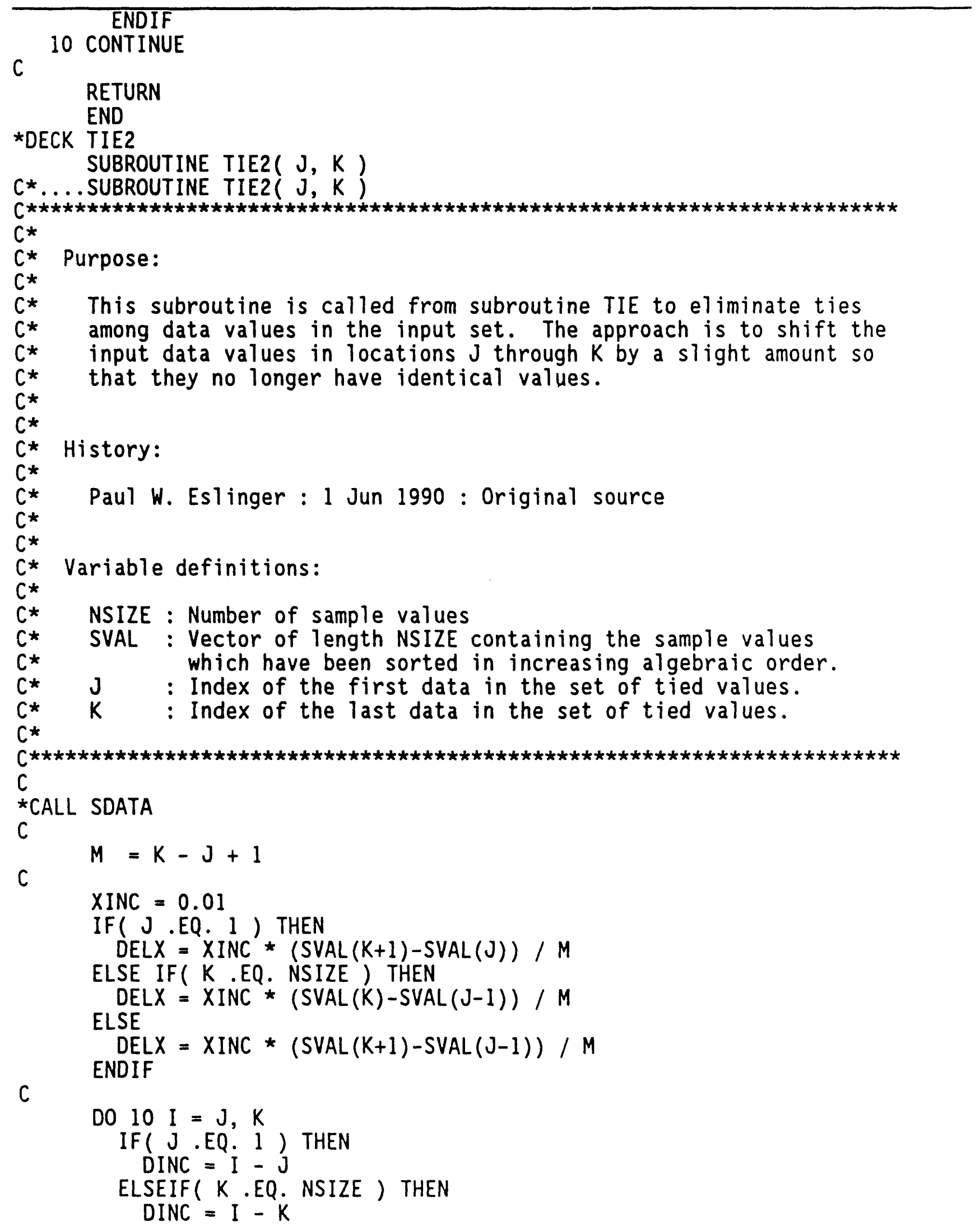


Table A-1. Source Code Listing. (sheet 58 of 62)

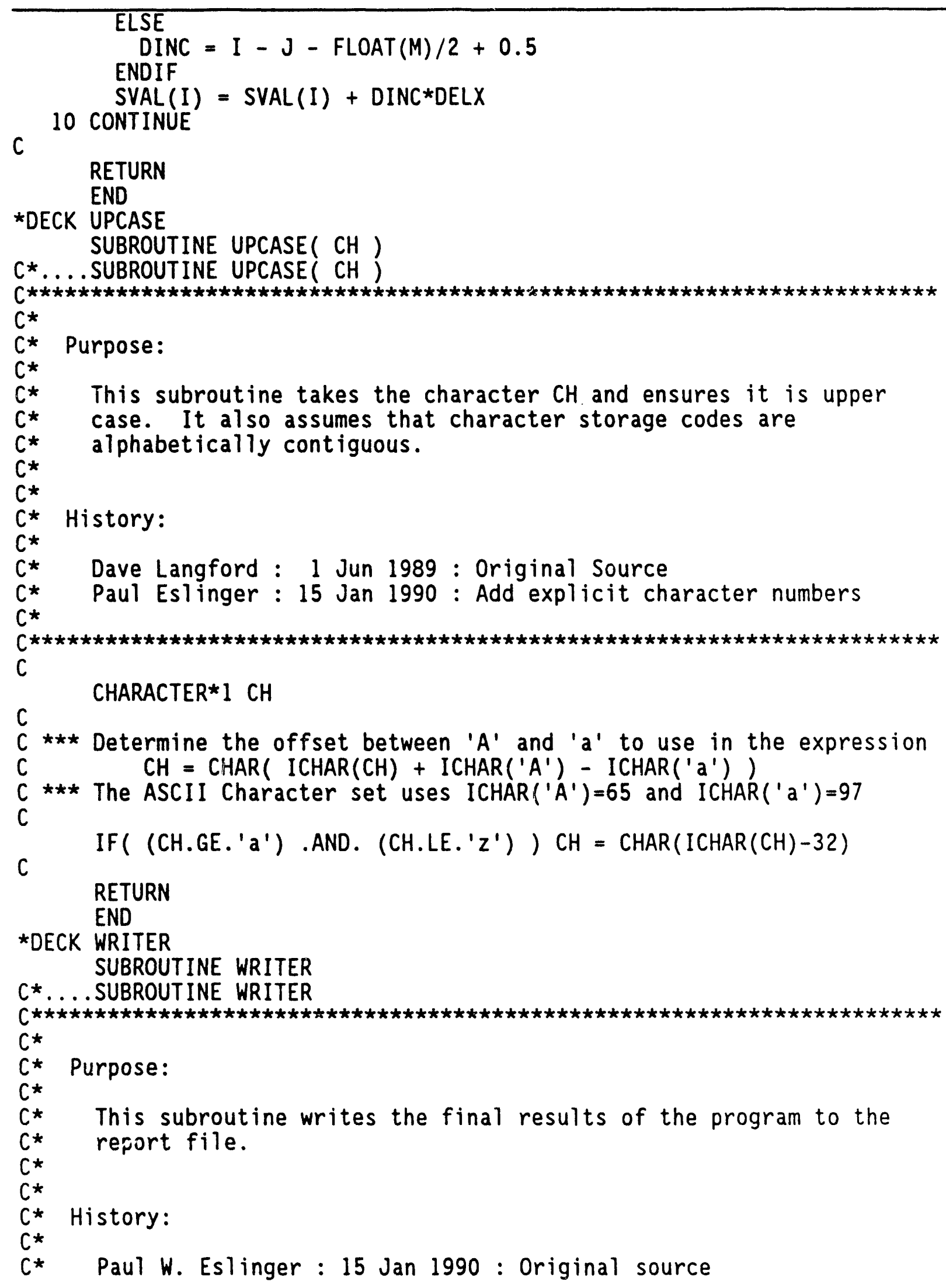

C* History:

$C^{*}$ Paul W. Eslinger : 15 Jan 1990 : Original source

This subroutine writes the final results of the program to the report file. 
Table A-1. Source Code Listing. (sheet 59 of 62)

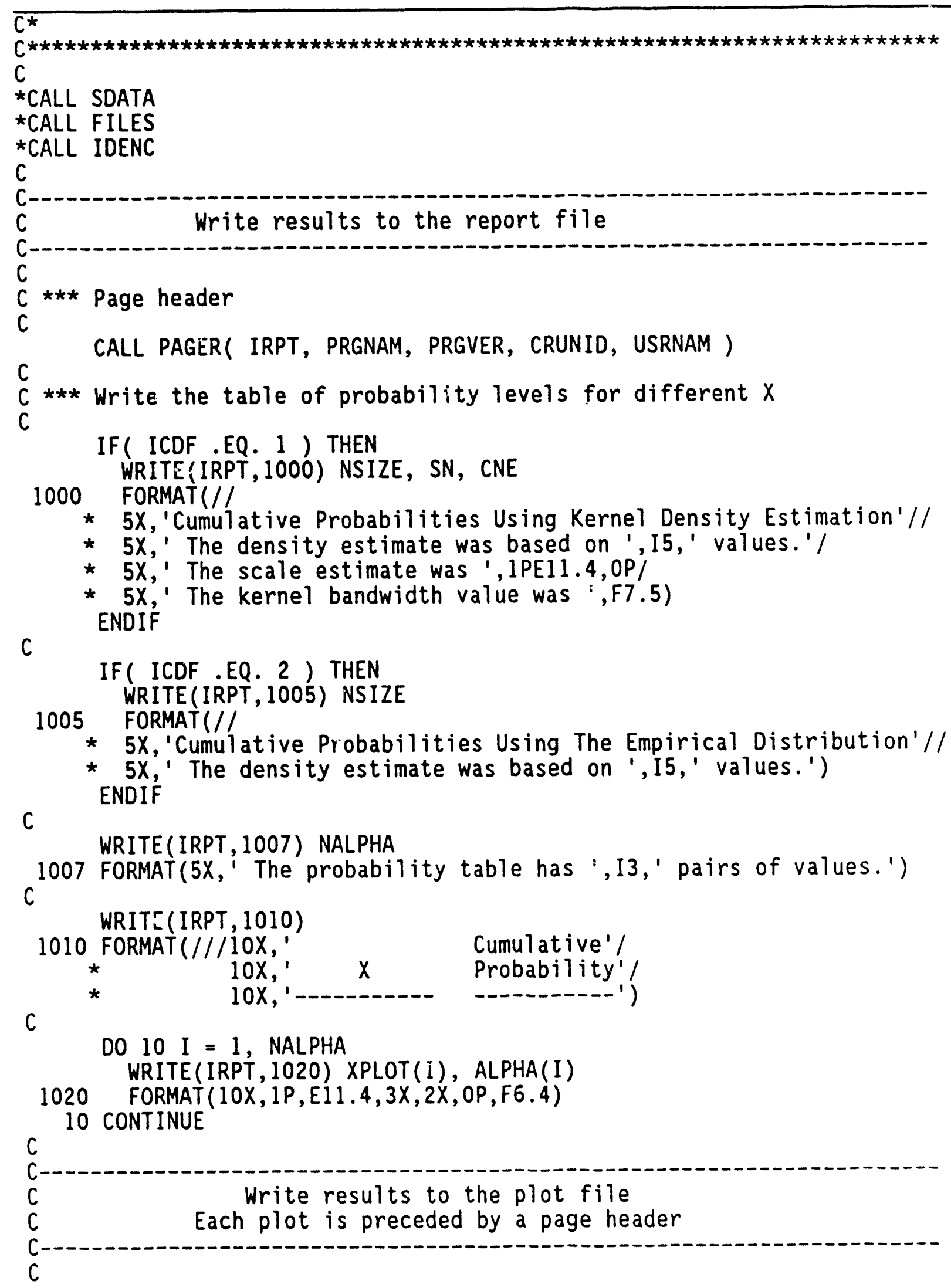


Table A-1. Source Code Listing. (sheet 60 of 62)

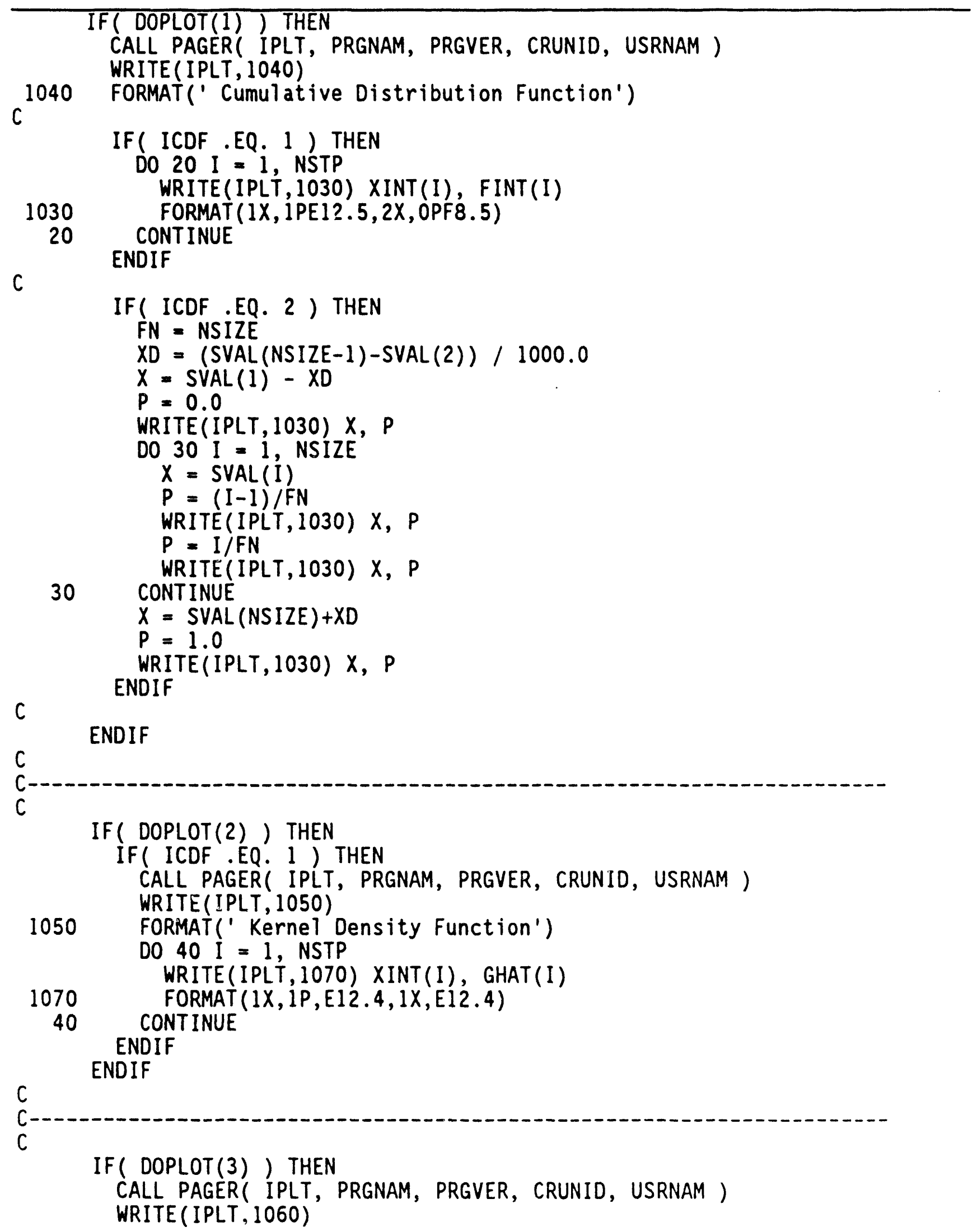


Table A-1. Source Code Listing. (sheet 61 of 62)

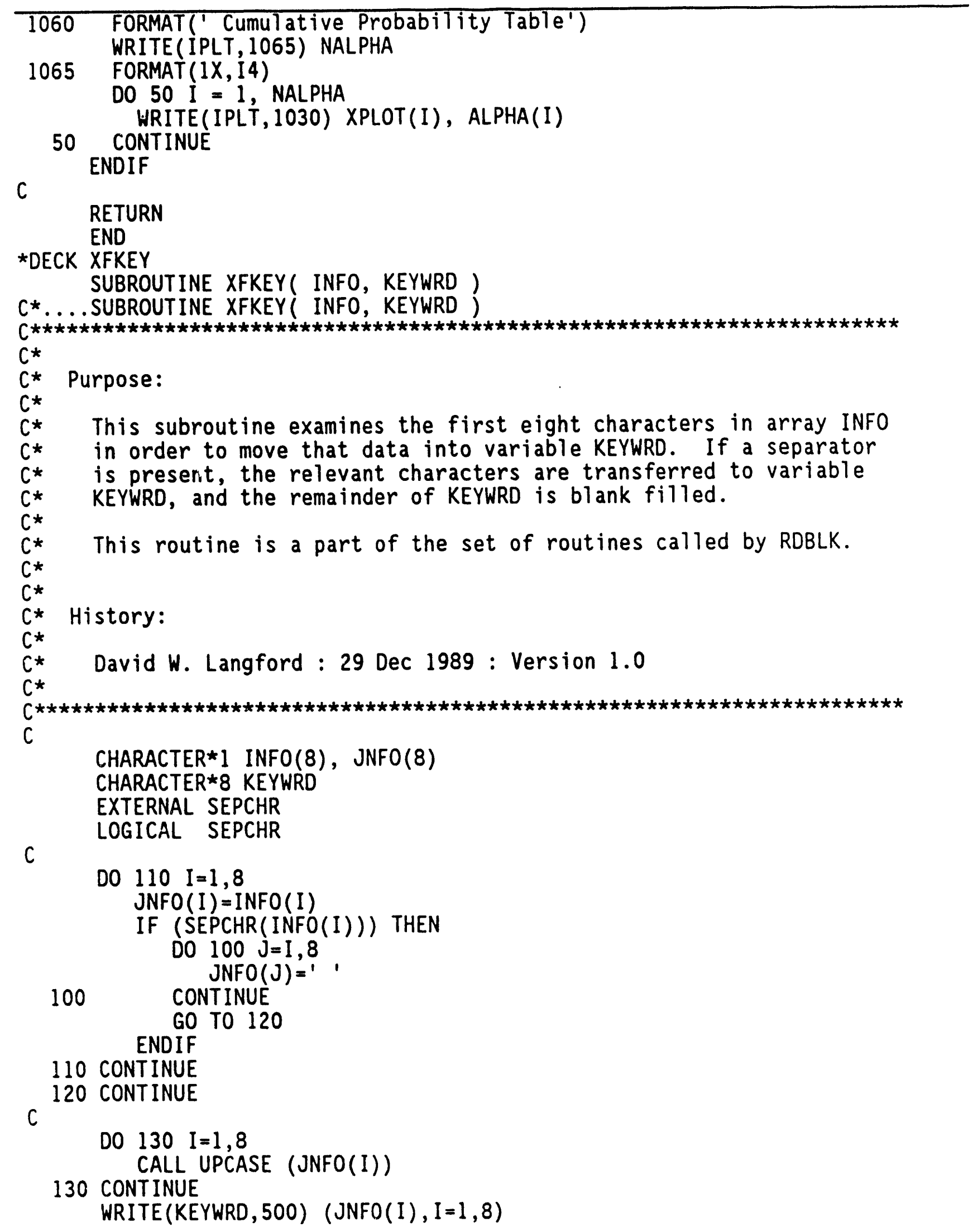


WHC-EP-0418

Table A-1. Source Code Listing. (sheet 62 of 62)

500 FORMAT(8A1)

C

RETURN

END

Table A-2. Listing of the VAX Version of Subroutine IDENC (sheet 1 of 3 )

*DECK IDENC

SUBROUTINE IDENC

$C^{\star} \ldots$... SUBROUTINE IDENC

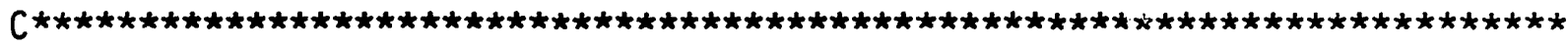

$C *$

C* Purpose:

C*

$C^{*} \quad$ This routine generates identification variables for this run

$C^{*}$ of the code. Variables are:

$C^{\star}$

$C^{*}$

1. A unique run identifier number, utilizing the date and time which this routine was called

2. Hard coded - Program name and version number

3. Hard coded - User name

4. Hard coded - Date that program was last modified

5. System date and time

$c^{*}$

$c^{*}$

C* Operating system:

C*

C* This subroutine is designed for the FORTRAN 77 compiler using

$C^{*} \quad$ a VMS operating system.

$C^{*}$

$C^{*}$

$C^{*}$ Variable Definitions:

$C^{*}$

$C^{\star}$

$c *$

C*

$c *$

$C^{*}$

C*

$c *$

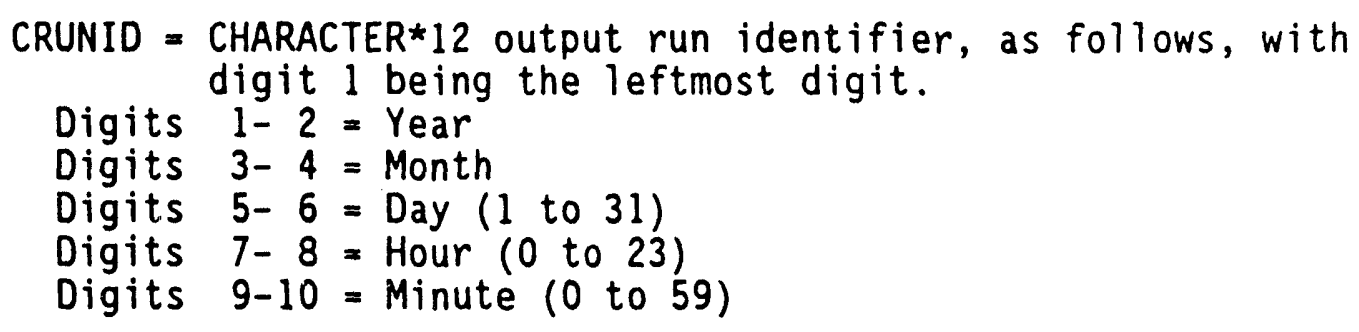


Table A-1. Source Code Listing. (sheet 2 of 3 )

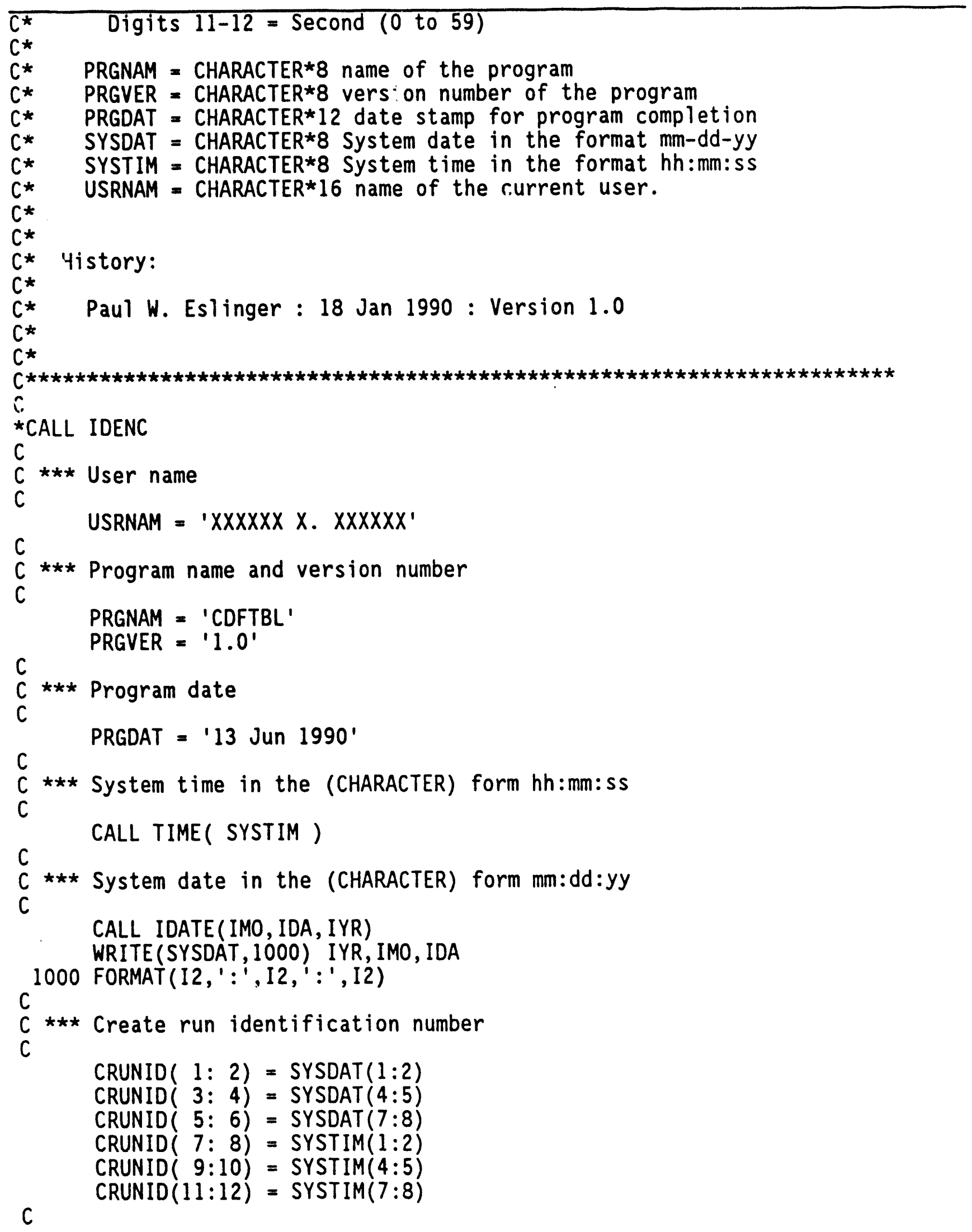


WHC-EP-0418

Table A-1. Source Code Listing. (sheet 3 of 3 )

$C^{\star \star \star *}$ Substitute a zero for any blank

C

DO $10 \quad I=1,12$

IF( CRUNID(I:I) .EQ. ' ' ) CRUNID(I:I) $=10$ '

c 10 CONTINUE

RETURN

END 
WHC-EP-0418

\section{DISTRIBUTION}

Number of copies

OFFSITE

5

U.S. Department of Energy

1000 Independence Avenue, S.W.

Forrestal Building

Washington, D.C. 20585

L. P. Duffy

EM-1

C. Frank

$E M-50$

S. Lien

$E M-54$

J. Lytle

$E M-30$

R. P. Whitfield

EM-40

1

U.S. Department of Energy

12800 Middlebrook Road

Germantown, Maryland 20874

K. Hain

EM-54

12

U.S. Department of Energy

office of Scientific and

Technical Information

P.0. Box 62

Oak Ridge, Tennessee 37831

1

Bureau of Economic Geology

University of Texas at Aust in

University Station

Box $X$

Austin, Texas 78713

B. Scanlon

1

Colorado School of Mines

Department of Chemistry and Geochemistry Golden, Colorado

D. Langmuir

3

EG\&G Idaho, Inc.

P.0. Box 1625

MS 2107

Idaho Falls, Idaho 83415

R. G. Baca

R. R. Seitz

J. C. Walton 
WHC-EP-0418

DISTRIBUTION (cont)

Number of copies

OFFSITE

2

Lawrsnce Livermore National Laboratory

University of California

P. 0. Box 808

Livermore, California 94550

K. Pruess

L. D. Ramspott

1

Los Alamos National Laboratory

P.0. Box 1663

Los Alamos, New Mexico 87545

B. J. Travis

1

New Mexico State University

Department of Agronomy

P.0. Box 30003

Las Cruces, New Mexico 88003

R. Hills

1

Oak Ridge National Laboratory

P.0. Box Y

Oak Ridge, Tennessee 37830

j. 0. Blomeke

1

Office of Civilian Radioactive

Waste Management

Forrestal Building

Washington, D.C. 20585

K. H. Kale

$\mathrm{RW}-20$

3

Office of Remedial Action

and Waste Technology

19901 Germantown Road

Germantown, Maryland 20585

J. A. Coleman

EM-35

T. W. McIntosh

EM-343

H. F. Walter

EM-343 
WHC-EP-0418

DISTRIBUTION (cont)

Number of copies

OFFSITE

11

Southwest Research Institute

Division 20

6220 Calebra Road

P.0. Drawer 0510

San Antonio, Texas 28510-78228

W. Patrick

B. Sagar (10)

2

University of Arizona

Department of Water Resources

Tucson, Arizona

N. J. Aimo

S. P. Neuman

2

University of California at Riverside

Department of Soils

Riverside, California 92502

W. A. Jury

M. Th. van Genuchten

1

University of Massachusetts

Department of Plant and Soil Science

$12 \mathrm{~A}$ Stockbridge $\mathrm{Hall}$

Amherst, Massachusetts 01003

D. Hillel

1

U.S. Environmental Protection Agency Washington, D.C.

D. Sherwood

B5-01

1

U.S. Environmental Protection Agency Office of Radiation Programs (ANR-458)

401 M Street, S.W.

Washington, D.C. 20460

S. Myers

1

U.S. Geological Survey

Federal Center, MS-413

Denver, Colorado 80225

E. P. Weeks 
WHC-EP-0418

\section{DISTRIBUTION (cont)}

Number of copies

OFFSITE

1

U.S. Geological Survey

Water Resources Division

Low-Level Radioactive Waste Program

12201 Sunrise Valley Drive

Reston, Virginia 22092

J. Fischer

2

U.S. Nuclear Regulatory Commission

Division of Engineering Safety

Washington, D.C. 20555

S. Coplan

NLS-260

T. J. Nicholson

$\mathrm{NL}-005$

2

Westinghouse Idaho Nuclear Company. Inc. P.0. Box 4000

Idaho Falls, Idaho 83401

J. A. Berreth

D. A. Knecht

ONSITE

U.S. Department of Energy-Richl and Operations office

J. C. Bartlett

A1-10

R. D. Freeberg

A5-19

M. J. Furman

A5-21

J. M. Hennig

A5-21

S. K. Moy

G. W. Rosenwald

Public Reading Room

Pacific Northwest Laboratory

S. Q. Bennett

K6-35

M. P. Bergeron

P. W. Eslinger

J. W. Falco

$\mathrm{K} 6-77$

M. J. Fayer (2)

K. $6-96$

M. D. Freshley

$\mathrm{K} 6-78$

K6-77

P. C. Hays

$K 6-77$

$\mathrm{K} 6-86$ 
WHC-EP-0418

DISTRIBUTION (cont)

Number of copies

ONSITE

Pacific Northwest Laboratory (cont)

D. J. Holford

K6-77

J. F. Keller

$\mathrm{K} 1-51$

C. T. Kincaid

$\mathrm{K} 6-77$

W. E. Nichols

K6-77

K. R. Roberson

K6-77

M. L. Rockhold

K6-77

C. S. Simmons

$\mathrm{K} 6-77$

R. L. Skaggs

J. L. Smoot

$\mathrm{K} 6-77$

J. A. Stottlemyre

$\mathrm{K} \sigma-77^{\circ}$

S. K. Wurstner

K6-75

Technical Files (5)

$\mathrm{K} 6-77$

Clearance office

$K 1-11$

K1-02

Westinghouse Hanford Company
L. C. Brown
H4-51
J. W. Cammann
H4-14
L. B. Collard
H4-14
M. P. Connelly
J. D. Davis
H4- 14
K. R. Fecht
H4-55
R. L. Jackson
$\mathrm{H} 4-56$
R. Khaleel
N. W. Kline
H4-56
H4-14
D. Langford
HO-31
A. G. Law
B2-25
T. LeGore
$\mathrm{H} 4-56$
R. E. Lerch
B4 -63
J. C. Sonnichsen (5)
B2-35
D. D. Wodrich
$\mathrm{H} 4-14$
R. D. Wojtasek
B3 -72 .
Central Files
L4-92
Document Clearance Administration
L8-04
Document Processing and Distribution (2)
H4-17
L8-15 

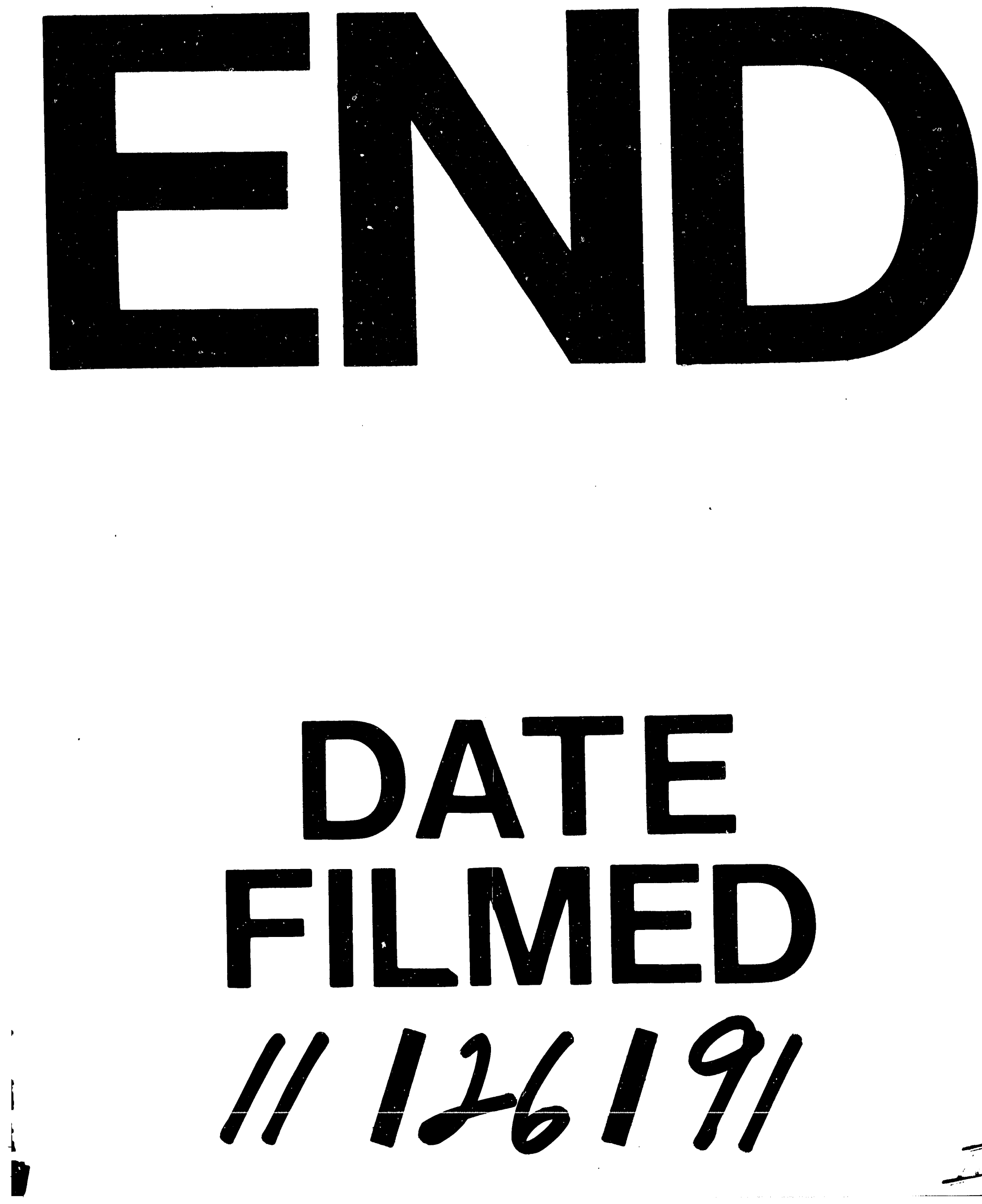
